OECD REGIONAL DEVELOPMENT PAPERS

\title{
Les Régions dans la Mondialisation
}

Une approche originale de l'internationalisation des régions et son application au cas français

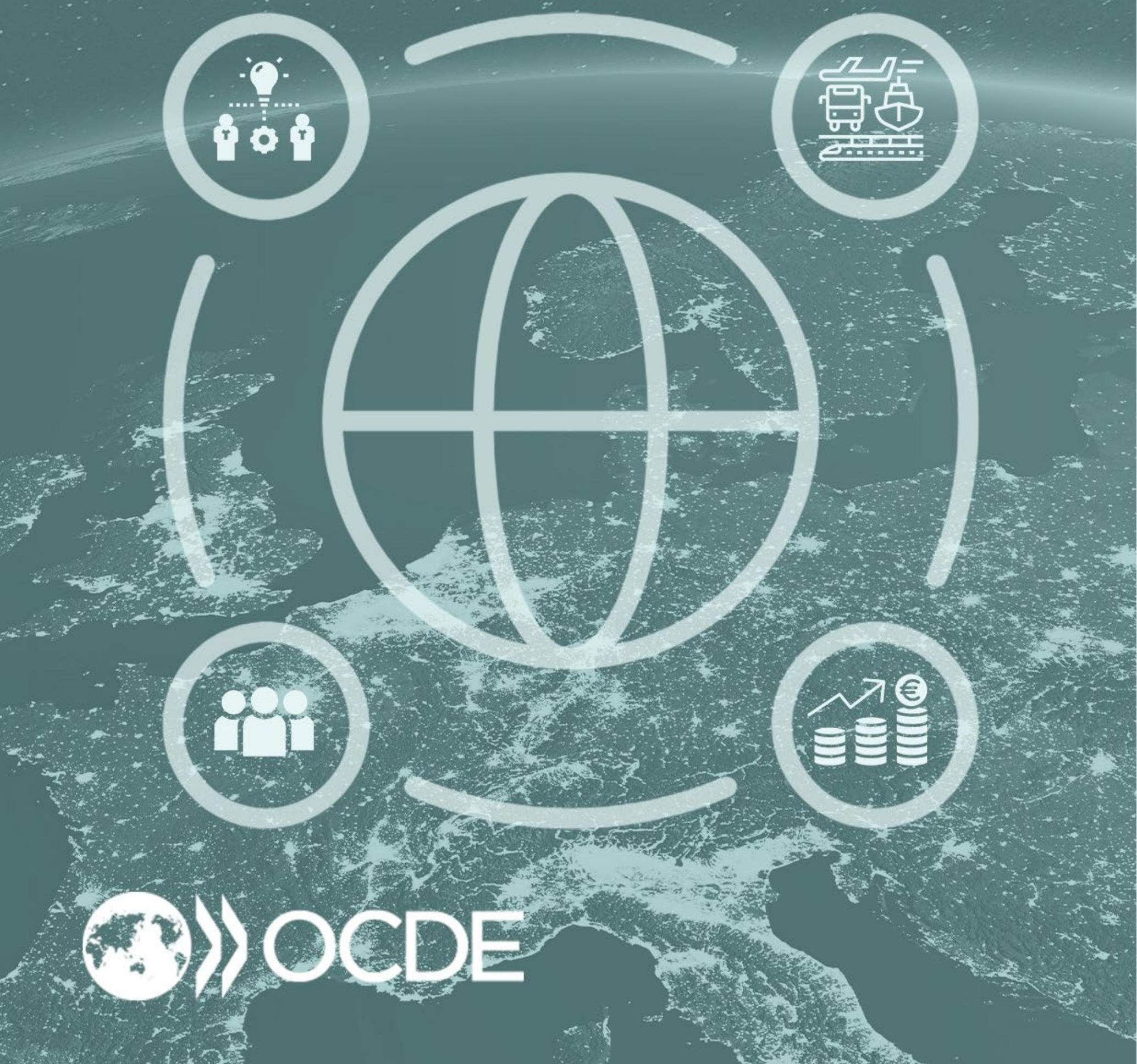


OECD Regional Development Papers

\title{
Les Régions dans la Mondialisation
}

\section{Une approche originale de l'internationalisation des régions et son application au cas français}

\begin{abstract}
La crise du COVID 19 a confirmé le rôle des autorités locales pour faire face aux différents effets de la mondialisation. En France, comme généralement dans les pays de l'OCDE, c'est à l'échelon régional qu'est allouée la responsabilité de produire et de mettre en œuvre les stratégies de développement économique, innovation et internationalisation.

Ce document de synthèse tire les principales leçons des travaux statistiques et des analyses des politiques publiques relatives à l'internationalisation des régions françaises menés par l'OCDE. II propose une méthodologie originale afin d'identifier le positionnement des régions dans la mondialisation, l'applique au cas des régions françaises et confronte ses observations statistiques aux stratégies d'internationalisation retenues par les régions. Des dispositifs de gouvernance pluri-niveaux dans lesquels s'inscrivent les acteurs de l'internationalisation des territoires sont aussi présentés.
\end{abstract}

JEL codes: R10, R11

Mots clés: mondialisation, attractivité territoriale, internationalisation, développement régional, résilience, relance, gouvernance pluri-niveaux, stratégie d'exportations, tourisme, infrastructures, réseaux de connaissance, chaînes de valeur mondiales, migrations 


\section{À PROPOS DE L'OCDE}

L'OCDE est une organisation intergouvernementale pluridisciplinaire regroupant 38 pays membres qui fait participer à ses travaux un nombre croissant de pays non membres de toutes les régions du monde. La principale mission de l'OCDE aujourd'hui est d'aider les gouvernements à œuvrer ensemble à la réalisation d'une économie mondiale plus forte, plus propre et plus juste. À travers son réseau de 250 groupes de travail et comités spécialisés, l'OCDE est un forum où les gouvernements peuvent comparer leurs expériences de l'action publique, rechercher des solutions à des problèmes communs, identifier les bonnes pratiques et coordonner les politiques nationales et internationales. Pour plus d'information: www.ocde.org.

\section{À PROPOS DES PUBLICATIONS DE L'OCDE SUR LE DEVELOPPEMENT REGIONAL}

Les publications du Centre pour l'entrepreneuriat, les PME, les régions et les villes de l'OCDE couvrent un large éventail de sujets, notamment l'analyse des statistiques régionales, les politiques urbaines et leur gouvernance, les politiques rurales et leur gouvernance, la gouvernance pluri-niveaux. Selon le programme de travail, ces publications peuvent couvrir des sujets spécifiques tels que les réseaux d'innovation régionaux, le développement durable, les déterminants de la croissance régionale ou la consolidation fiscale au niveau infranational. Les publications de I'OCDE sur le développement régional (OECD Regional Development Papers) sont publiées sur http://www.oecd.org/cfe/regional-policy.

La publication de ce document a été autorisée par Lamia Kamal-Chaoui, Directrice du Centre pour l'entrepreneuriat, les PME, les régions et les villes de l'OCDE.

Ce document et toute carte qu'il peut comprendre ne préjugent en rien du statut de tout territoire, de la souveraineté s'exerçant sur ce dernier, du tracé des frontières et limites internationales, et du nom de tout territoire, ville ou région.

Droits d'image pour la photo de couverture : Gettylmages/NicoEINino

\section{(c) OCDE 2021}

Vous êtes autorisés à copier, télécharger ou imprimer du contenu OCDE pour votre utilisation personnelle. Vous pouvez inclure des extraits des publications, des bases de données et produits multimédia de l'OCDE dans vos documents, présentations, blogs, sites Internet et matériel d'enseignement, sous réserve de faire mention de la source OCDE et du droit d'auteur (copyright). Les demandes pour usage commercial ou de traduction devront être adressées à rights@oecd.org. 


\section{Avant-propos}

La pandémie de COVID-19 et les politiques de réponse, pour couvrir les besoins immédiats en produits sanitaires (les équipements de protection individuelle par exemple) comme pour ralentir la contagion par des mesures de confinement, ont confirmé l'intense imbrication des économies et des sociétés dans un système globalisé.

Le débat public a récemment opposé deux visions de l'impact de la mondialisation. D'une part, ce phénomène est en partie tenu pour responsable de l'accroissement des inégalités territoriales et, par conséquent, de l'expression de "géographies de mécontentement ". D'autre part, les chaînes de valeur mondiales ont constitué un facteur de résilience, en permettant aux entreprises de s'approvisionner de manière plus efficace ; d'accéder à des connaissances et des capitaux au-delà du marché national et à étendre leurs activités sur de nouveaux marchés (OCDE, 2020f). La dimension locale de la mondialisation demeure cependant encore trop peu étudiée, alors même qu'il est unanimement reconnu que ses effets se ressentent d'abord à cette échelle.

Adopter une approche locale pour comprendre la mondialisation est d'autant plus nécessaire que la crise a aussi souligné les grandes disparités territoriales d'impact et de possibilité de réponses tant à court terme, pour ce qui concerne les questions de santé, qu'à plus long terme en matière de relance face à un choc de nature exceptionnelle. Alors même que l'emploi, notamment des jeunes, s'impose comme un objectif prioritaire, nos modes de vie et nos capacités de résilience, en même temps mondiaux et locaux, sont aujourd'hui questionnés. Des voix s'expriment pour s'appuyer sur la prise de conscience suscitée par la crise afin de se tourner vers des modes de développement plus sobres, plus adaptés aux réalités et aux potentialités locales et plus inclusifs. Ces voix soulignent aussi combien ce « virage » doit mobiliser les différentes parties-prenantes, publiques et privées (tournées ou non vers le profit), nationale (voire supranationale en Europe) et, bien évidemment, territoriales.

Au cœur de ces arbitrages figurent les autorités régionales. Elles sont en charge du développement économique et donc du dialogue avec les entreprises dans la plupart des pays de l'OCDE (avec plus ou moins d'exclusivité). Elles interviennent directement pour soutenir les investissements (de transport, de construction, de communication, etc.) qui conditionnent l'impact des activités économiques sur l'environnement et sur la cohésion. Elles sont, enfin, très souvent responsables de la formation, notamment professionnelle et de son adéquation aux besoins des marchés locaux de l'emploi, donc directement tournées vers l'inclusion et la réussite économique dans l'ensemble de ses composantes. Maillon incontournable des réponses de court et de long terme à la crise, les régions n'agissent cependant pas seules. Leur action, tout particulièrement en France, s'inscrit dans le cadre d'une gouvernance pluriniveaux qui doit permettre que s'harmonisent les compétences et les politiques publiques depuis le niveau local jusqu'au niveau national (voire supranational).

Comprendre la mondialisation, ses avantages et ses inconvénients et comment en tirer le meilleur pour le développement territorial, s'avère donc complexe. Tandis que certaines de ses dimensions concernent l'échelle nationale, telles que les accords internationaux, la politique de concurrence ou les taux de change, d'autres sont propres à l'échelle infranationale et sont difficiles à incarner dans des dispositifs nationaux. 
Ce rapport présente les résultats d'un travail commencé en 2019 et qui visait à équiper les acteurs régionaux et nationaux d'un outil de mesure partagé de l'internationalisation des régions. Fort du constat de la variété des dimensions de l'internationalisation des territoires et prenant en compte l'absence d'un outil méthodologique complet à ce sujet, l'OCDE, à la demande de la France, a engagé un travail d'analyse afin de proposer une approche originale à son Comité des politiques de développement régional (RDPC). Le Secrétariat de l'OCDE a bénéficié du soutien du gouvernement français dans cette démarche et en particulier de celui du Commissariat général à l'égalité des territoires (CGET) devenu, depuis, l'Agence nationale pour la cohésion des territoires (ANCT). Cet appui a permis de partager la réflexion dans l'élaboration de l'analyse, d'illustrer les indicateurs et de compléter l'information en appliquant la méthodologie au cas des régions françaises. La réalisation de ce travail a conduit à l'étendre à la question de la gouvernance pluri-niveaux des politiques d'internationalisation permettant de prendre en compte le rôle de l'État dans ce cadre partenarial.

Avec la crise ce travail se révèle anticipateur et opportun puisqu'aujourd'hui il n'y a pas un plan de relance à court ou long terme qui ne mentionne les relations entre la mondialisation et les territoires. En proposant un outil pour mesurer la position des régions dans la mondialisation à travers une variété de " connexions » internationales, ce premier travail entend aider les décideurs publics à mieux comprendre les caractéristiques " internationales " des territoires et à mieux identifier leurs besoins et leurs atouts spécifiques. Pour ce faire, cette étude exploite une approche statistique multidimensionnelle et innovante mais aussi une analyse des documents de référence sur les stratégies d'internationalisation des régions françaises : les Schémas régionaux de développement économique, d'innovation et d'internationalisation (SRDEII). Ceux-ci peuvent paraitre "datés » tant ce qui fait l'environnement socio-économique en 2021 diffère des conditions dans lesquels ils ont été élaborés en 2016. Cependant, en caractérisant les orientations d'internationalisation qui ont engagé l'action des régions depuis lors, leur analyse peut aider à identifier ce qui est structurel dans l'approche territoriale de la mondialisation ainsi que ce qui demeure prioritaire dans les stratégies régionales françaises et pourra faire l'objet d'une mise à jour dans la seconde étape de ce travail. Cette analyse a enfin permis de recenser les pratiques différenciées de mise en œuvre des stratégies d'internationalisation. Dans un contexte où la crise force à travailler ensemble, elle donne à voir les dispositifs de coordination déjà expérimentés et sur lesquels il sera possible d'appuyer les stratégies de demain.

Ce travail a suscité l'intérêt de la Direction générale pour l'appui à la réforme structurelle (DG REFORM) de la Commission européenne, et particulièrement du Programme d'appui à la réforme structurelle (PARS), qui, sollicité par la France, a décidé d'en soutenir financièrement le prolongement dans le cadre d'études de cas de régions françaises réalisées par l'OCDE au bénéfice des autorités françaises.

Ce rapport a été soumis pour validation par procédure écrite au Comité des politiques de développement régional avant le 17 juin 2021 sous la référence CFE/RDPC(2021)8. 


\section{Remerciements}

Ce rapport a été produit par le Centre pour l'entrepreneuriat, les PME, les régions et les villes (CFE) de I'OCDE, dirigé par Lamia Kamal-Chaoui et plus particulièrement sa division Développement Régional et Tourisme dirigée par Alain Dupeyras.

Le Dialogue France-OCDE sur les régions dans la mondialisation a été coordonné par Claire Charbit, Cheffe de l'unité Dialogues Territoriaux et Migrations, avec l'appui de Martin Lestra, Analyste des politiques junior. Le premier chapitre sur la méthodologie statistique a été rédigé par Eric Gonnard, statisticien et le deuxième chapitre sur l'analyse des politiques et de leur gouvernance par Martin Lestra. Les autres éléments ont été rédigés par Claire Charbit avec l'appui de Martin Lestra et ont bénéficié des suggestions de Clément Malgouyres, Économiste à l'Institut des politiques publiques (Ecole d'économie de Paris et Centre de recherche en économie et statistique). Chloé Gatignol, consultante, a contribué à la finalisation de ce document. La méthodologie statistique a bénéficié de la discussion du Groupe de Travail sur les indicateurs territoriaux dont les membres sont ici remerciés.

Ce projet a été réalisé par l'équipe OCDE en étroite collaboration avec les équipes de l'Agence nationale de la cohésion des territoires (ANCT - Ministère de la cohésion des territoires et des relations avec les collectivités territoriales) et l'association Régions de France. Nous remercions particulièrement : Luc Faraldi, Coordinateur politique internationale de l'ANCT et délégué de la France au RDPC, membre du bureau du Comité, qui a largement contribué à ce projet tant dans sa conception initiale que dans sa réalisation par son engagement infaillible et ses conseils; Jamila Jaaïdane, Coordinatrice des politiques de développement économique à l'ANCT dont l'expertise a permis de nourrir ce projet de documents, de conseils et de contacts très utiles ; Benoit de Lapasse, en charge de l'Observation des territoires dans le pôle Analyse et diagnostic territoriaux de l'ANCT pour ses suggestions et sa contribution à la récolte de données ; Jean-Christophe Baudouin, Délégué interministériel au développement de l'axe portuaire et logistique Méditerranée-Rhône-Saône pour sa disponibilité et ses éclairages sur les sujets logistiques et portuaires ; Marc Laget, chargé de projet du Programme "Nouveaux Lieux, Nouveaux Liens" à l'ANCT, pour les éléments qu'il a apportés concernant les infrastructures des technologies d'information et de communication ; et Philippe Cichowlaz, Chef du pôle Politique de Cohésion européenne pour ses suggestions précieuses. Jeremy Pierre-Nadal, Directeur des études et de l'observatoire des politiques régionales et Mickaël Vaillant, Conseiller économie, enseignement supérieur recherche et numérique, de Régions de France sont également chaleureusement remerciés pour l'intérêt qu'ils ont porté à ce projet et leurs conseils avisés.

Ce travail a enfin bénéficié des contributions du Ministère de l'Europe et des affaires étrangères, du Ministère de l'Économie, des finances et de la relance, de Business France, d'Atout France, du Groupe Caisse des dépôts et d'Expertise France. L'ensemble des responsables interviewés sont ici remerciés pour leur intérêt pour le projet et leur disponibilité à le nourrir de leur expérience. 


\section{Table des matières}

Avant-propos 3

Remerciements $\quad 5$

Liste des acronymes $\quad 8$

$\begin{array}{ll}\text { Introduction } & 13\end{array}$

1 Méthodologie et indicateurs d'internationalisation 18

Une proposition de cadre d'analyse de l'internationalisation des régions $\quad 19$

Connexions d'infrastructure $\quad 19$

$\begin{array}{lr}\text { Connexions humaines } & 20\end{array}$

Connexions de connaissance $\quad 20$

Connexions d'affaires $\quad 21$

Proposition méthodologique de mesure de l'internationalisation des régions $\quad 21$ Indicateurs de l'internationalisation $\quad 21$

Définition des indicateurs de référence 23

Positionnement des régions françaises selon les indicateurs d'internationalisation de référence 27

Discussion des indicateurs utilisés et des informations à compléter dans le futur 33

2 Exploration des politiques et de la gouvernance de l'internationalisation régionale 35

Les SRDEII, première expression de la compétence d'internationalisation des régions $\quad 36$

Méthodologie de l'OCDE pour l'analyse des SRDEII $\quad 37$

Les stratégies d'internationalisation des Régions françaises $\quad 40$

Quelle gouvernance pluri-niveaux des politiques d'internationalisation des régions ? 55

SRDEII : Les propositions des régions en matière de gouvernance pluri-niveaux pour

l'internationalisation des territoires $\quad 56$

Les autres partenaires de l'internationalisation des régions 60

La coordination actuelle État-Région pour l'internationalisation des régions : exemples de politiques publiques $\quad 62$

Autres stratégies nationales pour l'internationalisation des territoires $\quad 72$

Conclusion : Vers une vision plus intégrée et cohérente de l'internationalisation des régions 


\section{Tableaux}

Tableau 1.1. Indicateurs de l'internationalisation $\quad 22$

Tableau 1.2. Indicateurs de référence utilisés dans le graphique 1.6 des profils par région 30

Tableau 2.1. Taxonomie des politiques régionales d'internationalisation et de leur gouvernance 39

\section{Graphiques}

Graphique 1.1. Exemple de choix des indicateurs de référence pour les régions françaises 23

Graphique 1.2. Activité des ports maritimes français par zone partenaire, $2018 \quad 24$

Graphique 1.3. Activité des ports maritimes et fluviaux français, $2018 \quad 25$

Graphique 1.4. Trafic aérien régional de passagers par destination, moyenne 2017-19 26

Graphique 1.5. Convergence des régions en termes de productivité de travail, 2000-16 29

Graphique 1.6. Le profil des régions françaises $\quad 30$

Graphique 2.1. Répartition des dépenses des régions selon la Classification des fonctions des administrations

publiques (COFOG) (2016)

Graphique 2.2. Positionnement des régions françaises selon les indicateurs d'internationalisation : les

connexions d'infrastructure

Graphique 2.3. Positionnement des régions françaises selon les indicateurs d'internationalisation : les

connexions humaines

Graphique 2.4. Positionnement des régions françaises selon les indicateurs d'internationalisation : les

connexions de connaissance

Graphique 2.5. Positionnement des régions françaises selon les indicateurs d'internationalisation : les

connexions d'affaires

Graphique 2.6. Disparité de bien-être entre les régions hexagonales françaises et en référence aux régions

des pays de l'OCDE

Graphique 2.7. Dépenses des Régions en pourcentage du PIB et des dépenses publiques totales (2016)

Graphique 2.8. Cartographie institutionnelle des politiques territorialisées de soutien à l'export (incluant Team

France Export)

Graphique 2.9. Cartographie institutionnelle des politiques d'attractivité régionale (y compris Team France Invest)

\section{Encadrés}

Encadré 1.1. L'activité portuaire, un élément clé de développement régional 24

Encadré 1.2. Trafic aérien régional $\quad 26$

$\begin{array}{ll}\text { Encadré 1.3. Définitions } & 27\end{array}$

Encadré 2.1. Bien-être régional $\quad 53$

Encadré 2.2. SRDEII : Stratégies de marketing territorial et internationalisation 56

Encadré 2.3. L'engagement des Régions dans les agendas internationaux $\quad 59$

Encadré 2.4. Le rôle de l'Agence nationale pour la cohésion des territoires dans l'internationalisation des Régions

Encadré 2.5. Team France Export dans le contexte de crise liée à la pandémie liée au COVID-19

Encadré 2.6. L'organisation de l'attractivité dans les pays de l'OCDE et sa dimension territoriale 68

Encadré 2.7. Le COSPE, instance centrale du dispositif Team France Invest 69

Encadré 2.8. La politique d'attractivité des régions et leur coordination avec l'État face à la crise 71

Encadré 2.9. Renforcer la gouvernance pluri-niveaux : le cas des infrastructures portuaires sur l'axe

Méditerranée-Rhône-Saône 


\section{Liste des acronymes}

\begin{tabular}{l|l}
\hline ANCT & Agence nationale de la cohésion des territoires \\
ARD & Agence régionale de développement \\
\hline AURA & Région Auvergne-Rhône-Alpes \\
\hline CCIR & Chambres de commerce et d'industrie régionales \\
\hline CGCT & Code général des collectivités territoriales \\
\hline CITI & Classification internationale type, par industrie, de toutes les branches d'activité économique \\
\hline CRESS & Chambre Régionale de l'Économie Sociale et Solidaire \\
\hline CTAP & Conférence territoriale sur l'action publique \\
\hline DIRECCTE & Direction régionale des entreprises, de la concurrence, de la consommation, du travail et de \\
\hline l'emploi
\end{tabular}




\section{Résumé}

L'impact de la mondialisation sur nos économies et sociétés a suscité une grande attention ces dernières années. II n'en est pas de même pour ce qui concerne ses répercussions locales, malgré l'opinion générale selon laquelle ses effets sont plus ressentis à cette échelle, contribuant en partie à l'accroissement des inégalités et par suite aux manifestations de " géographies du mécontentement ».

Ce constat souligne la complexité de la mondialisation, dont les effets, positifs comme négatifs, ne peuvent être pensés sans considérer de nombreux facteurs. Tandis que certains concernent l'échelle nationale, tels que les accords internationaux, la politique de concurrence ou les taux de change, d'autres sont propres à l'échelle infranationale et sont difficiles à refléter dans des indicateurs nationaux. Les facteurs géographiques et culturels qui sont reconnus comme d'importants déterminants des échanges internationaux, sont sans doute encore plus marqués au niveau territorial. Les régions reculées par exemple bénéficieront moins de l'accès aux marchés étrangers et aux chaînes de valeur mondiales que les régions les mieux connectées. L'éloignement géographique est un défi de taille, même si de bons réseaux de transport et de communication peuvent aider à y répondre. De la même façon, l'environnement culturel varie d'un territoire à un autre, notamment du fait de la diversité des populations présentes.

Ce rapport constitue une première étape pour répondre à ces enjeux en proposant un outil synthétique d'évaluation de l'internationalisation des régions, fondé sur quatre types de "connexions » qui relient les régions à la mondialisation :

- Les connexions d'affaires : concernent les flux internationaux de biens, de services et de capitaux engendrés par les entreprises ;

- Les connexions de connaissance: reflètent les relations internationales qu'entretiennent les centres de recherche, privés et publics ainsi que les universités.

- Les connexions humaines : regroupent une variété de flux tels que le tourisme, l'immigration de court et de long terme, l'emploi saisonnier, qui contribuent à l'internationalisation des régions.

- Les connexions d'infrastructure : ont trait à l'ensemble des réseaux physiques sans lesquels les échanges de biens et de services ne peuvent avoir lieu.

Cette étude, initiée avant la pandémie de COVID-19, applique cette méthodologie au cas de la France. Elle arrive à point nommé alors que gouvernements et entreprises accordent une plus grande importance à la résilience et aux risques (notamment de rupture) associés aux chaînes d'approvisionnement. Les acteurs de nombreux pays et régions sont conduits à repenser leur positionnement et l'organisation des chaînes de valeur mondiales, comme l'attestent les politiques de relocalisation de certaines activités stratégiques (produits pharmaceutiques et équipements de protection personnelle par exemple), sans remettre en cause le fait que les chaînes de valeurs mondiales peuvent aussi être sources de résilience (OCDE, 2020). Ces évolutions peuvent constituer des opportunités comme des menaces pour les entreprises et les régions.

Ces considérations ne sont pas totalement nouvelles et déjà avant la pandémie il était clair que la mondialisation devait évoluer pour bénéficier à tous. La crise a cependant replacé la résilience et l'inclusion au centre des objectifs en accélérant des mégatendances telles que la transition verte et en 
offrant l'opportunité de "reconstruire mieux qu'avant ». Dans le même mouvement, elle a montré l'importance de l'implication des acteurs locaux et du capital social propre à chaque territoire pour adopter les bonnes décisions et réussir un développement plus équilibré, durable et résilient. Ces considérations soulignent le caractère crucial de la gouvernance et de la qualité des relations entre les divers niveaux de responsabilités administratives et politiques.

Ce rapport présente ces différents enjeux et fournit aussi un état des lieux des projets stratégiques développés par les régions françaises en ce qui concerne leurs politiques d'internationalisation. II s'appuie pour cela sur l'analyse de leurs Schémas Régionaux de Développement Économique, d'Innovation et d'Internationalisation (SRDEII). Bien que conçus en 2016-17 pour les cinq ans à suivre, dans un contexte qui ne connaissait pas encore l'ampleur des défis posés par la pandémie et ses conséquences, ces schémas permettent à la fois de valider la grille d'analyse proposée et de souligner l'importance pour leur mise en œuvre efficace de la bonne coordination tant entre les projets qu'entre les acteurs, publics et privés, qui les portent.

Le premier chapitre présente le cadre d'analyse et l'ensemble des indicateurs utilisés par famille de connexions internationales: connexions d'infrastructure; connexions humaines ; connexions de connaissance ; connexions d'affaires.

La liste des indicateurs de l'internationalisation est composée à partir des données disponibles au niveau des régions de la France, de l'Europe et des pays de l'OCDE. Le rapport suggère pour le futur la collection d'informations additionnelles, notamment sur les données relatives à :

- La diversité des partenaires commerciaux étrangers des entreprises dans la région,

- La valeur ajoutée par les entreprises de la région à leur importations et incluses dans leurs exportations,

- L'activité internationale des pôles d'innovation,

- La présence de biens et services culturels (musées, patrimoine, festivals).

Parmi les indicateurs disponibles certains, dits “de référence " sont retenus selon des critères de sélection afin d'illustrer les profils internationaux des régions françaises. Ceux-ci donnent notamment à voir la force des liens de proximité des régions hexagonales frontières avec leurs voisines étrangères et la diversité du positionnement des régions d'Outre-mer dans la mondialisation.

Le second chapitre confronte ces observations statistiques aux stratégies d'internationalisation retenues par les régions dans leur SRDEll. II ressort de cette étude et des éléments additionnels proposés concernant certaines stratégies nationales d'internationalisation des territoires (notamment exportation, attractivité des investissements et infrastructures) que :

(i) Les régions souhaitent agir dans les différents champs de l'internationalisation, sans pour autant toujours adopter une vision systémique de l'internationalisation ;

(ii) Les régions n'agissent pas seules en faveur de l'internationalisation de leurs territoires.

Plus particulièrement :

- Les régions s'intéressent avant tout aux mesures de soutien à l'export des entreprises et de l'attractivité des territoires auprès des investisseurs. Elles développent aussi les politiques en faveur du tourisme, de la coopération internationale en matière de recherche et d'innovation, et soutiennent activement la connectivité internationale des infrastructures. La multiplicité des documents stratégiques élaborés par les régions semble en revanche un obstacle à l'émergence d'une plus grande intégration des différentes facettes de l'internationalisation dans une stratégie régionale d'ensemble.

- Les régions adoptent pour la plupart une vision «multi-objectifs" de l'internationalisation, notamment pour lier la formation, la venue des « talents », la compétitivité des entreprises locales 
à l'international et l'attraction d'investisseurs étrangers. En revanche, elles proposent peu de solutions concernant l'attraction de talents étrangers pour répondre aux besoins immédiats et de plus moyen-terme dans des secteurs variés de leur économie ; et intègrent peu les dimensions du bien-être dans leurs stratégies d'attractivité.

- Les SRDEII proposent de nombreuses innovations institutionnelles pour soutenir l'internationalisation des territoires - coopérations interrégionale, transfrontalière, européenne marqués par le cadre européen de soutien à l'innovation et à la recherche et aux politiques de cohésion.

- Les régions et leurs partenaires, État et autres collectivités territoriales, agissent pour l'internationalisation des territoires, notamment dans le cadre de réformes encore en cours de mise en œuvre et proposant une vision intégrée du développement économique (par exemple : Plan France Haut Débit, dispositifs Team France Export et Team France Invest).

La pandémie a bouleversé les agendas aux niveaux régional et national, comme l'illustrent les débats autour des contrats de plan État-Régions ${ }^{1}$ ou les réorientations de la programmation européenne (Régions de France, 2020 ; Commission européenne, 2020). ${ }^{2}$ En effet, la crise sanitaire et les enjeux environnementaux interrogent non seulement les modalités d'engagement des régions dans des chaînes de valeur mondiales, mais plus fondamentalement la dynamique de mondialisation elle-même.

Dans ce contexte particulier, les régions sont en première ligne, et aux côtés de l'État, dans le cadre des accords de relance État-Régions et du Conseil économique État-Régions, ${ }^{3}$ pour répondre à la crise, notamment en matière d'internationalisation. L'Accord de méthode État-Régions (30 juillet 2020) et l'Accord de partenariat État-Régions (28 septembre 2020) proposent des objectifs prioritaires (transition écologique, souveraineté économique, réduction des inégalités territoriales, etc.) et des dispositifs d'internationalisation (renforcement des dispositifs Team France Export et Invest ; simplification de l'aide à l'innovation ; soutien à la montée en gamme de l'offre touristique, etc.) pour soutenir la relance dans, et par, les territoires.

Sur le court-terme, les régions ont agi pour répondre aux besoins de la demande en matériel de santé ou en soutien des populations ou entreprises les plus touchées afin de limiter l'impact sur l'emploi. À moyen et long terme elles expriment leur volonté d'agir sur les chaînes de valeur mondiales, du côté de l'offre, en relocalisant certaines productions jugées essentielles via notamment de possibles "pactes " de relocalisation pour les entreprises. ${ }^{4}$ Par ailleurs, les plans de relance annoncés par les régions comprennent des mesures fortes concernant des secteurs d'activités très "internationalisés " aéronautique, numérique, agriculture. Les régions ont surtout proposé, dans le cadre d'un "New deal industriel et environnemental » (Régions de France, 2020) une adaptation de court et long terme de l'internationalisation en coordination avec l'État :

- D'une part, les régions souhaitent initier des mesures favorables à la poursuite de l'internationalisation, par des « contrats de relance " pour des projets actuellement ralentis ou à l'arrêt faute de moyens dans le domaine des infrastructures de mobilité, des projets scientifiques et technologiques, déploiement du très haut débit, etc.; ou encore par la relance de l'activité touristique ;

\footnotetext{
${ }^{1}$ Les régions ont ainsi proposé que les projets de relance en réponse à la pandémie de COVID-19 fassent l'objet d'une contractualisation rapide entre l'État et les régions et se substituent aux actuels Contrats de plan État-Régions en y intégrant des dimensions complémentaires.

${ }^{2}$ Au-delà de l'approbation d'un cadre financier pluriannuel pour 2021-2027, l'Union européenne a annoncé d'ambitieux programmes de relance pour un montant total de 750 milliards d'euros (programme Next Generation EU, initiatives Recovery and Resilience facility, Recovery Assistance for Cohesion and the Territories of Europe - REACT-EU), ainsi que le renforcement programmes soutenant les régions européennes ( programmes de développement rural, Just Transition Mechanism, etc.)(Commission européenne, 2020b).

${ }^{3}$ Ce Conseil s'est réuni pour la première fois le 18 décembre 2019.

${ }^{4}$ L'lle-de-France, le Grand-Est ou l'Occitanie ont par exemple lancé des « pack » ou « pactes » de relocalisation.
} 
- D'autre part, les régions souhaitent mettre en œuvre une « nouvelle politique industrielle » afin de favoriser la résilience et la sécurité du système productif.

Ces nouveaux défis guideront l'élaboration de la prochaine génération de schémas stratégiques.

La pandémie de COVID-19 rappelle que l'internationalisation n'est pas une fin en soi. L'utilisation des données probantes et du panorama des politiques d'internationalisation proposées dans ce document, doivent asseoir les nouveaux modèles de développement esquissés par les régions dans le cadre de leurs plans de relance. Les nouvelles modalités de coopération État-Région doivent, quant à elles, permettre d'éviter que les stratégies d'internationalisation des territoires ne conduisent à un jeu à somme nulle, certains gagnant ce que les autres perdent, et qu'ouverture et résilience aillent de pair pour soutenir le développement inclusif et durable des régions françaises. 


\section{Introduction}

Les pays de I'OCDE font face à des déséquilibres territoriaux de tous ordres qu'ils s'emploient à faire évoluer favorablement. Ces déséquilibres se matérialisent par des disparités entre les différentes régions de chacun des pays ; entre les villes et les différents types de ruralités, entre les métropoles et leur « hinterland ». Ces disparités territoriales peuvent également concerner différents types de quartiers au sein même des villes. L'ensemble s'est souvent aggravé depuis la crise de 2008 et est porteur d'inégalités, de tensions non négligeables se traduisant dans une géographie du mécontentement, phénomène mondial. En France, la crise dite des « gilets jaunes » en est le principal marqueur.

Ces disparités ont des causes diverses et trouvent, pour une part, leurs racines dans les histoires, les géographies, les développements économiques singuliers des pays concernés. Qu'il s'agisse d'économies " émergentes " ou installées sur un écosystème ancien d'entreprises, d'infrastructures, de qualifications professionnelles, de générations de chercheurs et d'experts et de savoir-faire dans l'accueil et la mobilisation de talents étrangers, elles ont toutes en commun d'exister de manière contemporaine face à une mondialisation qui s'est considérablement accélérée au tournant du millénaire. Celle-ci a multiplié et intensifié les flux financiers (entrants et sortants), de biens (matières premières, de biens manufacturés, déchets, d'énergie), les flux de personnes (aussi bien les touristes que les migrants) et d'informations (d'innovation, d'expertise, d'œuvres artistiques). L'évolution continue de ces flux et des cours qu'ils empruntent redessine les chaînes de valeurs, déplace les sites de production, les centralités, les voies et les modes de communication. Ce faisant, elle multiplie également les rencontres et les opportunités mais aussi parfois les confrontations, les rejets, les enclavements.

L'existence des effets disparates de la mondialisation et des changements technologiques fait partie des constats qui sont partagés par les gouvernements des pays de l'OCDE et rappelés dans la Déclaration sur les politiques permettant de forger un avenir meilleur pour les régions, lors de la rencontre ministérielle du Comité des politiques de développement régional à Athènes en 2019. L'actualité demande, cependant, avec insistance de travailler plus profondément et plus efficacement la question. Du fait de la crise qui frappe l'économie mondiale, les décisions des acteurs, publics ou privés, doivent aujourd'hui être prises dans un contexte "d'incertitude radicale » (Knight, 1921; OCDE, 2020a) ${ }^{5}$. Celle-ci concerne non seulement l'ampleur du choc économique et social et le niveau des réponses à y apporter, mais aussi les motivations et l'organisation des activités humaines elles-mêmes. La prise de conscience des risques associés à nos modes de vie (globalisés, largement urbanisés mais territorialement diversifiés, consommateurs de ressources non renouvelables et souvent inégalitaires) pourrait constituer une occasion pour les transformer dans un sens positif. Tout en bénéficiant d'une sorte de "réenchantement » par rapport à la stricte logique de « marché », la décision publique dans ce contexte n'est pas simple : elle doit à la fois répondre aux énormes défis de court terme en soutenant les dépenses de santé et les entreprises comme les publics les plus précaires, tout en s'engageant dans des programmes de long terme ambitieux sous tendus notamment par la transition écologique. Elle doit à la fois « redistribuer » et « pré-distribuer » (Subramanian, 2020) en influençant les résultats de l'activité des marchés.

\footnotetext{
${ }^{5}$ Le dernier rapport des Perspectives économiques de l'OCDE tient compte du fort niveau d'incertitude et distingue ainsi deux scenarii pour établir sa prospective, voir https://www.oecd.org/fr/presse/sur-la-voie-de-la-reprise-leconomie-mondiale-est-sur-une-ligne-de-crete.htm
} 
Or, la décision publique n'émane pas d'un seul acteur mais de l'imbrication de l'action de l'État et des collectivités territoriales et, en Europe, du niveau supranational (OCDE, 2020b). Même si la coordination de cette action pluri-niveaux est un défi, la pluralité des engagements est une chance, et pas seulement pour les solutions de co-financement qu'elle permet. En contexte d'incertitude radicale, nul acteur n'est omniscient et nul ne peut s'appuyer uniquement, sans risques importants pour une décision publique, sur des principes normatifs standards. Chacun apporte sa connaissance et ses moyens, les acteurs publics comme, d'ailleurs, les entreprises, les associations de tous ordres et les individus - à l'élaboration d'une action qui ne peut être uniforme. La crise, en effet, a marqué les territoires de manière différenciée ; les possibilités pour y répondre et les nécessités auxquelles il faut pouvoir faire face, ne sont pas les mêmes partout. Les spécialisations sectorielles régionales et leur plus ou moins grande sensibilité à l'échange international et aux voyages (OCDE, 2020c) ; la taille des entreprises locales (Card et al., 2018) ; l'accès aux infrastructures et aux services (Brezzi et Luongo, 2016) ; la concentration urbaine (OCDE, 2020c) sont notamment des facteurs qui caractérisent à la fois l'impact mais aussi les trajectoires d'inflexion à apporter.

A ces considérations économiques, il convient d'ajouter des éléments plus difficilement évaluables et pourtant encore plus déterminants de la capacité à répondre à la crise et ses conséquences ; on peut notamment citer la cohésion sociale, le capital social, la confiance des individus dans les autres et dans les institutions. Ces aspects sont eux aussi géographiquement déterminés. Ces facteurs-là, comme les précédents, expliquent des disparités qui existaient déjà avant la pandémie que la crise de 2008 et parfois - les réponses apportées, avaient aussi aidé à façonner. Ils contribuent à expliquer la " géographie du mécontentement » qui s'est dessinée en France comme ailleurs, dans de nombreux pays de l'OCDE et hors OCDE (Rodríguez-Pose 2017 ; McCann 2020 ; Algan et al., 2020).

En quoi la crise actuelle rebat-elle les cartes pour les territoires plongés dans la mondialisation, leurs entreprises et leurs habitants? Comment transforme-t-elle leurs relations avec les autres mégatendances qui se surajoutent à la mondialisation économique - digitalisation, changement climatique, évolution démographique, (OECD, 2019a) ${ }^{6}$ - qui lui préexistaient? Et comment influence-t-elle l'agenda des politiques territoriales (en infléchissant celles déjà engagées et proposant des innovations) ? Le présent rapport n'a pas l'ambition de répondre à l'ensemble de ce vaste questionnement. II vise néanmoins à y contribuer en s'attachant à éclairer l'inscription des régions dans la mondialisation.

La mondialisation est en ce moment contestée. Sur quoi s'appuie cette remise en cause ? Les chaînes de valeur mondiales induisent la spécialisation dans des segments de filière et la généralisation de la gestion en flux (internationaux) tendus pour optimiser la fragmentation internationale de la production et de la consommation. La pandémie questionne fortement cette forme de mondialisation et en particulier ce qu'elle implique de dépendance en matière de produits essentiels. Des voix s'expriment donc aujourd'hui pour réclamer la « relocalisation » d'entreprises et d'activités jugées vitales ainsi que l'amélioration des politiques de stock. Des plans de relance sectoriels portés notamment par l'État français (automobile, aéronautique, santé) couplés à des plans de relance élaborés par les régions, sont d'ailleurs élaborés dans ce sens, en réinterrogeant la capacité des entreprises à réinvestir au niveau local ${ }^{7}$. À cette remise en cause s'ajoute celle qui souligne l'impact - et tout particulièrement au niveau local - sur l'environnement d'une organisation de la production fondée sur la logique de la performance/coût qui ignore ses externalités négatives notamment en termes d'émissions de $\mathrm{CO} 2$ issues des transports de marchandises et des déplacements de visiteurs dans le cadre du tourisme de masse.

Est aussi remise en cause la domination des marchés internationaux sur les besoins locaux pour décider des spécialisations jugées pertinentes, mettant en tension, parfois sans concertation, l'écosystème économique local et menaçant, à l'occasion, la biodiversité et la qualité des paysages. Enfin, de forts

\footnotetext{
${ }^{6}$ Ces mégatendances ont été soulignées par les pays-membres de l'OCDE durant la 4 e réunion ministérielle du Comité des politiques de développement régional, à Athènes, mars 2019.

${ }^{7}$ Les territoires intercommunaux (EPCl) dotés de la compétence de développement économique s'engagent aussi dans des études diagnostics évaluant le degré de dépendance de leur tissu économique au travers d'une cartographie des achats
} 
mouvements au sein des sociétés civiles soulignent que la croissance issue de cette dynamique de mondialisation ne s'associe pas toujours à un développement plus équilibré entre les personnes d'une part et, d'autre part entre les territoires mais est perçue comme participant au mouvement inégalitaire d'une concentration toujours plus forte des richesses et des moyens d'agir.

Un premier niveau de réponse pourrait être qu'en parallèle à tous ces défauts et tous ces inconvénients, l'internationalisation peut induire des retombées locales positives (Lembcke et Wildnerova, 2020 ; OCDE, 2020 $)^{8}$ en termes de compétences et d'innovations, améliorer la situation de l'emploi, permettre d'accéder à des ressources-clés, à des infrastructures et des services, et une meilleure répartition territoriale des activités économiques en évitant, par exemple, les surconcentrations industrielles que certaines régions françaises ont pu connaître dans le courant du $20^{\circ}$ siècle avec tous leurs désavantages en termes d'environnement et de mauvaise qualité de vie (OCDE, 2020f).

Un deuxième niveau de réponse pourrait être que, de fait, l'internationalisation n'est pas un objectif en soi et la crise pourrait permettre une évolution des objectifs, du « toujours plus » (d'économies, d'exportations, d'investissements directs étrangers, de touristes) au « bien meilleur » (pour les personnes, les entreprises locales, l'installation des centres de décision des firmes internationales (Giroud, 2013 ; Bassanini et al., 2017), notamment en ce qui concerne l'équilibre urbain-rural et l'environnement.

Cette perspective "gagnant-gagnant » entre internationalisation et développement territorial inclusif et durable ne peut pas être atteinte de manière "automatique " ou même "systémique ", par le seul fonctionnement du marché. Elle est largement façonnée par l'action publique, bien consciente que la crise ne doit pas conduire à fermer les frontières, les mouvements de personnes et les échanges de connaissance et de produits au niveau international. S'appuyant sur le constat qu'il n'est pas possible ni pertinent de « tout » relocaliser et de prendre le risque de ruptures d'approvisionnement et d'augmentation brutale des prix, ce troisième niveau de réponse, invite à penser qu'une transformation progressive ${ }^{9}$ et territorialement équilibrée doit tenir compte des caractéristiques locales et des liens internationaux existants entre les territoires. Par exemple, le tassement des chaînes de valeur mondiales au profit du recours accru à la production nationale peut avoir un double effet : positif sur l'emploi mais négatif sur les prix à la consommation.

Le quatrième niveau de réponse tient au fait que tous ces phénomènes sont traversés par une autre vague de fond, la tendance à la numérisation, que la crise actuelle a renforcée et qui accentue les différences régionales en transformant les modes de production, de travail, de consommation et de loisir. C'est notamment à l'intérieur même des régions, entre leurs territoires urbains et ruraux, que se jouent de nouvelles transformations. II est bien difficile aujourd'hui de savoir quel sera le résultat en termes d'attractivité territoriale de l'automatisation des fonctions les moins qualifiées dans les industries manufacturières traditionnellement localisées en zones peu denses (compte tenu de leurs besoins fonciers). II est de même, difficile d'anticiper les conséquences territoriales de l'adoption massive du télétravail. Si les zones urbaines semblent avoir bénéficié d'un avantage comparatif, avec une meilleure accessibilité aux réseaux haut débit et une concentration en moyenne plus élevée d'emplois à fort potentiel pour le télétravail, d'autres régions (les villes moyennes par exemple) pourraient gagner en attractivité avec le maintien durable du travail à distance (OCDE, 2021). Cette tendance pourrait remettre en cause l'intérêt à l'agglomération des fonctions clés en centre urbain si la volonté des cadres de se relocaliser dans des conditions plus avantageuses (en coût, en espace et en qualité de l'environnement) perdurait au-delà de la crise (OCDE, 2021). Les infrastructures de transport et d'accès au haut débit, par essence localisées, seront à ce sujet déterminantes.

\footnotetext{
${ }^{8}$ Lembcke and Wildnerova (2020) montrent que les PME locales bénéficient d'autant plus de l'investissement direct étranger dans leur région en termes de productivité que celui-ci concerne un secteur d'activité diffèrent de celui de l'entreprise locale.

9 Comme l'indique Mouhoud (2020), c'est plutôt à un «tassement » des délocalisations (offshoring) qu'à une croissance forte des « relocalisations » que l'on assistera, au moins à court terme.
} 
II n'y a donc pas de solution optimale universelle à la mise en place de politiques d'internationalisation inclusive et durable à l'ère de la pandémie de COVID-19. On peut tout au moins souligner que celles-ci doivent garder parmi leurs objectifs celui de la maitrise des biens et services essentiels au profit des territoires et de leurs habitants. II est utile de remarquer à ce sujet qu'être autonome localement, c'est aussi accepter de s'internationaliser en intégrant les personnels qui fournissent les services vitaux : la crise a en effet favorisé la prise de conscience qu'une large part de ceux qui fournissent ces services essentiels sont d'origine étrangère (Charbit et Tharaux, 2020). Pour un développement régional résilient, il convient donc de soutenir la diversité des sources d'approvisionnement, l'inclusion de tous, et la capacité locale à innover qui conditionne l'aptitude à adopter les innovations d'ailleurs et à en produire de nouvelles. L'action publique doit ainsi intégrer différentes dimensions de l'internationalisation et s'appuyer sur des dispositifs de gouvernance permettant la mise en œuvre de politiques d'internationalisation cohérentes et efficaces.

Ce rapport a pour objectif d'aider la décision publique en proposant dans son premier chapitre un outil d'évaluation de la position des régions dans la mondialisation. Pour ce faire, il distingue quatre familles de "connexions internationales" et les indicateurs représentatifs: d'infrastructures, de personnes, de connaissance et d'affaires. Cette approche pluridimensionnelle est ensuite appliquée au cas des régions françaises afin d'en présenter les différents profils d'internationalisation. II s'appuie sur la collecte inédite de données pour situer les régions françaises non seulement les unes par rapport aux autres, mais aussi, lorsque les données sont disponibles, par rapport aux autres régions européennes et des pays de l'OCDE.

Le second chapitre explore les projets retenus par les régions dans le cadre de leurs schémas stratégiques. Ce rapport, en effet, part du principe que les territoires sont en première ligne. Ce sont les régions qui peuvent élaborer une vision qui dépasse les logiques sectorielles et fragmentées géographiquement au profit de l'adaptation territorialisée des politiques aux opportunités et besoins locaux. De plus, elles sont des acteurs majeurs de l'internationalisation, notamment du fait de leurs compétences en matière de développement économique. Ainsi les Schémas régionaux de développement économique, d'innovation et d'internationalisation (SRDEII) adoptés, conformément aux dispositions de l'article 2 de Loi $n^{\circ}$ 2015-991 du 7 août 2015 portant nouvelle organisation territoriale de la République font figurer pour la première fois un volet « internationalisation » qui comprend notamment des mesures en faveur des exportations mais aussi de soutien à l'attractivité régionale. D'où l'intérêt de s'attacher à ces documents stratégiques (en l'occurrence, à leur premier génération) en vérifiant la pertinence de les analyser selon les différentes dimensions de connexions internationales proposées auxquels il convient d'ajouter deux dimensions pour rendre compte de la structuration des modes d'action régionaux:

- Les démarches d'intégration des stratégies régionales articulant différents objectifs d'internationalisation

- La coordination pluri-acteurs de la mise en œuvre des politiques, et en particulier des dispositifs État-Régions coordonnant les politiques d'internationalisation à travers différents exemples et tout particulièrement en ce qui concerne les connexions d'affaires.

La conclusion souligne la nécessité d'adopter des politiques d'internationalisation territorialisées, informées et complémentaires (plutôt que monodimensionnelles) et intégrant les différentes cibles pour plus d'efficacité. Elle propose enfin des pistes de réflexion pour la poursuite de ce travail initial.

Cette étude originale revêt un caractère préliminaire à différents égards qu'il conviendra de compléter :

- Tout d'abord, en ce qui concerne l'exercice statistique dans la mesure où certaines données manquent pour l'analyse statistique comparative. 
- Il convient aussi de noter que l'analyse des SRDEII, même si elle offre un échantillon pertinent de comparaison, devra être complétée par l'analyse des politiques d'internationalisation, de court et de long terme, en réponse à la crise.

- Enfin, la présentation exploratoire des relations entre les acteurs institutionnels de l'internationalisation des territoires en France s'attache aux aspects règlementaires mais ne permet pas de rendre compte de la diversité des réalités de leur mise en œuvre.

Un travail plus approfondi, prévu en lien avec la France et son Agence nationale pour la cohésion des territoires et avec l'appui de la Commission européenne permettra d'éclairer les bonnes pratiques comme les difficultés depuis l'expérience de terrain. 


\section{Méthodologie et indicateurs d'internationalisation}

Ce chapitre vise à répondre aux questions suivantes :

- Quels sont les thèmes et les indicateurs pertinents pour mesurer le degré et la nature de l'internationalisation des régions et aider ainsi à l'élaboration des politiques ?

- Les mesures sur l'internationalisation des régions disponibles à l'heure actuelle sont-elles suffisamment instruites ou devraient-elles être améliorées, notamment afin de favoriser les comparaisons entre les territoires et entre les différentes époques ?

Il y répond :

- En proposant un cadre conceptuel original qui mobilise des indicateurs sur la base des données disponibles organisés autour des quatre piliers identifiés pour refléter les différentes dimensions de l'internationalisation des régions :
- Les connexions d'infrastructure,
- Les connexions humaines,
- Les connexions de connaissance,
- Les connexions d'affaires.

- En précisant les problèmes liés à la collection de données ; l'objectif, sur ce point, étant de proposer aux autorités statistiques nationales intéressées par le sujet de l'internationalisation des régions des suggestions utiles pour améliorer la fourniture d'informations. Un nouvel ensemble d'indicateurs visant à mesurer le niveau d'internationalisation des régions de l'OCDE (au sens infranational).

L'élaboration de cette partie quantitative a bénéficié des contributions de l'ANCT (de ses services rattachés à la Direction générale déléguée à l'appui opérationnel et stratégique, notamment de son Pôle analyse et diagnostics territoriaux, de son Observatoire National des Territoires et de ceux de la Direction générale déléguée aux territoires et aux ruralités) et de celles de Business France.

La méthodologie présentée dans ce rapport a bénéficié de ces échanges ainsi que des travaux précédents du Groupe de travail sur les indicateurs territoriaux de l'OCDE, qui réunit des experts de tous les pays de l'OCDE et les pays, partenaires qui mènent des travaux statistiques sur la mesure et l'analyse des économies régionales. ${ }^{10}$

\footnotetext{
${ }^{10}$ Voir le rapport précédent «L'internationalisation des régions » présenté en octobre 2019 au groupe de travail sur les indicateurs territoriaux du comité des politiques de développement régional de l'OCDE.
} 


\section{Une proposition de cadre d'analyse de l'internationalisation des régions}

Les indicateurs suivants fournissent un cadre d'ensemble pour évaluer l'internationalisation des régions. Ils offrent un aperçu du niveau actuel des connexions internationales d'une région en s'appuyant sur les quatre piliers :

- Les connexions d'infrastructure

- Les connexions humaines

- Les connexions de connaissance

- Les connexions d'affaires

L'objectif de ce chapitre est de présenter un premier état des lieux des indicateurs disponibles pouvant décrire le niveau actuel des connexions internationales des régions. Nous suggérerons également des indicateurs additionnels permettant de consolider une vision holistique du phénomène d'internationalisation des régions.

Par ailleurs, les indicateurs présentés plus bas ne reprennent pas certains facteurs clés en termes de « potentiel » d'internationalisation, dont l'impact sur l'attractivité est majeur, notamment les cadres juridiques et l'environnement institutionnel national ; la qualité institutionnelle régionale ; la facilité à pratiquer des affaires pour se focaliser sur les dimensions qui permettent de rendre compte des interactions entre région et mondialisation.

\section{Connexions d'infrastructure}

Les « connexions d'infrastructure » font référence à l'offre de connexions physiques qu'une région propose à ses potentiels partenaires internationaux. Leur existence et leurs caractéristiques conditionnent l'existence et l'intensité des différents flux liant les régions à leurs partenaires internationaux que ce soit en termes humains, financiers, de marchandises ou de données.

L'OCDE ne collecte pas de données exhaustives à l'échelle régionale sur les infrastructures, mais dispose de certains indicateurs spécifiques tels que la part des ménages disposant d'une connectivité à large bande, au niveau des régions TL2 ${ }^{11}$.

À l'échelle européenne, cependant, Eurostat dispose de données sur les infrastructures et le trafic aérien, ferroviaire, maritime et routier que nous avons donc pu utiliser.

Cela nous a permis de sélectionner les indicateurs suivants :

(i) Concernant l'accès au réseau routier

- Accessibilité aux autoroutes et 2x2 voies

- Accessibilité aux autoroutes

(ii) Concernant l'accès au hubs ferroviaires et aéroportuaires

- Accessibilité aux gares

\footnotetext{
${ }^{11}$ Dans toute analyse économique au niveau infranational, le choix de l'unité territoriale est primordial. Aussi l'OCDE a-t-elle dressé dans chaque pays membre une carte des régions à deux niveaux. Le niveau supérieur, niveau territorial 2 (TL2) équivalent des régions françaises, compte 394 grandes régions et le niveau inférieur, niveau territorial 3 (TL3) équivalent aux départements français, 2258 petites régions. Toutes les unités territoriales s'inscrivent dans les frontières nationales et correspondent le plus souvent aux découpages administratifs. Cette classification (qui, pour les pays européens, coïncide largement avec celle d'Eurostat, NUTS2 et NUTS3) facilite la comparaison d'ensembles géographiques de même niveau territorial. Les deux niveaux retenus, officiellement reconnus et relativement stables dans tous les pays membres, servent d'ailleurs de cadre à la mise en œuvre des politiques régionales dans la plupart des pays. Grille territoriale de l'OCDE (pdf) : http://www.oecd.org/governance/regional-policy/42392313.pdf;
} 
- Accessibilité aux aéroports

(iii) Concernant la logistique

- Logistique terrestre : nombre d'entrepôts de plus de $5000 \mathrm{~m}^{2}$

- Logistique terrestre : part des chargements et déchargements étrangers dans les entrepôts*

- Logistique maritime : volume et part du fret maritime international

(iv) Concernant la couverture numérique et ses usages

- Couverture en fibre optique

- Ménages connectés à internet haut débit

- Utilisation d'internet : vente de biens et services

- Utilisation d'internet : usage des services bancaires

- Utilisation d'internet : participation aux réseaux sociaux

\section{Connexions humaines}

Une dimension importante de l'internationalisation est liée aux personnes et plus particulièrement aux visiteurs et aux migrants.

Les connexions humaines prennent ainsi en compte les données sur les migrations, non seulement la durée de séjour de migrants mais aussi la part de la population née à l'étranger. L'OCDE dispose de données sur la présence et l'intégration des migrants essentiellement au niveau NUTS2 et plus partiellement NUTS3 (niveau équivalent à celui des départements français).

Les connexions humaines prennent également en compte le tourisme. L'OCDE ne publie pas de données sur le tourisme régional pour ses pays membres, mais s'appuie sur les travaux de l'UNESCO (nombre de sites inscrits au patrimoine mondial) ou du Centre commun de recherche de la Commission européenne (par exemple, l'indicateur sur la vulnérabilité liée à l'exposition au tourisme - JRC) (Batista e Silva et al., 2018) $)^{12}$ et d'Eurostat (par exemple, le nombre de nuitées touristiques). En outre, de nombreux pays membres, comme la France, l'Espagne ou le Royaume-Uni, collectent des informations utiles concernant le nombre d'arrivées et l'emploi dans ce secteur au niveau infranational (OCDE, 2016).

\section{Connexions de connaissance}

Les flux de connaissance sont un aspect crucial de l'internationalisation et, dans une société numérique caractérisée par une évolution rapide, ils contribuent fortement au succès des activités des personnes, des entreprises et des territoires. Les connexions de connaissance comprennent en principe un grand nombre d'aspects, bien que la littérature existante ne fournisse que peu d'indicateurs permettant de comparer les régions d'un pays à l'autre. Parmi les indicateurs disponibles figurent la production de brevets, les dépenses de $R \& D$ et des mesures relatives aux industries à forte intensité de connaissance. Ce pilier prend comme hypothèse essentielle que les secteurs les plus innovants créent davantage de liens internationaux. En effet, la recherche empirique montre qu'un accès accru au marché étranger augmente les incitations à l'innovation qui augmente à son tour la productivité et accroit finalement la taille du marché (Lileeva, A. and D. Trefler, 2010). En outre, la R\&D permet aux entreprises de mieux résister

\footnotetext{
12 La vulnérabilité régionale au tourisme est mesurée par l'exposition d'une région aux chocs dans le secteur du tourisme et intègre deux notions : l'indice d'intensité touristique dans chaque région, calculé à partir du quotient de localisation du nombre de touristes en fonction de la population; de la saisonnalité régionale selon des données mensuelles obtenues à partir de données massives. Chaque région est notée de 1 à 4 pour chaque indicateur (intensité et saisonnalité) et la vulnérabilité du tourisme est calculée comme le produit des scores respectifs, allant ainsi de 1 à 16.
} 
à la concurrence étrangère (Hombert, $A$. and $A$. Matray, 2015). Le nombre de dépôts de co-brevets entre partenaires de différents pays représente l'une des mesures les plus appropriées car elle est par essence liée aux flux de connaissances (du moins entre inventeurs).

\section{Connexions d'affaires}

Les relations d'affaires sont un aspect clé, souvent d'ailleurs le seul retenu, des relations mondialisées. Elles se matérialisent en premier lieu par des échanges marchands, importations et exportations, au stade final ou intermédiaire. Les entreprises multinationales jouent un rôle moteur tant de la mondialisation que de la fragmentation internationale de la production qui en découle. En conséquence, elles font l'objet d'une demande croissante de meilleures mesures de leurs activités en termes d'échelle réelle (comprenant leurs filiales à l'étranger, leurs liens avec d'autres entrepreneurs indépendants, etc.). Les multinationales jouent également un rôle toujours croissant dans le développement des chaînes de valeurs mondiales, qui ne se limitent pas aux seuls commerce et investissements directs étrangers : elles ont un effet direct et global sur l'organisation des systèmes de production et des fonctions de services afférant (R\&D, marketing, maison-mère, etc.). L'OCDE dispose de données nationales et non pas infranationales sur les chaînes de valeur mondiales et le commerce à valeur ajoutée.

Dans l'ensemble, les indicateurs statistiques comparables au niveau régional sur les connexions d'affaires sont rares. Actuellement, les mesures les plus pertinentes concernent le commerce d'une région telles que la part de l'économie régionale dans les secteurs des «biens échangeables " (voir définition Encadré 1.3), le niveau d'importation/exportation, et la position de l'investissement direct étranger. Si certains pays (dont la France) disposent de données régionales sur les importations et les exportations de biens, plus de la moitié des pays de l'OCDE ne communiquent pas ces informations. La possibilité de disposer de données complémentaires comparées au niveau régional est en cours d'étude.

\section{Proposition méthodologique de mesure de l'internationalisation des régions}

\section{Indicateurs de l'internationalisation}

La liste d'indicateurs mise en forme dans le tableau ci-dessous vise à fournir une base de données cohérente, comparable et une mesure concrète de l'internationalisation des régions, en aidant aussi les régions à comparer leur niveau d'internationalisation.

Dans le Tableau 1.1, le symbole ** identifie les indicateurs de référence (voir Définition des indicateurs de référence), et le symbole ${ }^{* * *}$ signifie que ces indicateurs sont distribués par nationalité ou pays partenaires. 
Tableau 1.1. Indicateurs de l'internationalisation

\begin{tabular}{|c|c|c|c|}
\hline Indicateurs & Source & Couverture géographique & Période \\
\hline \multicolumn{4}{|l|}{ 1. Connexions d'infrastructure } \\
\hline Accessibilité aux autoroutes et $2 \times 2$ voies, source CGET & Observatoire & France, TL2, municipalités & 2009 \\
\hline Accessibilité aux autoroutes & $\mathrm{RCl}(\mathrm{CE})$ & EU 28 & 2016 \\
\hline Accessibilité aux gares & $\mathrm{RCl}(\mathrm{CE})$ & EU 28 & 2014 \\
\hline Accessibilité aux aéroports ${ }^{* *}$ & $\mathrm{RCl}(\mathrm{CE})$ & EU 28 & 2016 \\
\hline Couverture en fibre optique ** & OCDE & 18 pays, TL2, FUA & 2016 \\
\hline Ménages connectés à internet haut débit ** & OCDE & Pays de l'OCDE, TL2 & 2008 à 2019 \\
\hline Utilisation d'internet : vente de biens et services ** & Eurostat & EU 28 & 2011 à 2019 \\
\hline Utilisation d'internet : usage des services bancaires & Eurostat & EU 28 & 2011 à 2019 \\
\hline Utilisation d'internet : participation aux réseaux sociaux ** & Eurostat & EU 28 & 2011 à 2019 \\
\hline Logistique terrestre : nombre d'entrepôts de plus de $5000 \mathrm{~m} 2{ }^{\text {** }}$ & SOes & France hexagonale & 2014 \\
\hline Logistique terrestre : \% dé)chargements étrangers dans les entrepôts ${ }^{\star *}$ & SOes & France hexagonale & 2014 \\
\hline Logistique maritime : $\%$ fret maritime international & Eurostat & EU 28 & 2018 \\
\hline \multicolumn{4}{|l|}{ 2. Connexions humaines } \\
\hline \multicolumn{4}{|l|}{2.1 Tourisme } \\
\hline Nombre d'établissements d'hôtellerie source EU & Eurostat & EU 28 & 2000 à 2018 \\
\hline Tourisme (nombre de lits pour 1000 hab.) source EU ** & Eurostat & EU 28 & 2000 à 2018 \\
\hline Nuitées touristiques (étrangers et nationaux) & Eurostat & EU 28 & 2000 à 2019 \\
\hline Nuitées par km2 (étrangers et nationaux) & Eurostat & EU 28 & 2000 à 2018 \\
\hline Nuitées pour 1000 habitants (étrangers et nationaux) & Eurostat & EU 28 & 2000 à 2018 \\
\hline Part de nuitées effectuées par des étrangers ** & Eurostat & EU 28 & 2000 à 2018 \\
\hline Intensité touristique & JRC & EU 28 & 2014 \\
\hline Part des propriétaires étrangers (résidence principale) & Observatoire & France, TL2 & 2015 \\
\hline \multicolumn{4}{|l|}{ 2.2 Part des migrants } \\
\hline Part de la population de migrants (Total, UE, non-UE) ${ }^{* \star * *}$ & OCDE & 28 pays, TL2 & 2015 \\
\hline Part des migrants selon la durée de présence ( $<>10$ ans) & OCDE & 28 pays, TL2 & 2015 \\
\hline Différence entre le pourcentage femmes entre migrants et natifs & OCDE & 28 pays, TL2 & 2015 \\
\hline \multicolumn{4}{|c|}{ 2.3 Migrants selon l'éducation et leur positionnement sur le marché du travail } \\
\hline Part des migrants (UE, total) avec un diplôme du supérieur & OCDE & 28 pays, TL2 & 2015 \\
\hline Différence de taux d'emploi entre migrants et natifs (15-64) & OCDE & 28 pays, TL2 & 2015 \\
\hline Part de migrants ayant un emploi hautement qualifié ${ }^{\star *}$ & OCDE & 28 pays, TL2 & 2015 \\
\hline Part de migrants avec diplôme supérieur dans des emplois peu qualifiés & OCDE & 28 pays, TL2 & 2015 \\
\hline \multicolumn{4}{|l|}{ 3. Connexions de connaissance } \\
\hline Étudiants étrangers ${ }^{* \star \star \star}$ & Observatoire & France, TL2, municipalités & 2015 \\
\hline Enseignants-chercheurs étrangers & Observatoire & France, TL2 & \\
\hline Collaboration internationale en matière de brevets (co-inventeurs) ${ }^{* *}$ & OCDE & Pays OCDE - TL2, TL3 & 1990 à 2015 \\
\hline Part du personnel R\&D étranger ** & Observatoire & France, TL2 & 2015 \\
\hline R\&D: personnel et dépenses & OCDE & Pays OCDE - TL2 & 2000 à 2017 \\
\hline Emploi dans les secteurs à forte intensité de connaissance & OCDE & Pays UE, TL2 & 2008 à 2018 \\
\hline Pôles d'innovation & .. & .. & .. \\
\hline Biens culturels (musées, patrimoine, festivals, etc.) & .. & .. & .. \\
\hline \multicolumn{4}{|l|}{ 4. Connexions d'affaires } \\
\hline Part dans les secteurs commercialisables (VAB et emploi) ${ }^{* *}$ & OCDE & Pays OCDE - TL2, TL3 & 2000 à 2017 \\
\hline Importations et exportations de biens (final et intermédiaire) ${ }^{* * *}$ & Douane & France, TL2 & 2014 à 2018 \\
\hline Position des régions dans les Chaînes de Valeur Mondiale & .. & .. & .. \\
\hline Part de l'emploi dans les entreprises sous contrôle étranger ** & Observatoire & France, TL2 & 2015 \\
\hline Part de l'emploi dans les entreprises internationales & Observatoire & France, TL2 & 2015 \\
\hline Investissement direct étranger (nombre de projets d'investissements) ${ }^{* *}$ & Business France & France, TL2 & 2014 à 2018 \\
\hline Emplois créés ou maintenu au travers des IDE ${ }^{* * * *}$ & Business France & France, TL2, municipalités & 2014 à 2018 \\
\hline
\end{tabular}

Source : élaboration par les auteurs. 


\section{Définition des indicateurs de référence}

Nous avons identifié des indicateurs de référence afin de simplifier l'usage et la communication de cette méthodologie. Ces indicateurs de référence sont sélectionnés selon différents critères :

(i) Le premier (qui définit principalement la notion d'indicateur direct) veut que la relation internationale soit directement captée par l'indicateur (par exemple la part d'étudiants étrangers ou encore le commerce international) ; ou qu'il permette de mettre en valeur la capacité d'ouverture des régions françaises à l'étranger (par exemple, la part d'emploi dans les secteurs échangeables).

(ii) Le fait que l'indicateur ne soit pas corrélé avec d'autres indicateurs identifiés comme étant directs, ou qu'il apporte une information spécifique concernant l'internationalisation de la région. Pour donner une image à ce dernier cas : un indicateur qui est fortement corrélé avec le nombre d'habitants de la région n'apporte que peu d'informations supplémentaires, et est donc susceptible d'être écarté de la liste des indicateurs de référence.

(iii) La disponibilité de données récentes, notamment lorsque la valeur de l'indicateur évolue rapidement (typiquement la couverture en fibre optique).

Ainsi, pour les indicateurs d'infrastructures, l'indice de la 'Population vivant dans un rayon de $120 \mathrm{~km}$ pouvant accéder en 90 min. aux gares' (ou la moyenne pour l'UE28 est 100) est fortement corrélée avec le 'nombre de vols accessibles en 90 min. par voiture', ce dernier indicateur sera donc seul retenu comme indicateur de référence.

De même, pour l'utilisation d'internet, sera retenu 'l'usage pour la vente de biens et services' de préférence à l'usage des services bancaires. Chaque indicateur a fait l'objet d'une évaluation de cet ordre, consignée dans le fichier Excel constituant la base de données sur l'internationalisation ${ }^{13}$.

\section{Graphique 1.1. Exemple de choix des indicateurs de référence pour les régions françaises}

a. Accès aux infrastructures longs trajets

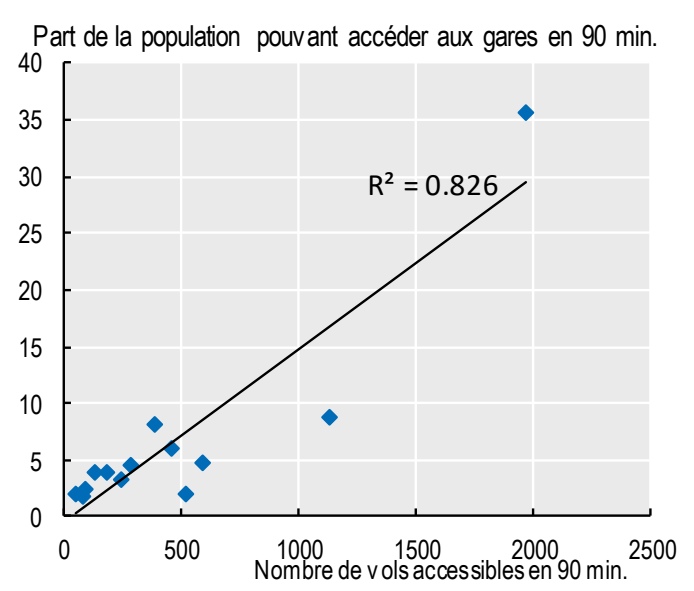

b. Usage d'internet

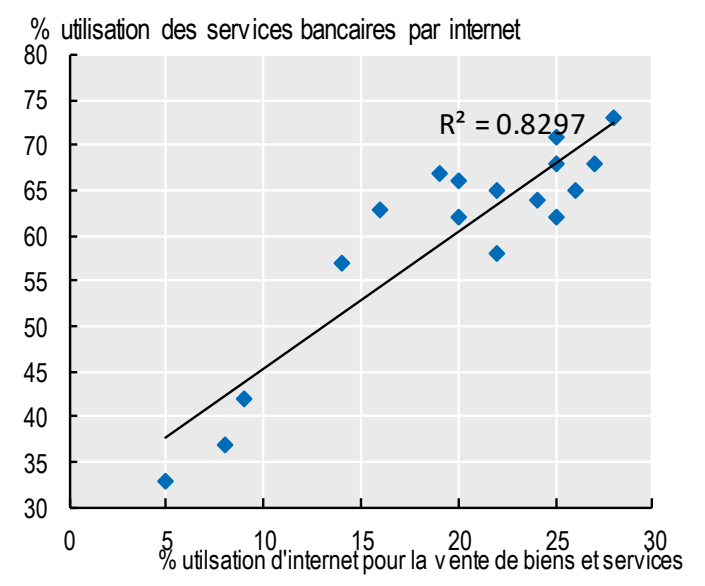

\footnotetext{
${ }^{13}$ Le fichier Excel de données sur l'internationalisation des régions est disponible sur le lien suivant : http://stats.oecd.org/wbos/fileview2.aspx?IDFile=15f69bbd-918d-4e48-b488-0678edcd1f51
} 


\section{Les indicateurs de référence issus de cette méthode de sélection sont les suivants :}

\section{En ce qui concerne les connexions d'infrastructure :}

- Accessibilité aux aéroports (nombre de vols de passagers accessibles à moins de 90 minutes en voiture)

- Couverture en fibre optique (pourcentage des bâtiments couverts (FTTH -Fiber to the home)

- Ménages connectés à internet haut débit en pourcentage du nombre total de ménages.

- Utilisation d'internet :

- Pourcentage d'individus effectuant des achats/ventes de biens et services sur internet dans l'année ;

- Pourcentage d'individus participant aux réseaux sociaux sur internet sur l'année.

- Logistique terrestre :

- Nombre d'entrepôts de plus de $5000 \mathrm{~m}^{2}$;

- Part de chargements et déchargements issus de pavillons étrangers dans les entrepôts sur le nombre total de chargements et déchargements.

\section{Encadré 1.1. L'activité portuaire, un élément clé de développement régional}

L'activité des ports maritimes et fluviaux représente une source de développement économique en profondeur dans les territoires.

Le trafic maritime français s'établit à 297,5 Mt de marchandises traitées dans les ports métropolitains en 2018. Trois régions représentent $75 \%$ du volume national: la Normandie, Sud et les Hauts-de-France avec respectivement 30,25 et $20 \%$ du volume traité. Marseille est le premier port français avec $75.7 \mathrm{Mt}$, devant Le Havre (64.9 Mt), Dunkerque (41.1,2 Mt) et Nantes Saint-Nazaire (31,9 Mt). Le marché européen représente $31.3 \%$ du volume échangé au niveau national, et plus de $99 \%$ pour les ports de Calais et de Cherbourg. Le marché extra-européen représente quant à lui plus de $75 \%$ de l'activité des ports du Havre, Marseille et Nantes Saint-Nazaire.

\section{Graphique 1.2. Activité des ports maritimes français par zone partenaire, 2018}

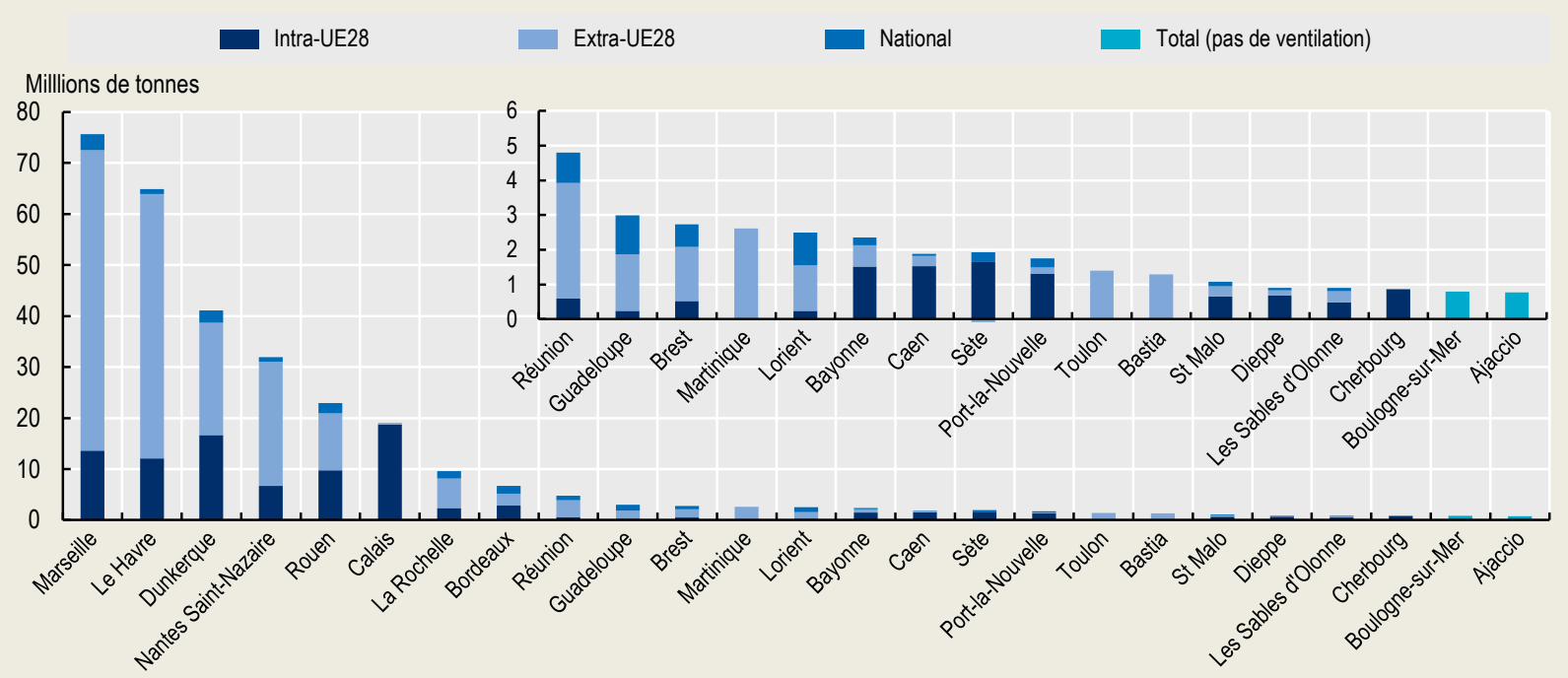

Source : Eurostat 
Le trafic fluvial de marchandises en France représente environ $20 \%$ de celui des ports maritimes français en 2018. L'activité des ports fluviaux du Grand-Est et de l'île de France est du même niveau que celui généré par les ports maritimes de Nouvelle-Aquitaine, de même ceux d'Auvergne-Rhône-Alpes en comparaison avec les ports maritimes de La Réunion et de Guadeloupe.

\section{Graphique 1.3. Activité des ports maritimes et fluviaux français, 2018}

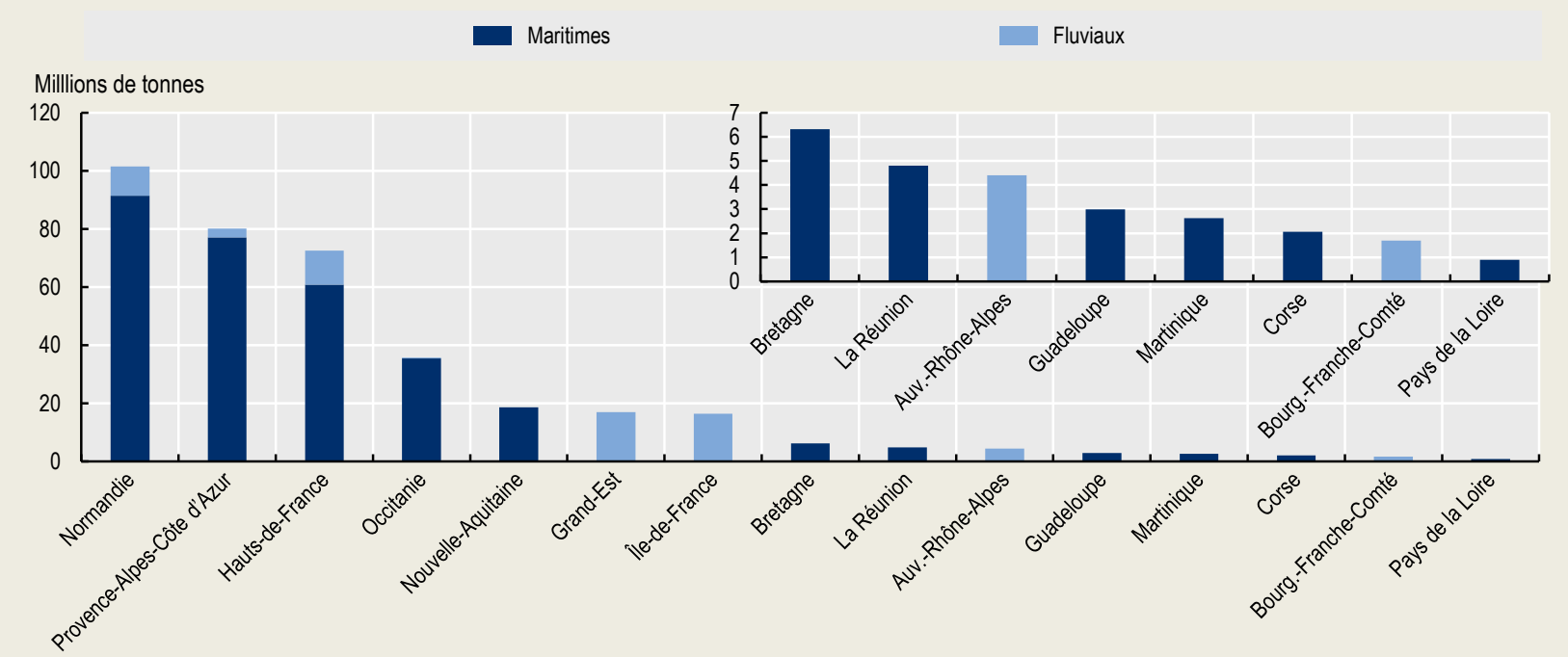

Source : Source: élaboration des auteurs, sur la base des données de Voies navigables de France (VNF) et Eurostat

\section{Pour les connexions humaines :}

- Tourisme :

- Nombre de lits en hôtel ou autres types d'hébergement pour 1000 habitants) (série temporelle disponible 2000-19);

- Nuitées effectuées par des étrangers en pourcentage du total des nuitées effectuées en hôtel ou autres types d'hébergement.

- Migrants :

- Population de migrants en pourcentage de la population totale (données disponibles par pays d'origine) (voir définition dans l'encadré 1.1) ;

- Part de migrants ayant un emploi hautement qualifié sur le total de migrants. 


\section{Encadré 1.2. Trafic aérien régional}

Le nombre total de passagers qui ont emprunté l'avion en France est de 193 millions en moyenne sur les années de 2017 à 2019, dont 68\% sur des vols internationaux. L'Île-de-France représente près de $55 \%$ du nombre de passagers, dont $80 \%$ internationaux. Seule la Région Centre-Val de Loire fait mieux en termes de part de vols internationaux, mais avec « seulement » 30000 passagers en moyenne.

\section{Graphique 1.4. Trafic aérien régional de passagers par destination, moyenne 2017-19}

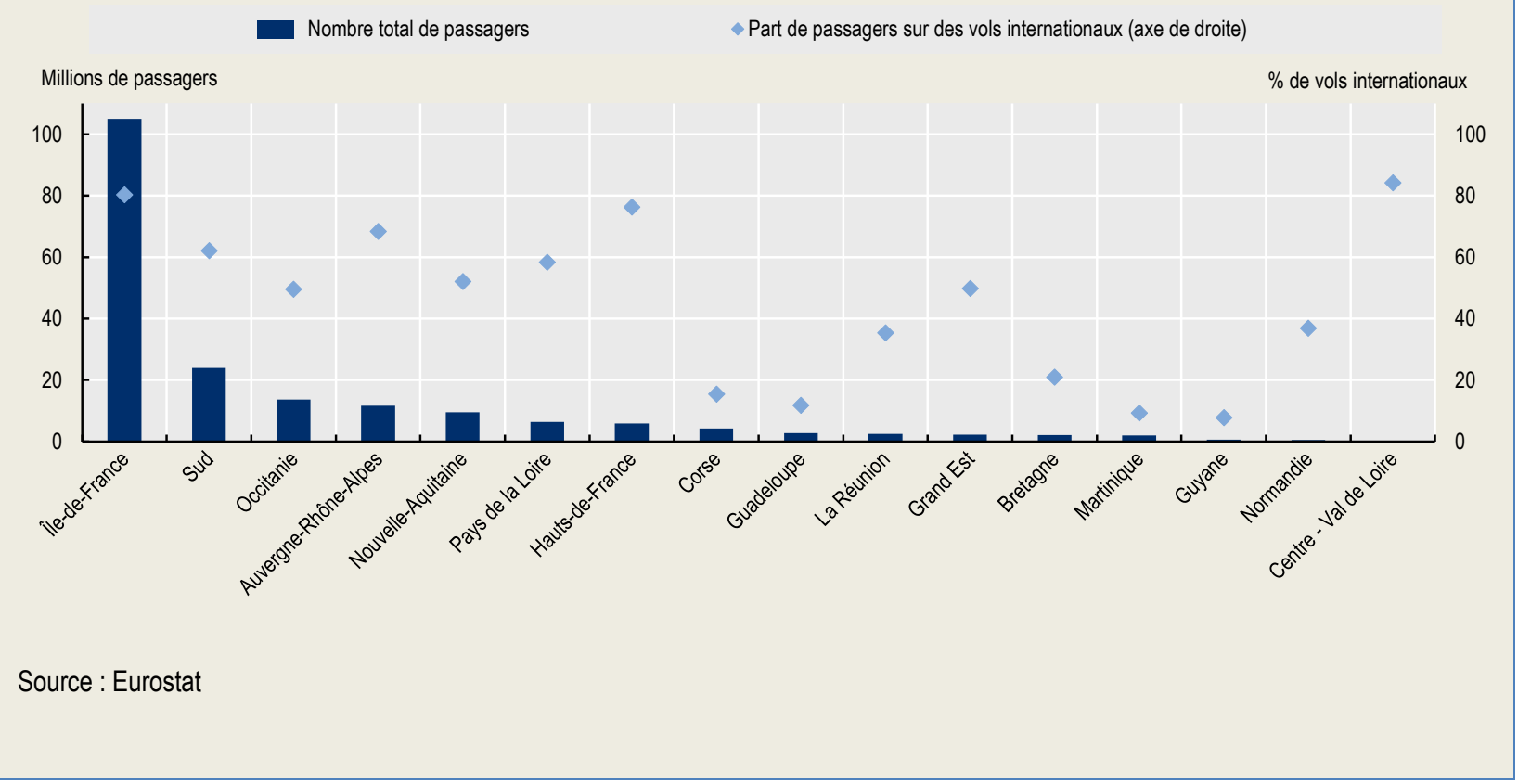

\section{Pour les connexions de connaissance :}

- Étudiants étrangers en pourcentage du nombre total d'étudiants (données disponibles par pays d'origine) ;

- Collaboration internationale en matière de brevets (part des co-brevets déposés avec un inventeur étranger en pourcentage du nombre total de co-brevets) (série temporelle disponible 2000-15) ;

- Part du personnel étranger en R\&D en pourcentage du personnel total en R\&D.

\section{Pour les connexions d'affaires :}

- Part dans les secteurs échangeables (VAB et emploi) (voir définition dans l'encadré 1.1) ;

- Importations et exportations de biens (final et intermédiaire) (série temporelle disponible 2013-18 et par pays partenaire) ;

- Investissement direct étranger :

- Nombre de projets d'investissements (série temporelle disponible 2014-18 et par pays d'origine) ;

- Emplois créés ou maintenus au travers des IDE (série temporelle disponible 2014-18 et par pays d'origine). 


\section{Encadré 1.3. Définitions}

La population de migrants est définie selon le lieu de naissance. Contrairement à la citoyenneté, ce critère n'évolue pas dans le temps, il n'est pas soumis à des différences de législation dans les pays et il est donc plus adapté pour effectuer des comparaisons internationales. Ainsi, les termes «non-natifs " et « migrants » sont utilisés de manière interchangeable dans ce rapport. Tout en étant le moins biaisé, ce critère présente des limites et peut parfois conduire à une sous-évaluation ou une surévaluation des migrants au niveau régional. Par exemple, il peut inclure des personnes nées à l'étranger qui sont néanmoins des ressortissants.

Les secteurs "échangeables ", selon les Perspectives régionales de I'OCDE 2016, sont définis comme étant l'agriculture, l'industrie, les services d'information et de communication, activités financières et d'assurance, et autres services. Les secteurs non-échangeables sont composés de la construction, du commerce de distribution, de la réparation, du transport, de l'hébergement, des activités de restauration, des activités immobilières, des services aux entreprises, et de l'administration publique.

La classification des secteurs échangeables et non échangeables exige un compromis puisque les données économiques pour les régions de l'OCDE ne sont disponibles que pour un maximum de dix groupes d'industries. Comme la plupart des biens physiques peuvent être expédiés assez facilement, la fabrication, la production et l'extraction des ressources sont considérées comme des secteurs échangeables. Inversement, les services non échangeables comprennent généralement les services gouvernementaux, l'éducation, les soins de santé, le secteur de la construction et le commerce de détail. De plus en plus de services commerciaux et techniques deviennent échangeables, mais un pourcentage important reste local : ainsi, les agences de relations publiques ou de marketing ont une portée mondiale, les avocats beaucoup moins et les services de nettoyage sont clairement un service local et non échangeable. L'hôtellerie et la restauration sont attribués au secteur non-échangeables, car même si dans certaines régions le tourisme est un contributeur important à ce type de commerce, ces industries fournissent principalement des services domestiques ou même uniquement locaux.

Source: OECD (2018), Productivity and Jobs in a Globalised World: (How) Can All Regions Benefit ?, OECD Publishing, Paris. http://dx.doi.org/10.1787/9789264293137-en.

\section{Positionnement des régions françaises selon les indicateurs d'internationalisation de référence}

Dans la représentation graphique ci-dessous (Graphique 1.8), la longueur du pétale représente la position de la région parmi les régions françaises selon l'indicateur de référence : vers l'extrémité du cercle lorsqu'elle est première, et vers le centre du cercle lorsqu'elle est dernière pour un indicateur donné. Pour plus de lisibilité, seulement trois indicateurs ont été sélectionnés pour chacun des quatre types de connexion. Du fait de manque de données pour certains indicateurs, ceux-ci ont été adaptés selon le Tableau 1.2. Cette visualisation permet de dégager quelques profils concernant la position des régions vis-à-vis de l'internationalisation :

- Les régions connectées à l'international de par leur situation géographique, telles que le Grand Est et les Hauts-de-France, régions frontières tissant un fort lien avec leur pays limitrophe. Ces régions sont performantes sur un large spectre d'indicateurs d'internationalisation. Ainsi, $8 \%$ des étudiants étrangers dans le Grand Est sont allemands et près de $30 \%$ des emplois créés ou maintenus au travers d'IDE proviennent d'Allemagne. De même, les Hauts-de-France exportent 
$20 \%$ de leurs marchandises vers la Belgique. Cette proximité géographique permet les échanges tant au niveau des biens que dans les secteurs d'innovation avec la R\&D et le dépôt de brevets en coopération avec des inventeurs étrangers.

- Des régions plus centrées sur une seule des dimensions de l'internationalisation, telle que l'accueil touristique et la présence de migrants qualifiés en Bretagne et dans la région des Pays de la Loire, ou encore la Normandie pour laquelle la valeur des importations et exportations de biens en pourcentage du PIB est la plus importante des régions françaises, l'Auvergne-RhôneAlpes qui draine de nombreux chercheurs étrangers ainsi que des flux d'investissements étrangers, la Région Sud qui consolide son offre touristique avec une forte présence de populations issues de mouvements migratoires, de diasporas et d'étudiants étrangers.

- Les régions d'outre-mer ont également une typologie marquée de l'internationalisation, avec des caractéristiques propres à chacune des régions ultra-marines, et qui semble bien plus relever de l'impact des politiques territoriales que de facteurs géographiques (par exemple : la fibre optique pour la Réunion, le tourisme pour la Martinique et la Guadeloupe, l'importance de la migration en Guyane française).

- Des régions pour lesquelles le profil d'internationalisation est moins spécifique, telles que le Centre-Val de Loire ou la Bourgogne-Franche-Comté.

- L'Île-de-France demeure une région avec une typologie exceptionnelle en comparaison des autres régions :

- En premier lieu, en termes de productivité du travail, la France est le seul pays qui se caractérise par une divergence de productivité de toutes les régions par rapport à la région dont la productivité est la plus élevée - l'île-de-France - et qui en détient aussi la plus forte croissance sur la période 2000-16 (Graphique 1.5).

- La région Île-de-France est la région ultra-connectée relativement aux autres régions : par exemple, elle représente plus de $55 \%$ du nombre de passagers effectuant un trajet par avion en France, avec $80 \%$ des passagers sur un trajet international ; près de $84 \%$ des immeubles de l'île-de-France sont connectés à la fibre en 2020. 
Graphique 1.5. Convergence des régions en termes de productivité de travail, 2000-16

Classification des grandes régions (TL2) en fonction de leur croissance de productivité de travail par rapport à leur frontière nationale (région avec la productivité la plus élevée en début de période)

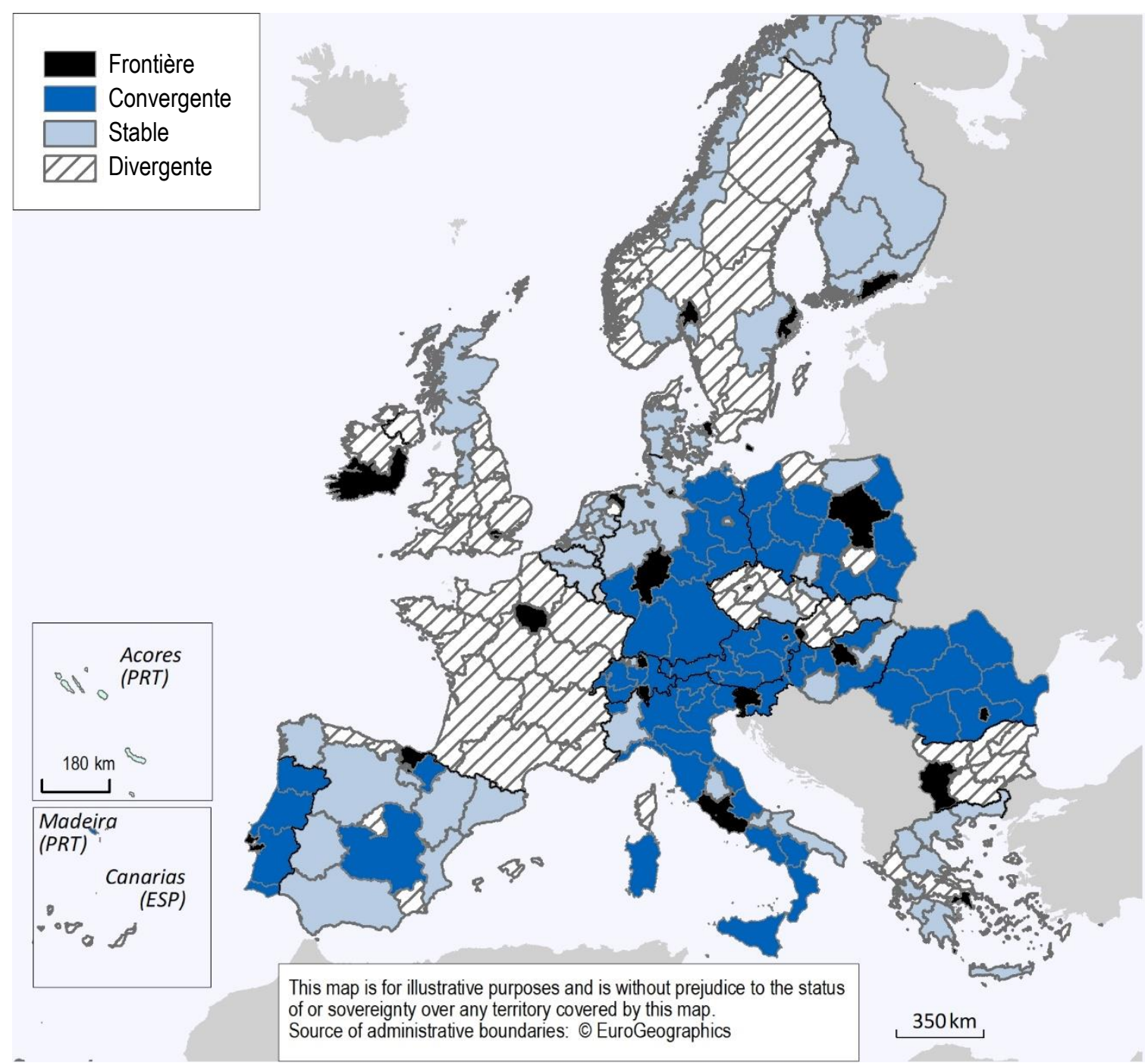

Source: OECD (2016), OECD Regional Outlook 2016: Productive Regions for Inclusive Societies, OECD Publishing, Paris, https://doi.org/10.1787/9789264260245-en. 
Tableau 1.2. Indicateurs de référence utilisés dans le graphique 1.6 des profils par région

\begin{tabular}{|c|c|c|c|c|}
\hline Pilier & Libellé dans le graphique & Indicateur & $\begin{array}{c}\text { Régions } \\
\text { hexagonales }\end{array}$ & $\begin{array}{c}\text { Régions } \\
\text { d'outre-mer }\end{array}$ \\
\hline \multirow{3}{*}{$\begin{array}{l}\text { Connexions } \\
\text { d'infrastructure }\end{array}$} & Accès aéroports & $\begin{array}{l}\text { Accessibilité aux aéroports (nombre de } \\
\text { vols accessibles à moins de } 90 \text { min.) }\end{array}$ & $x$ & $\mathrm{x}$ \\
\hline & Fibre optique & $\%$ couverture en fibre optique (FTTH) & $\mathrm{x}$ & $\mathrm{x}$ \\
\hline & Réseaux sociaux & $\begin{array}{l}\% \text { de personnes qui utilisent internet } \\
\text { pour participer aux réseaux sociaux }\end{array}$ & $\mathrm{x}$ & $\mathrm{x}$ \\
\hline \multirow{4}{*}{$\begin{array}{l}\text { Connexions } \\
\text { humaines }\end{array}$} & Accueil touristique & Tourisme, nombre de nuitées par km2 & $x$ & $\mathrm{x}$ \\
\hline & Migrants (présence) & $\%$ de population de migrants & $x$ & $x$ \\
\hline & Migrants (qualification) & $\begin{array}{l}\text { Part des migrants ayant un emploi } \\
\text { hautement qualifié en différence de la } \\
\text { part des natifs (points de pourcentage) }\end{array}$ & $\mathrm{x}$ & \\
\hline & Propriétaires étrangers & $\%$ des propriétaires étrangers & & $x$ \\
\hline \multirow{4}{*}{$\begin{array}{l}\text { Connexions } \\
\text { de } \\
\text { connaissance }\end{array}$} & Étudiants étrangers & $\%$ d'étudiants étrangers & $x$ & $x$ \\
\hline & Personnel R\&D étranger & $\%$ personnel R\&D étranger & $x$ & $\mathrm{x}$ \\
\hline & Co-brevet avec inventeur étranger & $\begin{array}{l}\% \text { de brevetages effectués avec des } \\
\text { inventeurs étrangers }\end{array}$ & $\mathrm{x}$ & \\
\hline & $\begin{array}{l}\text { Emploi dans les services } \\
\text { marchands à forte intensité de } \\
\text { connaissance }\end{array}$ & $\begin{array}{l}\% \text { d"emploi services marchands à forte } \\
\text { intensité de connaissance }\end{array}$ & & $\mathrm{x}$ \\
\hline \multirow{4}{*}{$\begin{array}{l}\text { Connexions } \\
\text { d'affaires }\end{array}$} & Échanges commerciaux & Imports plus exports en $\%$ du PIB & $\mathrm{x}$ & $\mathrm{x}$ \\
\hline & Emploi Groupe étranger & $\begin{array}{l}\text { Part de l'emploi dans les entreprises } \\
\text { sous contrôle étranger }\end{array}$ & $x$ & $\mathrm{x}$ \\
\hline & Investissements directs étrangers & $\begin{array}{l}\text { Nombre de projets d'investissement } \\
\text { directs étrangers (IDE) sur la période } \\
2014-18\end{array}$ & $\mathrm{x}$ & \\
\hline & $\begin{array}{l}\text { Part de l'emploi dans les secteurs } \\
\text { échangeables }\end{array}$ & $\begin{array}{l}\% \text { des emplois dans les secteurs } \\
\text { échangeables }\end{array}$ & & $\mathrm{x}$ \\
\hline
\end{tabular}

\section{Graphique 1.6. Le profil des régions françaises}

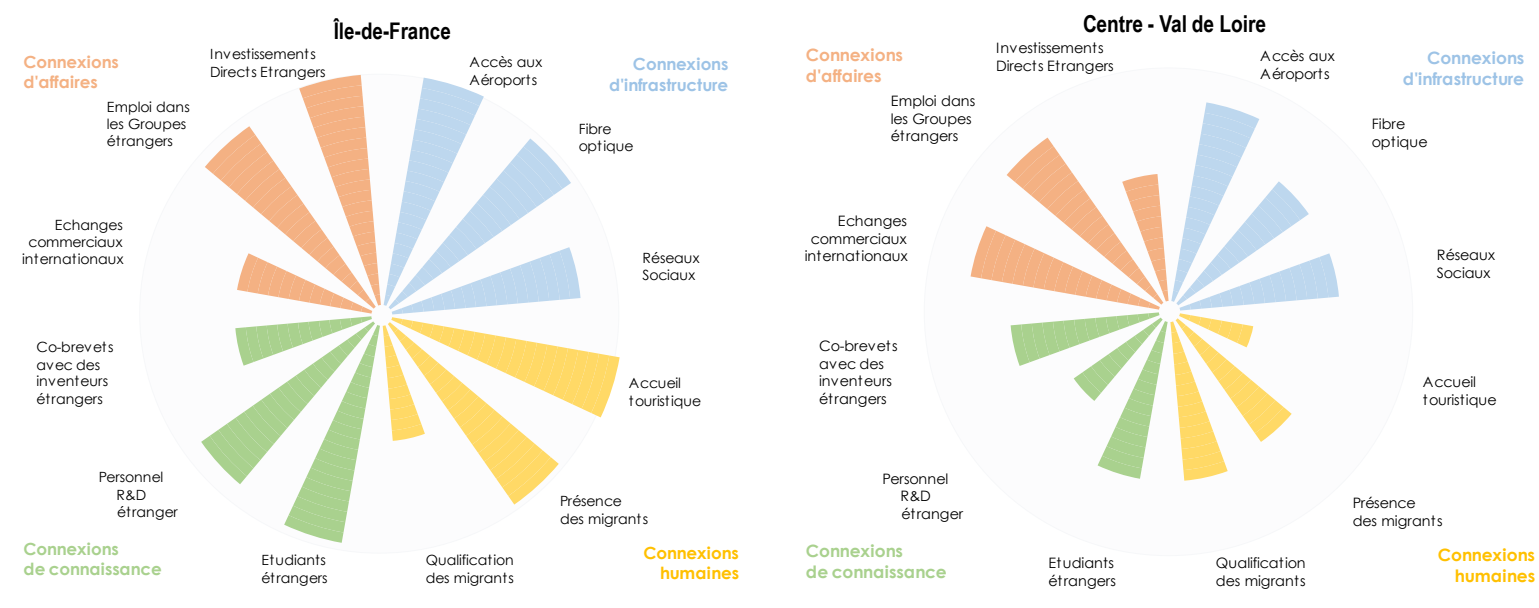

${ }^{14}$ Part de l'emploi dans les services marchands à forte intensité de connaissance (à l'exception de l'intermédiation financière et des services de haute technologie), en pourcentage de l'emploi régional, voir définition : https://ec.europa.eu/eurostat/statistics-explained/index.php?title=Glossary:Knowledge-intensive services (KIS)/fr 

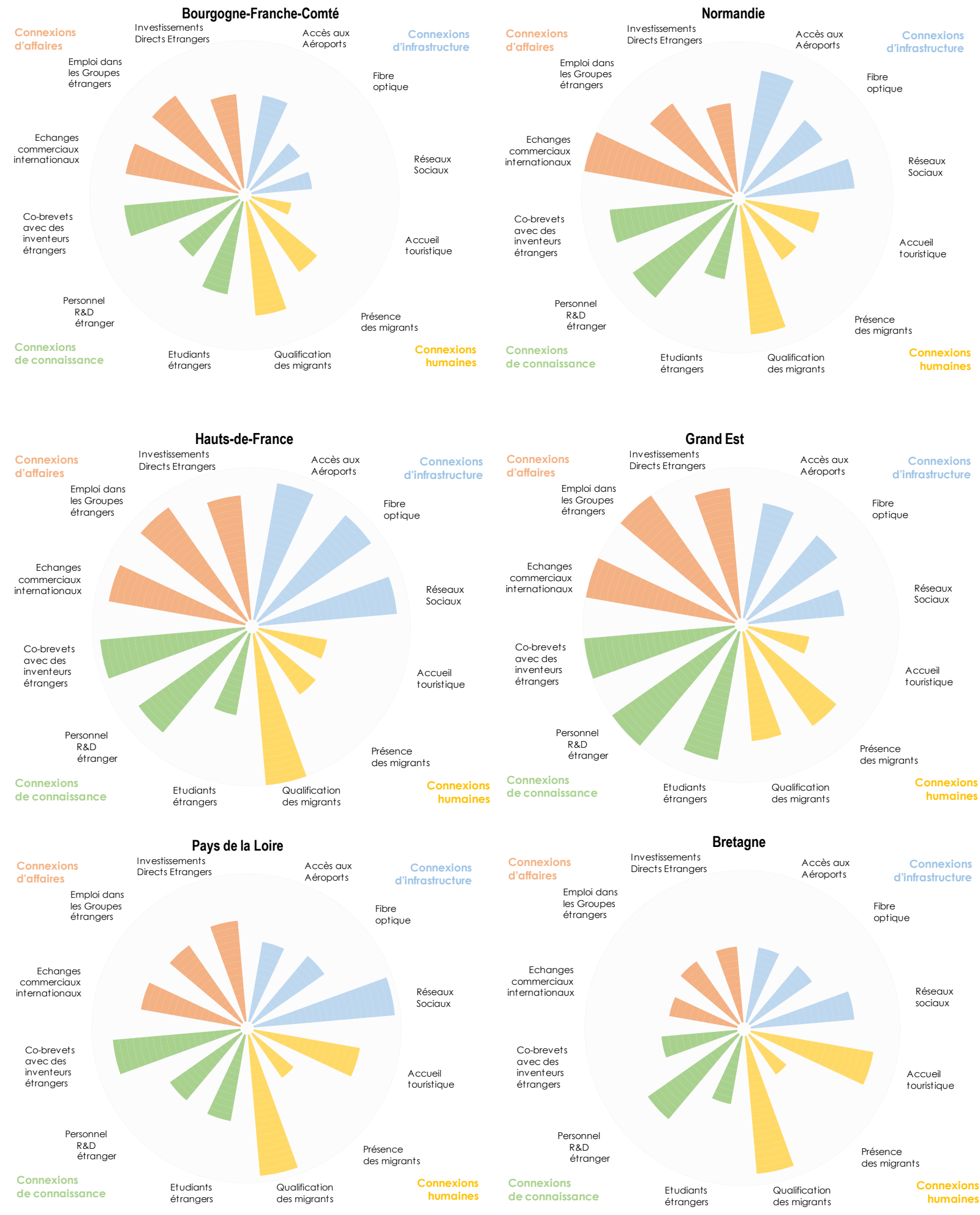

Accueil
touristique Présence
des migrants Connexions
humaines 

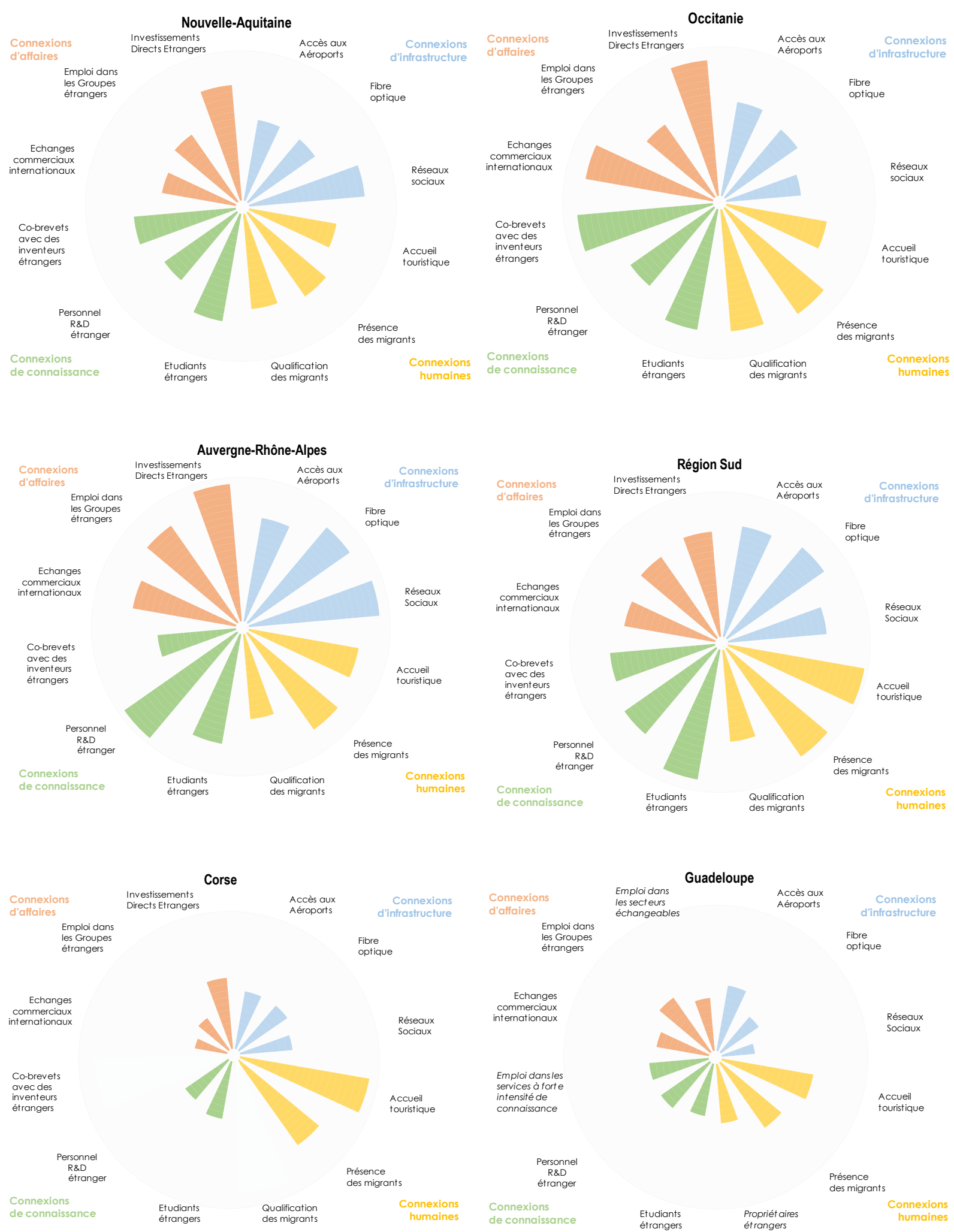


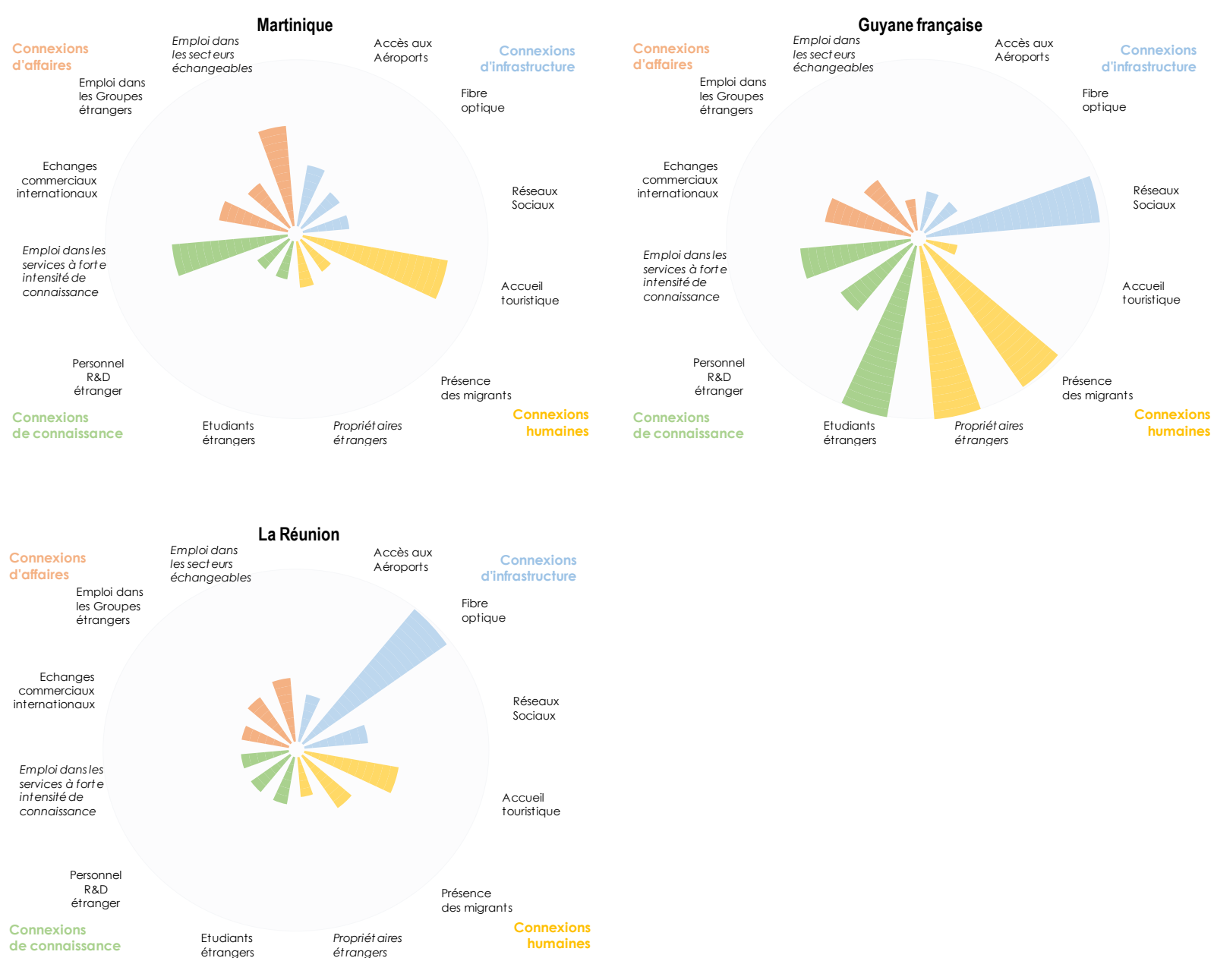

Source : élaboration par les auteurs.

\section{Discussion des indicateurs utilisés et des informations à compléter dans le futur}

À l'échelon national, il existe des cadres d'étude de la mondialisation qui constituent un socle important de connaissances et d'expériences. Toutefois, l'application à l'échelon régional de certains indicateurs reste problématique. La compréhension de l'intégration des régions dans les marchés mondiaux serait plus précise et permettrait de mieux couvrir l'ambition de traiter à la fois des connexions humaines, des affaires, de connaissance et des infrastructures de connexion, si elle intégrait des indicateurs régionaux concernant :

- Les chaînes de valeurs mondiales. II serait souhaitable d'évaluer le degré de participation des régions dans la production de la valeur ajoutée, avec la fourniture de données sur les réimportations/réexportations, et distinguer la valeur ajoutée dans la région sur la part des importations intermédiaires intégrées dans les exportations.

- Les investissements directs étrangers, avec la mesure des flux d'investissement entrants et sortants par région et pays partenaires (au-delà de l'emploi créé et/ou maintenu au travers des IDE, données disponibles pour les régions françaises, source Business France).

- Les données concernant les pôles d'innovation et leurs collaborations internationales.

- Les données d'emploi dans les entreprises internationales dans les régions des pays de l'OCDE (au-delà des régions françaises pour lesquelles les données sont disponibles). 
- La composition d'une base de données internationale du tourisme à l'échelon régional, au-delà des pays UE.

- Des données concernant la présence régionale des étudiants étrangers et des chercheurs, par nationalité (au-delà des régions françaises pour lesquelles les données sont disponibles).

- Les données des transferts financiers des migrants des régions d'accueil vers leur région et pays d'origine.

- Les connexions de connaissance pourraient aussi inclure des indicateurs relatifs aux échanges culturels transfrontaliers et aux aménités culturelles (musées, opéras, théâtres, etc.) qui participent également de l'internationalisation des territoires ${ }^{15}$.

La crise liée à la pandémie de COVID-19 a aussi mis en lumière l'importance d'indicateurs relatifs à la dépendance et la résilience des Régions dans une économie mondialisée. Certains figurent déjà dans la liste ci-dessus (notamment la mesure de l'inscription des régions dans les chaînes de valeur mondiales). Les propositions additionnelles ci-dessous, sans prétendre à l'exhaustivité, sont des pistes de réflexion pour mieux situer les Régions dans leurs stratégies d'internationalisation :

- Les données relatives à la diversité des partenaires commerciaux étrangers des entreprises dans la région

- Les données relatives à la part des entreprises achetant/vendant des biens et/ou services directement à l'international (sans l'intermédiaire par exemple d'une firme étrangère implantée dans la région)

- Les données concernant la diversification sectorielle de l'économie régionale, y compris des données sur la concentration des exports à l'échelle des entreprises ${ }^{16}$

- Les données relatives à la part des entreprises - y compris étrangères - ayant localisée leur siège dans la région

- Les données sur les entreprises étrangères engageant de nouveaux investissements, soit sur le site d'implantation, soit dans d'autres régions.

\footnotetext{
${ }^{15}$ De telles études pourraient s'appuyer sur le travail déjà réalisé par l'OCDE, que ce soit dans l'animation d'un réseau international des musées en partenariat avec le Conseil international des musées (ICOM) ; ou du travail conduit sur la culture et le développement local dans le cadre du Programme d'action et de coopération concernant le développement économique et la création d'emplois au niveau local.

${ }^{16}$ Cet indice permet de mesurer en particulier la dépendance des revenus réalisés par une entreprise sur un type de bien ou de service exporté.
} 


\section{Exploration des politiques et de la gouvernance de l'internationalisation régionale}

Les résultats de l'approche statistique présentés dans le chapitre précédent donnent à voir la variété des profils d'internationalisation des régions françaises. Afin de rendre compte des stratégies d'internationalisation régionale, ce travail se focalise dans ce deuxième chapitre sur les SRDEII, produits fin 2016-début 2017, documents cadre stratégiques de référence pour les Régions en matière d'internationalisation.

Les SRDEIl se veulent une réponse aux défis à la fois nationaux et locaux auxquels les régions doivent faire face. Les diagnostics réalisés dans le cadre de leur élaboration permettent de guider l'action des Régions. Les problématiques soulevées par la crise du COVID-19 (comme notamment la dépendance aux importations de composants ou ressources essentielles pour répondre aux besoins des personnes et des organisations, publiques ou privées,; la sécurisation des approvisionnements de filières stratégiques, y compris par des politiques de stock appropriées ainsi que leur diversification ; l'absence de coordination entre acteurs des écosystèmes à l'international, l' insuffisante lisibilité des aides nationales et européennes dont peuvent bénéficier les acteurs économiques.) trouveront leurs réponses renforcées dans la prochaine génération de SRDEII (dont la préparation est enclenchée actuellement) et les contractualisations et autres documents stratégiques de référence comme les plans de relance.

L'analyse comparée des orientations et projets d'internationalisation qu'ils contiennent n'est donc pas seulement un moyen de vérification de la pertinence de la méthodologie proposée. Elle permet aussi de fournir un " état des lieux " des politiques d'internationalisation au moment de décider de l'évolution des programmes.

Enfin, la focale sur les SRDEII ne doit pas donner à penser que les politiques d'internationalisation territoriale dépendent des seules Régions. Les autres parties prenantes nationales (mais aussi infrarégionales comme les métropoles ou autres intercommunalités) disposent de compétences et de moyens qui appellent à une gouvernance pluri-niveaux efficace ${ }^{17}$.

Afin d'illustrer les relations entre les acteurs des politiques d'internationalisation régionale, ce chapitre explore de manière préliminaire les mécanismes de coordination entre niveaux de gouvernement relatifs à quelques domaines clés tels que l'export, l'attractivité des investissements ou les infrastructures.

\footnotetext{
17 L'OCDE et son Comité des politiques de développement régional ont largement développé cette approche pour mettre en évidence les besoins et les bonnes pratiques de coordination dans une grande variété de politiques touchant le développement régional - pour une synthèse voir (Charbit, 2020 ; Allain-Dupré, 2020).
} 


\section{Les SRDEll, première expression de la compétence d'internationalisation des régions}

En France, comme dans la plupart des autres États unitaires de l'OCDE, le développement économique - comprenant en particulier les politiques liées aux entreprises, au transport, aux communications et à l'énergie (OCDE, 2019b) - est une compétence largement détenue par les régions : il représente en moyenne $27 \%$ des dépenses des Régions (OCDE, 2020d). La loi du 7 août 2015 portant une nouvelle organisation territoriale de la République (loi NOTRe) a renforcé la compétence des régions en matière de développement économique, notamment en l'élargissant aux dispositifs d'aides aux entreprises, et en particulier dans le cadre du soutien à leur l'internationalisation et à l'innovation (République française, 2020 ; Régions de France 2020b).

Ainsi, le développement économique représentait 32\% des dépenses régionales en 2016, soit l'un des plus forts taux des pays unitaires de l'OCDE (avec la Pologne et la Norvège) comme le montre le tableau ci-dessous. Les régions françaises présentent de fortes ressemblances avec les régions norvégiennes, consacrant l'essentiel de leur dépense à deux postes principaux : éducation/formation et développement économique.

Graphique 2.1. Répartition des dépenses des régions selon la Classification des fonctions des administrations publiques (COFOG) (2016)

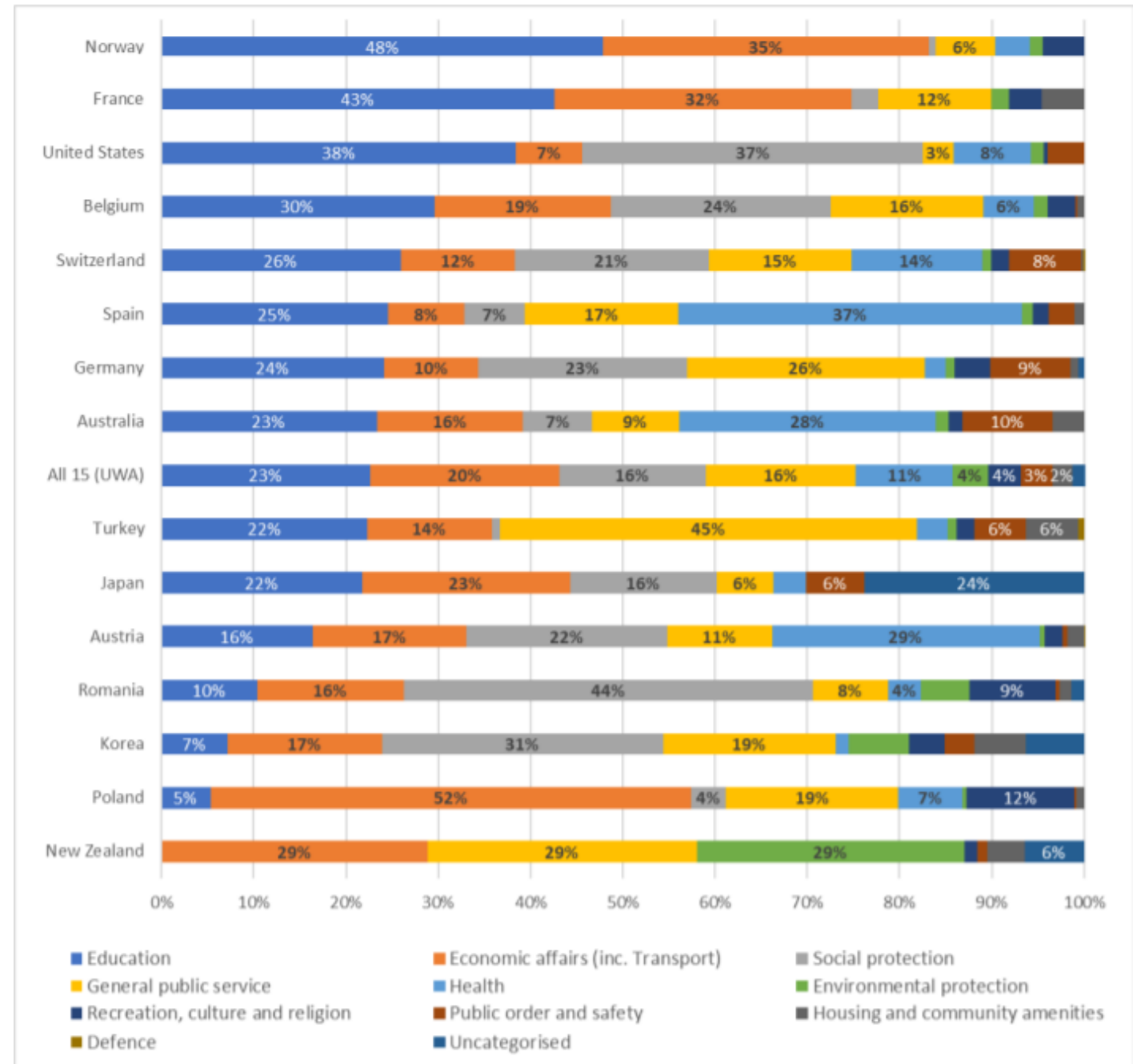

Source: Regional Government Finance and Investment Database, OECD 
Dans ce cadre, cette loi NOTRe a requis des régions (alors agrandies par fusion) qu'elle produisent un Schéma régional de développement économique, d'innovation et d'internationalisation (SRDEII) présentant à cette occasion pour la première fois leur stratégie d'internationalisation pour la période 2017$2021^{18}$. Ce schéma stratégique a pour vocation de définir la feuille de route des régions pour 5 ans en matière d'aides aux entreprises, dont le soutien à l'internationalisation, d'appui à l'investissement immobilier et à l'innovation, ainsi que les orientations relatives à l'attractivité du territoire régional (article L 4251-13). II consacre pour la première fois la dimension internationale de l'action régionale notamment vis-à-vis des entreprises. II comporte également un volet dédié à l'économie sociale et solidaire.

II s'agit d'un schéma prescriptif, ce qui signifie qu'il encadre l'action des autres collectivités locales en matière de développement économique, et qu'il encadre leurs interventions auprès des entreprises. Le SRDEII reflète l'orientation stratégique de la Région. II n'a pas vocation à proposer des stratégies pour tous les domaines de politiques publiques. D'autres thématiques, sont abordées dans le cadre d'autres documents stratégiques - comme le Schéma régional d'aménagement, de développement durable et d'égalité des territoires, et la Stratégie régionale pour l'enseignement supérieur, la recherche et l'innovation. ${ }^{19}$

Au-delà du soutien à l'internationalisation des entreprises et du soutien à l'attractivité du territoire, qui figurent parmi ses thématiques obligatoires, ${ }^{20}$ il comprend aussi, pour certaines Régions, dont l'interprétation de l'internationalisation est plus large, des thématiques optionnelles, notamment des volets touristique et transfrontalier, ces derniers pouvant être élaborés en concertation avec les collectivités territoriales des États limitrophes. ${ }^{21}$

Le SRDEII constitue, enfin un exercice de gouvernance : l'article 4251-14 du Code général des collectivités territoriales prévoit que l'élaboration du SRDE-, qui est donc un document prescriptif, inclut la concertation notamment avec les métropoles et les établissements publics de coopération intercommunale (EPCl) ainsi que l'organisation de débats au sein de la Conférence territoriale sur l'action publique (CTAP). Bien souvent, les Régions ont étendu cet effort de démocratie participative au-delà des personnes morales prévues par la loi pour inviter entre autres, les acteurs économiques privés, les représentants de la société civile, les universités, etc. (voir Section 3.2).

\section{Méthodologie de l'OCDE pour l'analyse des SRDEII}

Cette section détaille la manière dont a été réalisée l'analyse du contenu des SRDEll au regard d'une taxonomie des mesures de politique d'internationalisation et de leur gouvernance proposée par l'OCDE en lien avec les dimensions explorées dans le chapitre précédent.

L'analyse qualitative des SRDEII complète l'analyse statistique réalisée dans le premier chapitre de ce document. La taxonomie employée reprend d'abord les quatre familles de connexions internationales

\footnotetext{
18 2019-2021 dans le cas de la Guyane ; Schéma "territorial " de développement économique, d'innovation et d'internationalisation dans le cas de la Martinique. À notre connaissance, le SRDE-II de Mayotte n'a pas encore été adopté.

19 On peut aussi mentionner la Stratégie de cohérence pour l'aménagement numérique (SCORAN), afin d'accompagner la transformation numérique du territoire et des acteurs; ou les Contrat de plan régional de développement des formations et de l'orientation professionnelles (CRPDFOP). Les SRDE-II font souvent écho aux Plans régionaux d'internationalisation des entreprises (PRIE) et aux Schémas régionaux d'innovation et d'internationalisation (SRII).

${ }^{20}$ Les autres thématiques obligatoires concernent les aides aux entreprises (création, extension, difficulté) ; aides à l'investissement immobilier des entreprises, aides à l'innovation des entreprises; soutien au développement de l'Économie Sociale et Solidaire (ESS); et les actions en matière d'égalité professionnelle entre les hommes et les femmes.

21 Les autres thématiques optionnelles comprennent orientations des aides aux activités agricoles ; artisanales ; industrielles ; pastorales ; et forestières.
} 
identifiées dans la base de données sur l'internationalisation des régions, à savoir, les connexions d'infrastructure, les connexions humaines, les connexions de connaissance et les connexions d'affaires. Cette grille de lecture vise à comprendre la variété des actions et des orientations des politiques d'internationalisation des territoires inscrites dans les SRDEII de l'ensemble des 17 régions françaises, ${ }^{22}$ hexagonales et ultra marines. Elle permettra également d'identifier les mesures principales (qu'il s'agisse de politiques de transport, de soutien aux PME-TPE, de mesures en faveur des étudiants ou chercheurs étrangers, etc.).

À ces quatre «familles", la taxonomie proposée pour cette analyse des politiques ajoute deux dimensions :

\section{- Les politiques « multi-objectifs » d'internationalisation}

- La gouvernance de l'internationalisation.

L'analyse spécifique des "politiques d'internationalisation multi-objectifs " permet d'identifier les synergies déjà initiées par les régions entre diverses dimensions du SRDEII (par exemple entre tourisme et préoccupations environnementales, entre investissements et attraction des «talents»). Celles-ci donnent à voir la vision stratégique intégrée des Régions, qui bien souvent pensent l'internationalisation par-delà les dispositifs (pourtant déjà complexes à bien cibler et à mettre en œuvre) d'aides aux entreprises.

L'analyse spécifique de la " gouvernance de l'internationalisation » permet, quant à elle, de prendre en compte les dispositifs institutionnels soutenant la coordination entre les niveaux de gouvernement (national, mais aussi infranational), ainsi qu'avec les représentants du secteur privé et de la société civile, sans lesquels ces politiques d'internationalisation seraient difficiles à décliner au niveau infrarégional. II s'agit, par ailleurs, de comprendre comment les équipes régionales envisagent de piloter, d'assurer le suivi et de mettre en œuvre la dimension internationale du SRDEII. Leur analyse est importante car cette première génération a été mise en œuvre à la suite de la fusion des régions : l'élaboration des SRDEII a entraîné des premières transformations administratives territoriales majeures au regard de l'internationalisation (fusion ou création d'agences de développement économique et d'attractivité par exemple). ${ }^{23}$

Enfin, et de manière pragmatique, c'est cette lecture en termes de gouvernance qui permet de prendre correctement en compte l'ensemble des leviers internationaux que les régions souhaitent mettre en œuvre pour leurs territoires. Même si les Régions consacrent un volet spécifique du SRDEII à l'internationalisation, de plus ou moins grande envergure, beaucoup reconnaissent la transversalité de cet objectif, qui apparait dans diverses composantes de leur document stratégique. C'est ainsi que l'internationalisation peut se présenter sous la forme d'un volet séparé spécifique comme dans le cas de Grand Est qui y consacre un « défi » sur six ( « l'ouverture à l'international ») mais qui a élaboré également un volet (optionnel) concernant la dimension transfrontalière ; ou de manière plus disséminée comme dans le cas de la Réunion, qui mobilise le thème de l'internationalisation dans quatre de ses dix fiches-actions trois concernent l'attractivité (SRDEII, région La Réunion). Afin de pouvoir rendre compte des contenus des SRDEII, ceux-ci ont été analysés et répartis en groupe d'items décrivant chacun les différents types de "connexions " ( s'il s'agit bien des mêmes " connexions », il ne s'agit évidemment pas des même descripteurs que pour l'analyse quantitative dont le premier modèle présenté dans ce travail a été établi a priori en partant de l'analyse des données pertinentes et des indicateurs disponibles), en y ajoutant les deux dimensions supplémentaires (Gouvernance et Politiques multi-objectifs) .

\footnotetext{
22 À notre connaissance, le SRDE-II de Mayotte n'a pas encore été adopté.

${ }^{23}$ L'Association Régions de France (2018) a souligné nombre de ces réformes dans une étude sur le rôle économique des Régions.
} 
Ces items permettent donc de rendre compte de l'ensemble des thématiques qui ont été utilisées par les Régions pour décrire les stratégies qu'elles ont déployées dans le cadre de cette première génération de SRDEII (voir Tableau 2.1).

\section{Tableau 2.1. Taxonomie des politiques régionales d'internationalisation et de leur gouvernance}

\begin{tabular}{|c|c|}
\hline \multirow[t]{3}{*}{ Connexions humaines } & Identification des métiers en tension (secteur public/privé) \\
\hline & Mesures spécifiques pour les visiteurs/touristes \\
\hline & Mesures spécifiques pour les entreprises du secteur touristique \\
\hline \multirow[t]{5}{*}{ Connexions d'affaires } & Identification des secteurs prioritaires - IDE \\
\hline & Identification des secteurs prioritaires - exportations \\
\hline & Mesures spécifiques pour les PME et TPE \\
\hline & Mesures pour la formation professionnelle ciblées pour l'internationalisation \\
\hline & Mesures spécifiques pour la création de zones d'activités économiques, zones franches, etc. \\
\hline \multirow[t]{4}{*}{ Connexions de connaissance } & Mesures spécifiques pour les étudiants étrangers \\
\hline & Mesures spécifiques pour les chercheurs étrangers \\
\hline & Mesures spécifiques pour la recherche et développement \\
\hline & Mesures spécifiques pour les connexions internationales culturelles (échanges scolaires, etc.) \\
\hline \multirow[t]{2}{*}{ Connexions d'infrastructure } & Mesures spécifiques pour le transport international \\
\hline & Mesures spécifiques pour les infrastructures numériques \\
\hline \multirow{8}{*}{$\begin{array}{l}\text { Politiques multi-objectifs } \\
\text { d'internationalisation }\end{array}$} & Marketing territorial \\
\hline & Identification des pays/régions partenaires prioritaires \\
\hline & Articulation avec les programmes nationaux pour le développement économique (programme) \\
\hline & Articulation avec les programmes européens de financement (programme) \\
\hline & Vision intégrée des « cibles » de l'internationalisation (investisseurs, talents, visiteurs) \\
\hline & Objectifs en termes d'emploi local (nombre et niveau) \\
\hline & $\begin{array}{r}\text { Articulation avec l'Agenda } 2030 \text { et ses } 17 \text { Objectifs du Développement Durable (objectifs en termes de } \\
\text { développement durable, notamment par la préservation des ressources, de certains territoires ou espèces, } \\
\text { recherche de diversification en termes de ressources énergétiques, etc.) }\end{array}$ \\
\hline & Valorisation de territoires spécifiques (urbain, périphérie urbaine, territoires à dominante rurale, etc.) \\
\hline \multirow{10}{*}{$\begin{array}{l}\text { Gouvernance de } \\
\text { l'internationalisation }\end{array}$} & Mécanisme de consultation ex ante (parties prenantes) \\
\hline & Mécanisme de consultation ex post (parties prenantes) \\
\hline & Institution(s) chargée(s) de la mise en œuvre de la stratégie (agence, département de la Région, etc.) \\
\hline & Évaluation de la réalisation et/ou d'impact \\
\hline & Coopération intra régionale avec les autres collectivités territoriales ou agences \\
\hline & Dispositif de coordination Région/État (mécanisme(s)) \\
\hline & Dispositif de coordination Région/Union européenne (mécanisme(s)) \\
\hline & Dispositif de coordination interrégionale (mécanisme(s)) \\
\hline & Dispositif de coordination transfrontalière (mécanisme(s)) \\
\hline & Mécanisme régional spécifique de gouvernance de l'attractivité (parties prenantes) \\
\hline
\end{tabular}

Source : Les auteurs, sur la base des SRDEIl des 17 Régions.

Les mesures figurant dans le tableau 2.1 précédant, classés selon les quatre familles de connexions internationales, sont retenues et citées de manière variable dans les SRDEII. L'analyse textuelle des SRDEII permet de voir que les différentes dimensions de l'internationalisation, proposées dans la méthodologie originale de positionnement des régions dans la mondialisation (incarnées par les quatre familles de « connexions ", voir chapitre 1) recouvrent l'ensemble des mesures d'internationalisation. Les moyens de leur mise en œuvre ici ajoutés (politiques pluri-objectifs et gouvernance pluri-acteurs), constituent complément visiblement utile compte tenu du nombre de fois où les régions y font référence dans leur stratégie et permettent de refléter la variété des pratiques régionales d'internationalisation. 


\section{Les stratégies d'internationalisation des Régions françaises}

Après quelques observations générales, l'analyse s'attache à présenter les stratégies d'internationalisation retenues par les régions françaises selon les 4 familles de connexions, en mobilisant des informations à la fois statistiques et qualitatives, puis conclut en ciblant quelques résultats de l'analyse et leur actualité dans le cadre de la crise de COVID-19.

Si les différentes dimensions de l'internationalisation des Régions proposées dans cette taxonomie sont présentes dans les SRDEII, ce qui en confirme l'intérêt en termes de "grille de lecture ", c'est vers les entreprises que se tournent en premier lieu les stratégies d'internationalisation retenues par les Régions. Les connexions d'affaires sont en effet mieux «traitées " 24 dans les SRDEIl que les autres familles de connexions. Cela n'est pas surprenant, compte tenu du rôle des Régions en matière d'aides aux entreprises que l'on retrouve dans le soutien accordé à leurs activités d'exportation, ou à l'implantation d'entreprises étrangères sur le territoire (Banque des territoires, 2017) ${ }^{25}$.

A l'inverse, la thématique de l'internationalisation par les connexions de connaissance, notamment des politiques envers les «talents» (en particulier les chercheurs et étudiants étrangers), est proportionnellement moins abordée dans les SRDEII, puisque qu'incluse dans un autre document d'orientation qui lui est spécifique - la Stratégie régionale pour l'enseignement supérieur, la recherche et l'innovation.

Cette taxonomie rend également compte, au-delà des mesures spécifiques présentées dans la section suivante, de l'existence d'une vision " multi-objectifs » de l'internationalisation des politiques d'attractivité, présente dans les SRDEII qui mentionnent notamment le lien entre la formation et l'attraction des «talents » d'une part, et, d'autre part, l'accueil d'investisseurs étrangers ${ }^{26}$.

Elle permet également de documenter les innovations proposées par les Régions en matière de gouvernance pluri-niveaux, notamment pour inclure les acteurs infranationaux (EPCl en particulier), nationaux, économiques, mais aussi les partenaires européens et transfrontaliers pour définir et mettre en œuvre les politiques d'internationalisation (voir Section 2.2.1).

Les mesures d'internationalisation proposées par les régions sont à présent exposées selon les quatre sections suivantes consacrée chacune à une famille de connexions internationales. Chaque section est introduite par un tableau statistique utilisant les indicateurs présentés au premier chapitre qui permet de positionner les régions françaises entre elles et par rapport à la médiane des régions de l'OCDE. Cette approche permet de voir si les politiques d'internationalisation retenues par les régions sont en adéquation avec les atouts et difficultés repérés par la comparaison statistique.

\footnotetext{
${ }^{24} 62$ mesures sont identifiées et 11 abordées de manière plus générale dans les SRDE-II des 17 régions.

25 Le caractère prescriptif du Schéma signifie qu'il contraint l'aide financière des Régions auprès des entreprises (en fonction des priorités pour le soutien à l'export ou pour l'attractivité identifiés dans le Schéma).

26 On peut mentionner par exemple le couplage « innovation-exportation » promu par la Bretagne; le lien entre tourisme et implantations d'entreprises étrangères en Nouvelle-Aquitaine, le lien entre recherche et internationalisation par l'attraction des talents dans le domaine de l'infrastructure dans les Hauts de France - la liste n'est pas exhaustive.
} 


\section{(i) Connexions d'infrastructure}

\section{Graphique 2.2. Positionnement des régions françaises selon les indicateurs d'internationalisation : les connexions d'infrastructure}

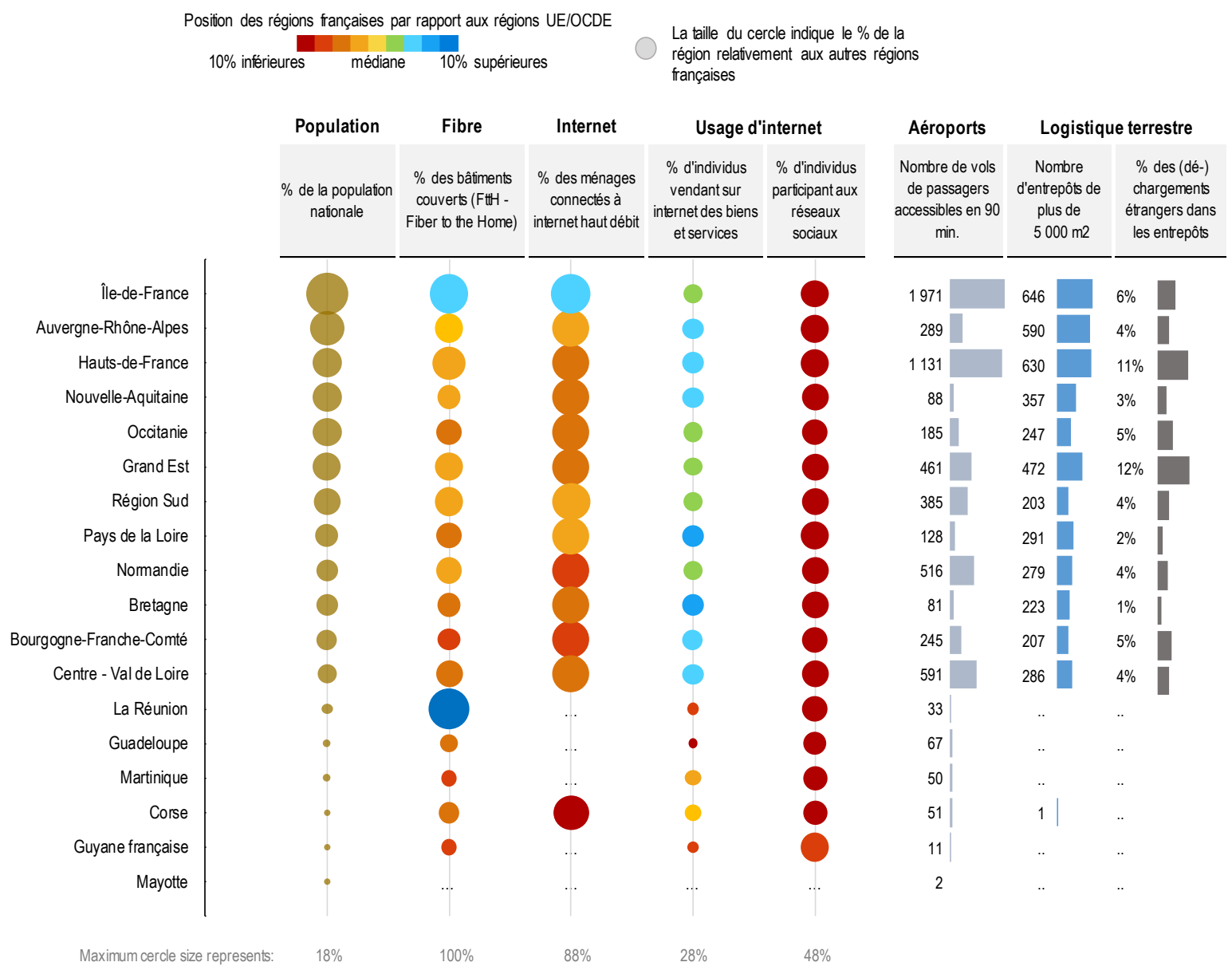

Note : Les régions sont triées par ordre décroissant de leur population. Dans ce graphique, la couleur des cercles identifie la position des régions françaises par rapport aux régions de l'OCDE, sauf en ce qui concerne l'usage d'internet (par rapport aux régions européennes).

Source : Base de données de l'OCDE sur l'internationalisation des régions françaises, données ARCEP (fibre), Eurostat (internet et usage d'internet), la Commission Européenne (accès aux aéroports, et Agence nationale de la cohésion des territoires (logistique terrestre).

Les indicateurs sur les connexions d'infrastructure (Graphique 2.2) apportent plusieurs types d'informations sur les régions françaises :

- Le déploiement de la fibre reste inégal sur le sol français fin 2019. L'ensemble des habitations de la Réunion est connecté à la fibre, et près de $90 \%$ pour les habitations de l'île-de-France, la troisième région (les Hauts-de-France) n'étant seulement couverte qu'à un peu plus de $60 \%$. Cet écart est probablement dû à un lancement tardif du déploiement lorsque l'on compare cet indicateur avec les autres pays de l'OCDE (données circa 2016), où la plupart des régions françaises étaient en-deçà de la médiane de la zone OCDE. Le même constat de retard par rapport aux régions étrangères les plus performantes s'affiche en ce qui concerne la part des ménages connectées au haut-débit en 2019, avec en revanche, une plus grande homogénéité parmi les régions françaises.

- En termes d'usage d'internet, les régions françaises semblent moins en retard qu'en matière d'équipement. Plus de $27 \%$ des habitants des régions Pays de la Loire et Bretagne utilisent internet 
pour l'achat-vente de biens et services. Ces régions font partie des $20 \%$ des régions européennes où cet usage est le plus développé. En revanche, très peu de français utilisaient internet pour participer aux réseaux sociaux en 2019.

- L'Île-de-France et les Hauts-de-France constituent les principaux 'hubs' du transport aérien des passagers, ainsi que des grands entrepôts de marchandises, indicateurs pour lesquels il n'y a pas de données comparatives des régions OCDE et seule la comparaison nationale entre régions est possible. Avec plus de $11 \%$ de leur chargements (et déchargements) en destination (et provenance) de l'étranger, le Grand Est avec les Hauts-de-France sont en tête des régions françaises, alors que les déchargements étrangers en Île-de-France, la troisième région, sont bien inférieurs avec seulement $6 \%{ }^{27}$.

Les indicateurs de l'internationalisation permettent donc de rendre compte des disparités régionales en matière d'accès et d'usage des infrastructures.

C'est pourtant unanimement que les régions considèrent les infrastructures comme un levier majeur de l'internationalisation qu'elles souhaitent mobiliser au service de leurs territoires et de leurs entreprises. Même si la question des infrastructures et des équipements structurants est traitée dans d'autres documents programmatiques et opérationnels, ${ }^{28}$ la connectivité internationale des régions est mentionnée dans 14 des 17 SRDEII, et toutes les Régions soulignent l'importance des infrastructures numériques pour favoriser le développement international de leurs territoires.

Les Régions proposent des orientations en matière de transport international - portuaire, aéroportuaire, terrestre - pour favoriser l'intégration des entreprises dans des chaînes de valeur mondiales. Parmi les mesures envisagées, on peut mentionner par exemple l'extension ou la construction d'aéroports (régions Pays de la Loire et Auvergne Rhône-Alpes), la consolidation ou la création de lignes maritimes internationales et d'installations portuaires (Corse, Réunion, Pays de la Loire, Guadeloupe, Bretagne). Pour certaines régions, la logistique et les transports sont des priorités pour le développement des territoires : la région Sud considère par exemple le transport comme l'un des trois axes majeurs de son SRDEII, car "la connectivité de la région avec le monde entier sera l'un des principaux enjeux du développement économique et touristique régional et un fort facteur d'attractivité ».

Certaines régions accentuent l'importance des infrastructures, y compris numériques, comme facteur d'attractivité pour les visiteurs étrangers : les Hauts de France, par exemple, souhaitent faire un usage multiple - logistique, touristique mais aussi à des fins de recherche scientifique - des infrastructures (fluviales et fret). La Normandie souhaite développer "l'internet de séjour " pour ses visiteurs, tandis que la Martinique prévoit de soutenir de nouvelles lignes aériennes vers l'hexagone, la zone intra-Caraïbes et les Amériques.

Les infrastructures doivent aussi permettre l'inscription des régions dans des espaces transfrontaliers. Ainsi, les routes frontalières (région Sud, Grand-Est, Bourgogne Franche-Comté), les liaisons portuaires (transmanche, dans le cas des régions Normandie, Sud et Hauts-de-France) ou fluviales (régions Sud et AURA), sont utiles à la fois à l'intégration des régions dans les chaînes de valeurs mondiales, mais aussi pour accroitre la circulation des travailleurs et des visiteurs (voir aussi la section Connexions humaines). Pour les régions non-frontalières, les infrastructures visées doivent aussi s'inscrire dans une démarche interrégionale - comme dans le cas par exemple de la Vallée de la Seine ou le Canal Seine-Nord Europe - afin de connecter les territoires à l'international, en coopération avec les régions voisines.

Les régions investissent aussi dans l'infrastructure numérique qu'elles considèrent comme un vecteur nécessaire pour l'intégration des entreprises régionales dans l'économie mondiale. Ainsi,

\footnotetext{
${ }^{27}$ La comparaison internationale n'est pas disponible à ce stade pour cet indicateur.

28 Notamment le Schéma régional d'aménagement, de développement durable et d'égalité des territoires (SRADDET) et le Schéma Directeur Territorial d'Aménagement Numérique (SDTAN)
} 
la région Centre-Val de Loire reconnait les « besoins différenciés, en fonction de leur taille, de leur secteur d'activité ou de leur degré de maturité » des entreprises pour rester concurrentielles dans les marchés internationaux, tandis que pour la Martinique, le soutien à la numérisation - via des fonds ciblés - doit permettre de « faciliter la transformation digitale des entreprises, leur ouvrant ainsi la porte à une meilleure organisation managériale, commerciale et à terme un meilleur positionnement à l'international ».

Pour de nombreuses régions, le renforcement des infrastructures est enfin une condition du développement de nouveaux débouchés à l'international, que ce soit pour soutenir les exportations ou attirer les investissements étrangers. La région Occitanie souhaite ainsi promouvoir son expertise en matière de logistique portuaire et d'intermodalité port/fret/fluvial/route dans les salons internationaux. La région Pays de la Loire considère par exemple que le projet de réseaux électriques intelligents SMILE, coordonné avec la Bretagne depuis 2016, « a vocation à constituer à l'horizon 2020 une vitrine industrielle française, exportable dans d'autres régions et à l'étranger ». L'lle-de-France insiste, concernant les infrastructures numériques, sur le développement d'une culture des services et de la transformation numérique pour attirer les investisseurs, tandis que les Hauts-de-France inscrivent le numérique comme un secteur de spécialisation économique comprenant notamment les questions de big data ou de cyber-sécurité. L'aspect numérique est d'ailleurs fréquemment au cœur des problématiques régionales en ce qui concerne les connexions humaines. 
(ii) Connexions humaines

Graphique 2.3. Positionnement des régions françaises selon les indicateurs d'internationalisation : les connexions humaines

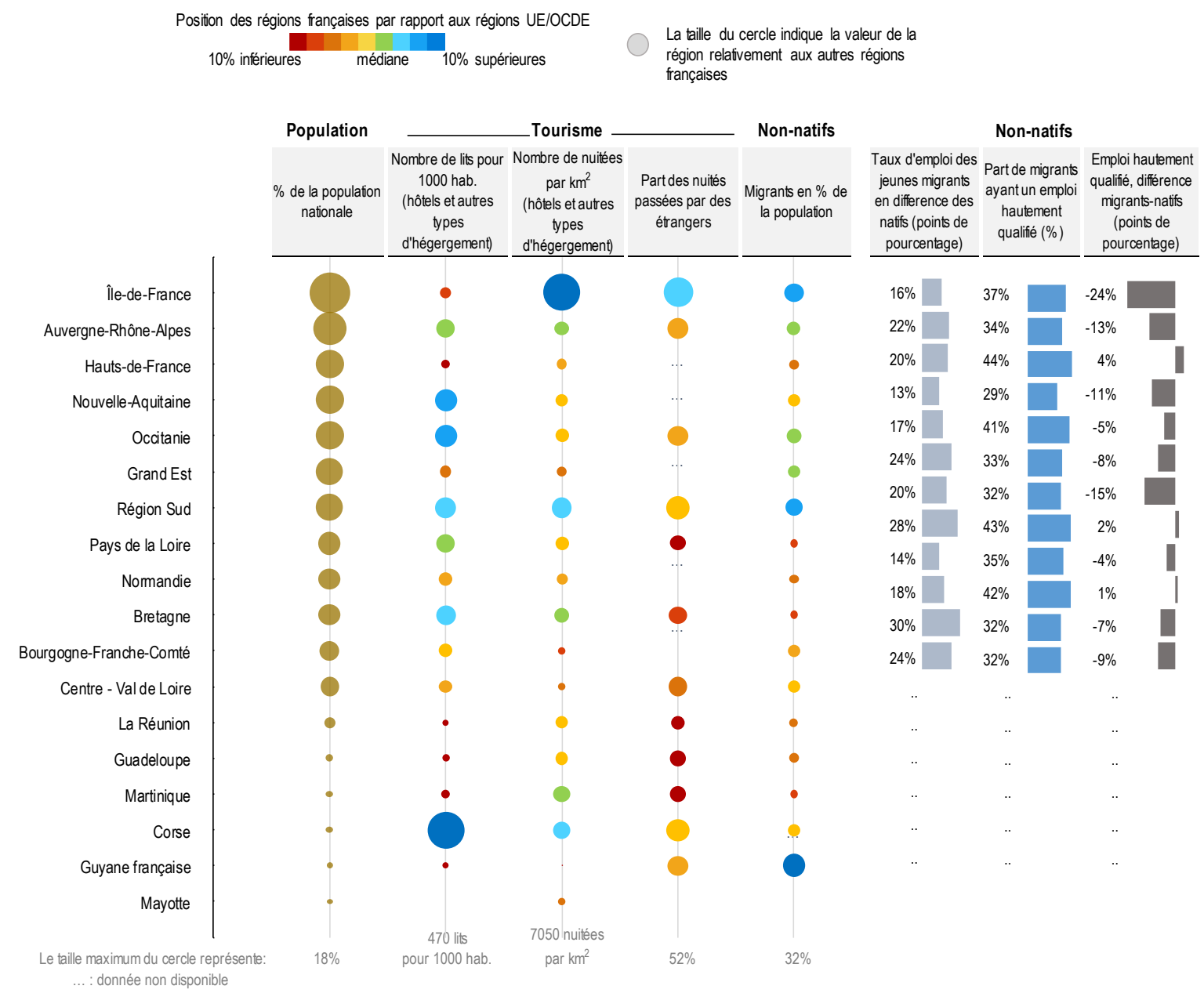

Note : Les régions sont triées par ordre décroissant de leur selon leur population.

Source : Base de données de l'OCDE sur l'internationalisation des régions françaises et Eurostat (tourisme).

Les indicateurs sur les connexions humaines (Graphique ci-dessus) apportent plusieurs types d'informations sur les régions françaises :

- L'infrastructure hôtelière est particulièrement développée en Corse en regard de sa population, avec une capacité d'accueil touristique de 470 lits pour 1000 habitants, soit plus de trois fois celles de la Nouvelle-Aquitaine et de l'Occitanie. La Corse se situe ainsi parmi les 10\% régions européennes les mieux dotées à cet égard. L'Île-de-France, bien plus dense en termes de population, obtient le nombre le plus élevé de nuitées par km2 des régions françaises, démontrant une saisonnalité moins importante que d'autres régions touristiques. L'île-de-France est la seule région française faisant partie des $20 \%$ des régions européenne accueillant une part élevée de touristes étrangers, ceux-ci représentant plus de la moitié des nuitées.

- Plus de $30 \%$ de la population en Guyane française est constituée de non-natifs, soit 10 points de pourcentage de plus que l'île-de-France et Sud. L'intégration des jeunes migrants est relativement élevée en Bourgogne-Franche-Comté et en Pays de la Loire où les jeunes 
migrants ont un taux d'emploi de 28 points de pourcentage supérieur à celui des natifs. Hauts-deFrance, Pays de la Loire et Bretagne attirent les migrants les plus qualifiés, alors que l'île-deFrance et Sud accusent un important écart entre les migrants et les natifs en termes de niveau de qualification des travailleurs.

La revue des SRDEll confirme l'importance des activités touristiques et des mesures pour répondre aux besoins en matière de main d'œuvre, $y$ compris étrangère ${ }^{29}$ des entreprises dans les territoires.

Dans le contexte de la mégatendance à la numérisation, les régions sont concernées par la question de la disponibilité des compétences nécessaires pour aider à la digitalisation des entreprises. Il s'agit à la fois de former et d'attirer les talents, dont l'absence peut non seulement pénaliser le développement international des entreprises locales mais aussi freiner l'accueil des investisseurs étrangers. Bien souvent, les métiers en tension considérés dans les SRDEll ne le sont pas spécifiquement dans une perspective internationale - comme dans le cas des métiers de la pêche, de l'agriculture ou des travaux publics (Martinique, Guyane, Occitanie, Nouvelle-Aquitaine). La majorité des SRDEll expriment d'importants besoins en main d'œuvre spécialisée dans le domaine du numérique - codeurs, développeurs, etc. - (Corse, Guadeloupe, Bretagne, Pays de la Loire, AURA, Centre-Val de Loire). Par exemple, AURA rappelle que 1,900 emplois ne sont pas pourvus dans les entreprises du numérique.

Par ailleurs, certaines Régions notent le difficile recrutement de personnel dans l'industrie touristique dans certains territoires (Nouvelle-Aquitaine, Normandie). La Normandie souligne ainsi que « le recrutement et la fidélisation d'une main d'œuvre formée et qualifiée est la difficulté principale des entreprises qui croissent aujourd'hui en Normandie. Problème de formation, mais aussi d'attractivité, tant des métiers que des entreprises et des territoires où elles se situent ${ }^{30}$

Plus largement, alors que les mesures liées aux touristes et entreprises touristiques figurent dans le Schéma régional de développement du tourisme et des loisirs (SRDT), ${ }^{31}$ les SRDEll s'emparent très souvent de cette thématique à la fois pour proposer des orientations générales concernant l'accueil des visiteurs étrangers, mais surtout pour proposer des mesures de soutien aux entreprises touristiques (11 des 17 régions proposent des mesures précises à ce sujet et 4 autres abordent cette thématique).

Les ambitions touristiques des Régions exprimées dans leur SRDEll reflètent soit leur souhait de consolider une position déjà favorable sur le marché (Corse, AURA, Occitanie), soit de répondre à la stagnation - voire le déclin conjoncturel des activités touristiques (Guadeloupe ${ }^{32}$ ) ; ou encore, dans le cas de Régions traditionnellement moins touristiques, de devenir un nouvel acteur du marché (Guyane, Hautsde-France).$^{33}$ En général, les mesures proposées sont celles d'une montée en gamme des activités touristiques par la structuration de filières d'excellence et la politique de labellisation (Occitanie, Martinique, ${ }^{34}$ Guadeloupe) ; l'innovation touristique, y compris par la digitalisation et l'analyse fine des parcours touristiques (Corse, AURA, Occitanie) ; ainsi que la diversification des expériences proposées (tourisme fluvial pour les Hauts-de-France, "parcours alternatifs » en lien avec l'Office national des forêts pour la Guadeloupe).

\footnotetext{
29 L'attraction spécifique de chercheurs et d'étudiants étrangers est traité dans la section Connexions de connaissance)

30 SRDE-II, région Normandie

${ }^{31}$ Les Régions Ile-de-France, Sud ou Bourgogne-Franche-Comté, qui ne traitent pas spécifiquement du sujet, font expressément référence au Schéma régional du tourisme et des loisirs. La région Grand Est mentionne que " le Schéma régional de développement du tourisme pourra donc constituer le volet tourisme du SRDEll ».

32 Ainsi, le SRDEII de la Guadeloupe la diversification de l'offre touristique, la montée en gamme et le développement du tourisme de croisière a permis à la filière de se redresser après la crise de 2008-2009.

${ }^{33} \mathrm{La}$ Guyane souhaite se positionner dans ce secteur via la valorisation des événements culturels et sportifs.

34 La Martinique souhaite faire émerger les filières bien-être nature, saveurs-gastronomie-spiritourisme, Affaires, Culture et Sport ; Plaisance et Nautisme, et Croisière.
} 
Pour réaliser leurs ambitions, les Régions proposent diverses options financières, administratives et d'ingénierie afin de favoriser la formation du personnel (notamment en lien avec les CPRDFOP), préserver le foncier et l'immobilier, l'aide au marketing et à la commercialisation, et soutenir la digitalisation du secteur (AURA, Corse, Occitanie). L'innovation touristique, en particulier, passe par la mise en place de dispositifs d'échange d'informations et d'analyse spécifiques ("Tourisme Living Lab » en Corse), mais aussi par le soutien à la création d'emplois spécifiques et qualifiés (10,000 sont envisagés dans le tourisme digital dans la région AURA). Ainsi, de même que les infrastructures, les connexions humaines - qu'elles soient en lien avec les métiers en tension ou les mesures en faveur de l'industrie du tourisme - témoignent de l'importance de l'innovation, de la digitalisation, et donc la meilleure intégration des régions dans l'économie de la connaissance.

\section{(iii) Connexions de connaissance}

Graphique 2.4. Positionnement des régions françaises selon les indicateurs d'internationalisation : les connexions de connaissance

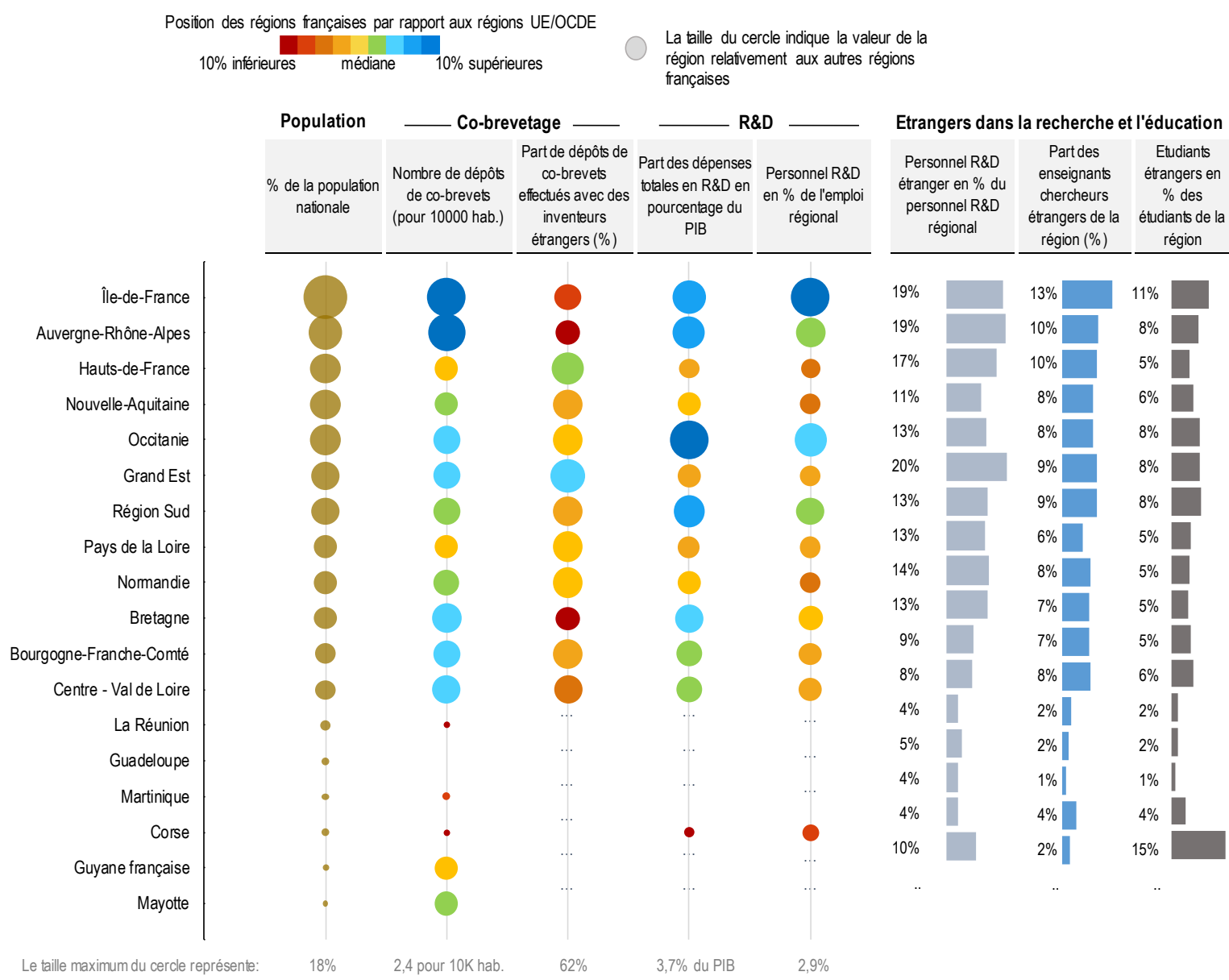

Note : Les régions sont triées par ordre décroissant de leur population. Dans ce graphique, la couleur des cercles identifie la position des régions françaises par rapport aux régions de l'OCDE.

Source : Base de données de l'OCDE sur l'internationalisation des régions françaises, Eurostat (dépenses et personnel R\&D), l'Observatoire des territoires - ANCT (enseignants chercheurs et étudiants étrangers). 
Les indicateurs sur les connexions de connaissance (Graphique ci-dessus) apportent plusieurs types d'informations sur les régions françaises :

- Les régions île-de-France et Auvergne-Rhône-Alpes sont les moteurs des régions françaises en termes de brevets déposés par des co-inventeurs avec plus de 2 brevets pour 10000 habitants. Sept régions françaises sont parmi les 30\% premières régions de l'OCDE déposant ce type de brevets. En revanche, seule le Grand-Est reste positionné dans les 30\% premières régions de l'OCDE pour ce qui est du co-brevetage effectué avec un ou des inventeur/s situé/s dans une région étrangère.

- En Occitanie la dépense en recherche et développement représente 3.7\% du PIB. Seules quatre régions françaises sont par ailleurs au-dessus de la médiane des régions européennes (1.6\%) qui allouent le plus de personnel à la recherche et développement.

- Près de $20 \%$ du personnel R\&D employé dans la recherche dans les régions du Grand Est, de l'île-de-France et de l'Auvergne-Rhône-Alpes est d'origine étrangère. L'île-de-France reste la région concentrant le plus de d'enseignants-chercheurs et d'étudiants étrangers, respectivement $13.5 \%$ et $10.5 \%$.

En matière d'action publique, les régions considèrent que l'innovation conditionne le développement économique des territoires. Si certaines envisagent l'innovation par le prisme plus étroit du marché "domestique ", la grande majorité - qu'elles se positionnent parmi les régions les plus innovantes ou non (voir Graphique 2.5) - mentionne des mesures en faveur de la recherche et du développement dans le but d'ouvrir les territoires sur des collaborations européennes, voire internationales, et de bénéficier de l'innovation au service des activités internationales de leurs entreprises. Dans une moindre mesure, les régions entendent aussi favoriser la venue de chercheurs et étudiants étrangers sur leur territoire.

Les connexions de connaissance européennes occupent une place centrale de l'internationalisation des régions. Les SRDEll se fondent sur les travaux menés par les régions dans le cadre de l'élaboration des Smart Specialisation Strategies (S3) ${ }^{35}$ Ainsi les stratégies d'internationalisation des régions par la connaissance s'inscrivent dans les programmes de recherche initiés par l'Union européenne, et engagent donc une mise en œuvre coordonnée avec le niveau national et supranational Horizon 2020 en particulier, mentionnés par un grand nombre de régions (voir aussi section 2.2 sur les dispositifs de gouvernance). Les régions les plus actives en matière de recherche "internationalisée " (Ile-de-France, Occitanie, Grand Est) sont aussi les plus ambitieuses concernant la coopération internationale en matière de recherche et de développement. Certaines souhaitent poursuivre la mise en œuvre de projets transfrontaliers (Minnovarc et Innovarc pour la Bourgogne-Franche-Comté en partenariat avec la Suisse). D'autres promeuvent la création de nouvelles dynamiques de recherche européenne : c'est le cas des Hauts-de-France dans le cadre du projet Welcome EU, qui vise à accueillir des chercheurs et projets européens dans des secteurs spécifiques (cybersécurité, fintech, etc.) ou de la Région GrandEst qui veut proposer des projets transfrontaliers de R\&D industrielle, agricole, viticole et forestière. D'autres régions souhaitent faire émerger des pôles " globaux » ou renforcer la coopération entre pôles de compétitivité et clusters au niveau mondial (Occitanie, Ile-de-France, Nouvelle-Aquitaine). Enfin, des régions moins actives en matière de recherche et développement, comme la Corse ou la Guadeloupe, affichent, elles aussi, leur ambition de s'inscrire dans des dynamiques de recherche européenne et internationale.

Les régions conçoivent par ailleurs l'innovation comme un réel facteur d'attractivité des entreprises étrangères. Ainsi, les Pays de la Loire considèrent que l'implantation d'un Institut de recherche technologique sera favorable aux PME, mais aussi aux « grands groupes ». De la même façon,

35 Dans le cadre de la programmation 2014-2020 des fonds européens, l'Union européenne a demandé à toutes les régions d'Europe d'élaborer une « stratégie de spécialisation intelligente » (《 smart specialisation strategy ») pour la recherche et l'innovation sur leur territoire (CGET, 2015). 
les entreprises sont encouragées à participer à l'effort d'innovation pour devenir plus compétitives à l'échelle internationale (Occitanie, lle-de-France, Pays de la Loire, Guyane). Pour l'Occitanie, les chefs d'entreprise de «l'Industrie du futur » doivent participer à des collaborations avec des équipes de recherche internationales aux côtés des instituts régionaux ; tandis que la Guyane considère que le cadre de l'internationalisation de ses entreprises réside dans leur compétitivité hors-prix, soutenue par un réseau régional d'innovation.

Les régions sont par ailleurs très conscientes de l'importance des "talents" pour le développement économique des territoires, ainsi que de la concurrence internationale accrue pour les attirer. Comme le mentionne le SRDEII de la Nouvelle-Aquitaine, les Régions doivent prêter attention aux différentes dimensions de l'attractivité des territoires, ce qui requiert de «mobiliser et attirer les talents à partir d'atouts en termes de cadre de vie, de conditions de travail, de modes de management et d'articulation entre vie professionnelle et vie personnelle " (région Nouvelle-Aquitaine, 2017). Les SRDEII ont permis de préciser parfois les mesures envisagées pour renforcer l'attractivité des territoires vis-à-vis des "talents ", ${ }^{36}$ telle que la création de campus « internationaux » (AURA, Grand-Est). Les Régions d'Outre-mer, qui accueillent de nombreux étudiants étrangers sont particulièrement attentives à ce sujet. La Guadeloupe souhaite par exemple profiter de sa localisation privilégiée pour " favoriser les échanges avec les chercheurs des pays voisins de la Caraïbe, mettre en place des programmes de recherche et projets communs avec les pays voisins ". La Réunion souhaite favoriser la venue d'étudiants étrangers levant certains « points bloquants " (bourses, logements, ${ }^{37}$ visas, etc.). D'autres Régions souhaitent aussi capitaliser sur la circulation de talents (anciens chercheurs ou étudiants étrangers - Bretagne, Corse, Pays de la Loire) pour développer de nouveaux réseaux et alliances. Cependant, et contrairement à la thématique du tourisme (voir section Connexions humaines), les Régions sont dans l'ensemble peu nombreuses à proposer dans leur SRDEII des mesures pour les chercheurs et étudiants étrangers, cellesci figurant par ailleurs dans leur Schéma régional de l'enseignement supérieur, de la recherche et de l'innovation (SRESRI). ${ }^{38}$

Les SRDEII reflètent donc en grande partie les "S3 » régionales, qu'ils se proposent de prolonger et de consolider. Or, les secteurs innovants des S3 sont aussi fréquemment ceux mentionnés pour favoriser les exportations et l'attractivité des territoires (nous l'avons déjà vu dans le domaine du numérique). Aussi, les SRDEII appliquent les S3 pour " mettre l'innovation au service des entreprises et de l'exportation » et de l'attractivité des territoires, comme l'explique la Guyane.

\footnotetext{
${ }^{36}$ L'analyse de l'OCDE corrobore les résultats de l'enquête de l'Observatoire territorial de la mobilité internationale des étudiants et des chercheurs (2018), selon laquelle 10 régions ont intégré le thème de la mobilité internationale des étudiants-chercheurs au SRDE-II - 11 selon la taxonomie de l'OCDE.

37 L'lle-de-France inscrit aussi dans ses priorités la facilitation de l'accès aux logements pour les chercheurs et étudiants étrangers.

${ }^{38} 5$ régions mentionnent des mesures spécifiques aux étudiants étrangers, et 6 pour les chercheurs étrangers.
} 
(iv) Connexions d'affaires

Graphique 2.5. Positionnement des régions françaises selon les indicateurs d'internationalisation : les connexions d'affaires

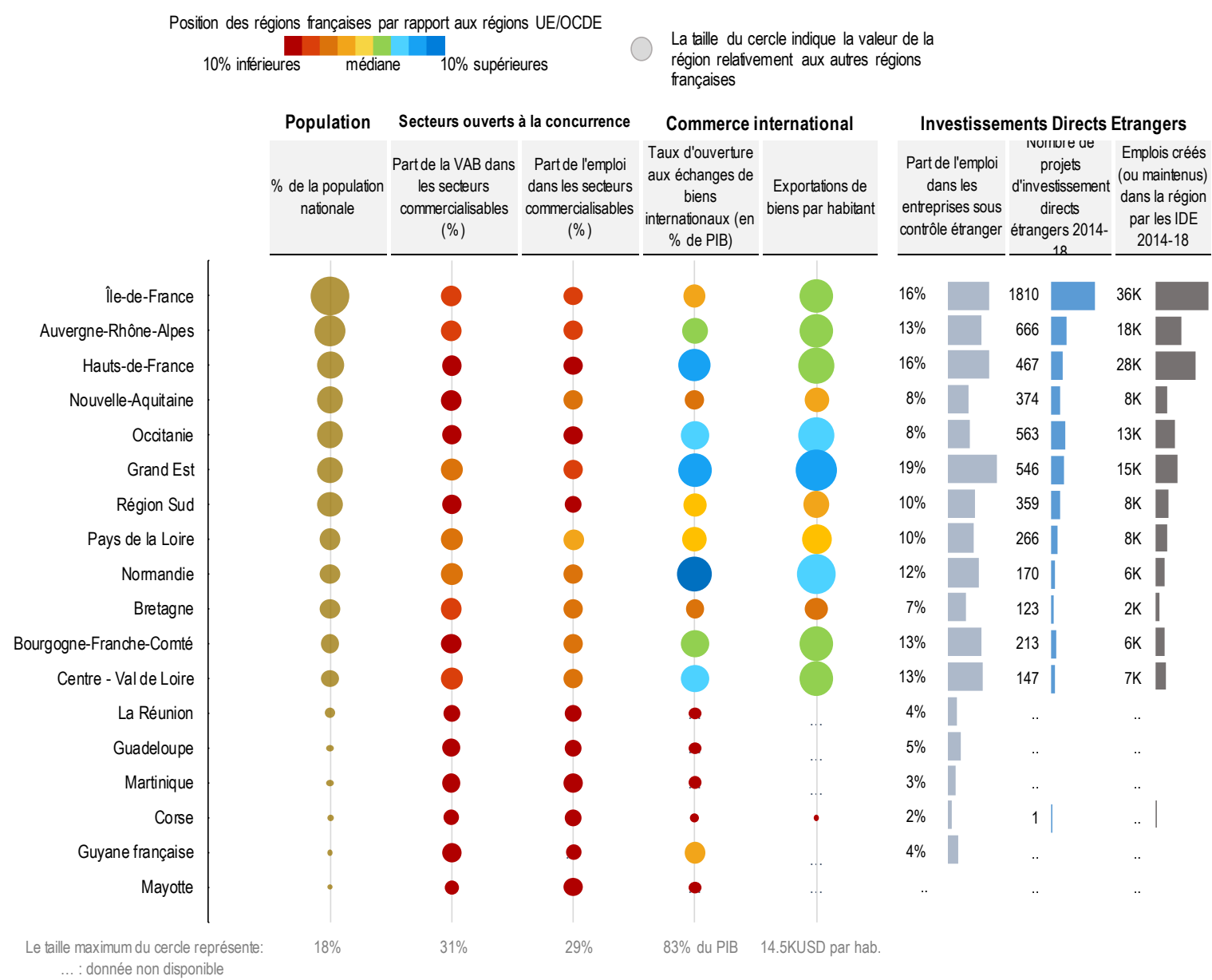

Note : Les régions sont triées par ordre décroissant de leur population. Dans ce graphique, la couleur des cercles identifie la position des régions françaises par rapport aux régions de l'OCDE.

Source : Base de données de l'OCDE sur l'internationalisation des régions françaises, Douanes françaises (commerce international), Observatoire des territoires, ANCT (Groupes étrangers), Business France (Investissements Directs Étrangers).

Les indicateurs sur les connexions d'affaires (Graphique 2.5) apportent plusieurs types d'informations sur les régions françaises:

- Les secteurs de biens échangeables concentrent moins d'emplois et de productions de richesses dans les régions françaises qu'ils ne le font dans les régions des autres pays de l'OCDE. En moyenne nationale, la part des secteurs échangeables dans la VAB de la France est de $28 \%$ en 2016, la valeur la plus faible des pays de l'OCDE, après le Portugal et la Norvège. Concernant la part de l'emploi dans les secteurs échangeables, le France à la sixième valeur plus faible avec $25 \%$, et se situe entre les États-Unis et l'Australie.

- Le taux d'ouverture aux échanges de biens internationaux, mesuré par la somme des imports et exports sur le PIB régional, est relativement important en Normandie, dans le Grand Est et dans les Hauts-de-France. 
- Les entreprises sous contrôle étranger représentent près de $20 \%$ des entreprises du Grand Est et $16 \%$ de l'île-de-France et des Hauts-de-France. L'Île-de-France concentre les investissements directs étrangers avec 1810 projets effectués sur la période 2014-18 et 36 000 emplois créés ou maintenus.

Les SRDEIl définissent avant tout un cadre d'action pour les Régions vis-à-vis des entreprises, notamment au travers de politiques en faveur de l'exportation et de l'attractivité. Le SRDEII des Pays de la Loire exprime cette intention très clairement dès son préambule :

« Notre action doit en effet s'enraciner dans cette évidence qui, trop souvent, a été oubliée : ce sont les entreprises qui créent l'emploi, pas les collectivités. Revenir à cette évidence, c'est rappeler que notre rôle n'est pas d'empiler des dispositifs ou des projets sans modèles économiques viables, mais bien de créer les conditions de la liberté mais surtout de la compétitivité des entreprises grâce à la simplification, l'innovation, l'internationalisation ou la formation. »

Les orientations des SRDEII en direction des entreprises couvrent de nombreux domaines, tant en ce qui concerne les exportations (mesures spécifiques pour les PME et TPE, définition des secteurs prioritaires) que l'attractivité (secteurs prioritaires pour les investissements étrangers, mesures spécifiques pour la valorisation de certaines zones d'activités et pour l'exportation). ${ }^{39}$

La stratégie d'internationalisation vis-à-vis des entreprises est avant tout une stratégie d'exportation pour les PME et TPE. Alors que les Régions disposent déjà de Plans régionaux pour l'internationalisation des entreprises (PRIE), ${ }^{40}$ toutes proposent dans les SRDEII des mesures très variées à l'attention des petites entreprises. Celles-ci comprennent entre autres des appels à projets pour la levée de fonds privés (Martinique, Corse), structuration en grappes et filières (Martinique, Guyane, AURA) ; aides financières et expérimentations fiscales (Corse) ; expérimentation fiscale (Centre Val de Loire, Réunion, Corse) ; services d'information et d'intelligence économique à l'international (Bourgogne-Franche-Comté, Pays de la Loire, Occitanie) ; aides au « scale-up » des PME, notamment par le passage au statut d'entreprise de taille intermédiaire (ETI) (Bretagne, Région Grand Est) ; soutien à la participation aux salons internationaux (Occitanie) ; mise en œuvre de tutorats entre « pairs " pour les entreprises primo-exportatrices et celles déjà implantées à l'étranger (Région Grand-Est).

Par ailleurs, 16 des 17 SRDEII définissent clairement les priorités sectorielles pour l'exportation, fondées sur les S3. Les secteurs les plus mentionnés sont le numérique, l'agro-alimentaire, la santé et la silver economy, les énergies, les transports (y compris l'aéronautique) ou le tourisme notamment. D'autres secteurs d'exportation sont plus spécifiques : c'est le cas par exemple des activités minières (Guyane) ou du naval (Bretagne, Région Sud).

Dans une logique de spécialisation, les secteurs prioritaires d'exportation sont aussi généralement ceux dans lesquels les régions visent à attirer des investisseurs étrangers. Certaines Régions considèrent que les entreprises exportatrices de leur territoire doivent aussi servir de «vitrines » pour attirer d'éventuels investisseurs étrangers. La Corse souhaite par exemple mettre en place " un réseau de $\mathrm{VIE}^{41}$ dans une optique de promotion de l'exportation des entreprises corses et de promotion de l'image économique et de l'attractivité du territoire " (Collectivité Territoriale de Corse, 2017). Comme pour les exportations, les régions proposent des mesures spécifiquement adressées aux investisseurs étrangers. Deux régions par exemple mentionnent explicitement les synergies recherchées entre exportations et investissements. La Région Grand Est, très sensible à la présence d'entreprises étrangères (Graphique 2.5), souhaite « capitaliser » sur leur implantation afin d'attirer des centres de décision

\footnotetext{
${ }^{39}$ Ces mesures de soutien financier complémentent l'action des intercommunalités et des communes.

40 L'objectif des PRIE consiste à renforcer l'action des régions en matière d'identification et d'accompagnement des entreprises à l'export. Les PRIE fixent des objectifs et des actions et organisent sur leur territoire le dispositif d'appui à l'export en associant l'ensemble des acteurs concernés (banques publiques, chambres de commerce et d'industrie et les pôles de compétitivité notamment).

41 Volontariat International en Entreprise
} 
d'entreprises et créer des zones d'activités transfrontalières, tout en reconnaissant que ses exportations dépendent pour trop grande partie des activités de filiales étrangères. La Guyane, où « seulement » $4 \%$ concernent des entreprises sous contrôle étranger, considère que la poursuite de l'exploitation minière représente des opérations que « seules des multinationales peuvent (...) financer » et souhaite adapter le cadre juridique de l'exploitation minière industrielle. Pour ces régions, mais surtout pour celles d'Outremer en général, l'attraction de capitaux étrangers doit permettre de se repositionner dans les chaînes de valeur mondiales autour d'activités à plus forte valeur ajoutée et plus compétitives à l'échelle internationale. ${ }^{42}$

Attirer des investisseurs étrangers s'inscrit dans une stratégie spatiale. Dans la plupart des cas (10 régions sur 17$),{ }^{43}$ les régions souhaitent valoriser des zones destinées à l'activité économique grâce à des mesures financières, immobilières et foncières. Néanmoins, il n'apparait pas dans la plupart des SRDEII de stratégie propre aux zones d'activités économiques. La question foncière est traitée dans les SRADDET ${ }^{44}$, dans le cadre de la compétence aménagement du territoire, partagée avec l'État. Par ailleurs, le foncier économique au travers de la création, gestion et attractivité des zones d'activités intéresse plusieurs niveaux d'administration, encadrés par les documents d'urbanisme locaux (PLU/PLUi/Scot ${ }^{45}$ au niveau des EPCI) et par le SRADDET au niveau régional qui est un document prescriptif vis-à-vis des documents locaux. Le SRADDET peut ainsi venir limiter le développement de ce foncier économique, sur des considérations environnementales le plus souvent (biodiversité, lutte contre l'artificialisation des sols...). Certaines régions, comme Sud ou la Réunion, identifient néanmoins des axes de renforcement de l'attractivité des zones d'activités économiques à travers le prisme des transports et de la connectivité ; tandis que l'lle-de-France souhaite diversifier les filières présentes dans les zones d'activités économiques « en s'appuyant sur les orientations du SRDEll » (Région lle-de-France, 2017).

Enfin, certaines régions souhaitent mobiliser et faire émerger les compétences pour "l'internationalisation " dans leur territoire, ${ }^{46}$ tout d'abord pour créer des emplois. ${ }^{47}$ Les SRDEII comportent aussi un volet pour la montée en compétences à l'international. Alors qu'existent les «Contrats de plan régional de développement des formations et de l'orientation professionnelles " (CPRDFOP), certaines régions s'emparent néanmoins des SRDEII pour rappeler leur attachement au soutien à la formation professionnelle à des fins d'internationalisation (Bourgogne-Franche-Comté, Normandie, Occitanie, Grand Est). La région Pays de la Loire propose des actions pour l'accompagnement des professionnels travaillant à l'international pour maitriser l'anglais, ou encore pour le soutien aux programmes de mobilité européenne et internationale ; tandis que la Région Grand-Est souhaiterait systématiser le «trilinguisme professionnel » (visant à la fois l'internationalisation " de proximité » et l'échelle plus globale). Enfin, l'Occitanie propose à la fois des services spécifiques pour former les chefs d'entreprises à l'international et un soutien à la structuration des équipes commerciales aux entreprises ayant adopté des plans d'export à l'horizon de deux ans au moins.

Les leviers traditionnels de l'attractivité des territoires auprès des investisseurs étrangers (avantages fiscaux, souplesse dans l'application des normes, ...) n'apparaissent que de manière exceptionnelle dans les stratégies d'internationalisation des régions. La Guyane mentionne ainsi une simplification des normes en matière environnementale pour renouveler l'exploitation minière dans le respect du développement durable ou encore des aides financières pour favoriser l'intégration de la main d'œuvre locale dans les

\footnotetext{
$42 \mathrm{Ce}$ sont surtout les régions d'Outre-mer qui mentionnent cette dimension alors que l'évolution des règlements internationaux en matière de commerce affaiblit leur compétitivité.

${ }^{43}$ Ces Régions sont soit celles qui reçoivent le plus - lle-de-France, AURA, Grand Est) soit le moins (Bretagne) d'investissements directs étrangers (en part des IDE nationaux - les régions d'outre-Mer ne sont pas comprises).

44 Schéma Régional d'Aménagement, de Développement Durable et d'Egalite des Territoires, pour vingt ans.

${ }^{45}$ Plan Local d'Urbanisme, Plan Local d'Urbanisme intercommunal et Schéma de Cohérence Territoriale

4612 Régions sur 17 abordent ou détaillent des mesures en faveur de la formation professionnelle en lien avec l'internationalisation.

47 La Région Guadeloupe (2017), par exemple, considère que « l'insertion des jeunes dans le monde de l'entreprise et du travail sous-tendra l'ensemble des thématiques développées dans le schéma ».
} 
entreprises étrangères ${ }^{48}$. Les régions souhaitent surtout agir via des dispositifs de formation, d'investissement, la fourniture d'infrastructures et de services et enfin de gouvernance. Les approches les plus innovantes à ce sujet résultent de coopération entre acteurs publics et privés, nationaux et infranationaux, régionaux et étrangers. À titre d'exemple, la majorité des Régions incite les entreprises du territoire à « chasser en meute » auprès des partenaires commerciaux potentiels.

\section{Observations sur les SRDEII, dans le contexte de la crise du COVID-19}

Cette vue d'ensemble des SRDEll permet de conclure à l'appropriation par les Régions de leur compétence en matière de développement international, surtout dans sa dimension économique (relative aux « connexions d'affaires »). Quelques observations sont tirées de cette analyse :

- Les régions françaises ne mentionnent pas leur recours aux instruments " traditionnels " des politiques d'attractivité des investisseurs étrangers, focalisés sur les incitations financières, dont les effets sont d'ailleurs contestés (Poulhès, 2018; OCDE, 2015 ; OCDE, $2016)^{49}$.

- Elles engagent des projets favorisant l'attractivité plutôt axés sur les infrastructures, les services et la qualification de la main d'œuvre - qui bénéficient tant aux investisseurs qu'aux habitants et entreprises locales dans une vision qui s'accorde avec la notion de bien-être régional.

- On peut noter que les stratégies régionales de l'attractivité et leur communication ne valorisent pas leur situation en matière de bien-être régional. En particulier, si les Régions recherchent un équilibre entre développement économique et respect de l'environnement et de la biodiversité, certaines envisagent des mesures plus concrètes concernant la valorisation des aménités environnementales, surtout pour attirer visiteurs et investisseurs (notamment dans l'innovation et la recherche et développement pour ces derniers), moins pour attirer de nouveaux résidents. Les régions françaises présentent pourtant, pour la dimension environnementale comme pour d'autres dimensions du bien-être, de nombreux avantages en comparaison des autres régions des pays de l'OCDE (voir Encadré 2.1 et Graphique 2.6).

\footnotetext{
48 Collectivité Territoriale de Guyane (2019) : «il importe de maintenir l'attractivité du territoire pour les investisseurs étrangers, notamment en sécurisant juridiquement le cadre de l'exploitation minière industrielle ».

${ }^{49}$ L'OCDE (2015) a identifié 12 domaines de politique générale qui affectent les flux d'investissement. II s'agit de la politique d'investissement, de la promotion et de la facilitation des investissements, de la concurrence, des échanges, de la fiscalité, du gouvernement d'entreprise, de la finance, des infrastructures, du développement des ressources humaines, des politiques visant à promouvoir un comportement responsable des entreprises, de l'investissement en faveur de la croissance verte et de la gouvernance publique. La Recommandation de l'OCDE pour l'investissement public efficace entre niveaux de gouvernement (2014) soutient les acteurs publics dans la mise en œuvre des politiques d'investissement visant le développement régional, permet la comparaison internationale des approches et identifie les bonnes pratiques (cette recommandation est mise à jour régulièrement).
} 


\section{Encadré 2.1. Bien-être régional}

Les travaux de l'OCDE sur le bien-être se fondent sur le rapport remis en septembre 2009 par la commission Stiglitz-Sen-Fitoussi sur la mesure de la performance économique et du progrès social. Dans ce rapport, la commission a privilégié le caractère multidimensionnel du bien-être. Sur cette base, I'OCDE a développé une initiative pour la mesure du bien être en créant l'Indice du Vivre Mieux au Niveau national, le « Better Life Index », et sa déclinaison au niveau régional pour mesurer le bien-être là où il se vit. Chaque personne bénéficie de son territoire et y contribue : le cadre de mesure régional s'appuie sur 11 dimensions du bien-être et comprend des indicateurs de résultats concernant les conditions matérielles, la qualité de la vie et le bien-être subjectif. Le bien-être régional est mesuré pour plus de 400 régions de l'OCDE et peut être visualisé sur le site interactif www.oecdregionalwellbeing.org

Huit régions françaises se classent parmi les $20 \%$ des meilleurs régions de l'OCDE en termes de santé, les habitants de la région-capitale ayant l'espérance de vie la plus longue du pays et l'une des plus élevées de l'ensemble de la zone de l'OCDE (Graphique 2.8). Les disparités régionales les plus importantes sont observées en matière de liens sociaux (la perception du soutien apporté par son réseau social), l'accès aux services (dont l'indicateur de référence est la part des ménages ayant accès à internet à haut débit), et la sécurité, la Corse se situant dans les $25 \%$ inférieurs des régions de l'OCDE et la Bretagne dans les $25 \%$ supérieurs. Par ailleurs, la Corse se classe au premier rang des régions françaises en matière de liens sociaux, et la Région Sud en ce qui concerne l'auto-évaluation sur la satisfaction de la vie.

Source : OCDE (2020), www.oecdregionalwellbeing.org

\section{Graphique 2.6. Disparité de bien-être entre les régions hexagonales françaises et en référence aux} régions des pays de l'OCDE

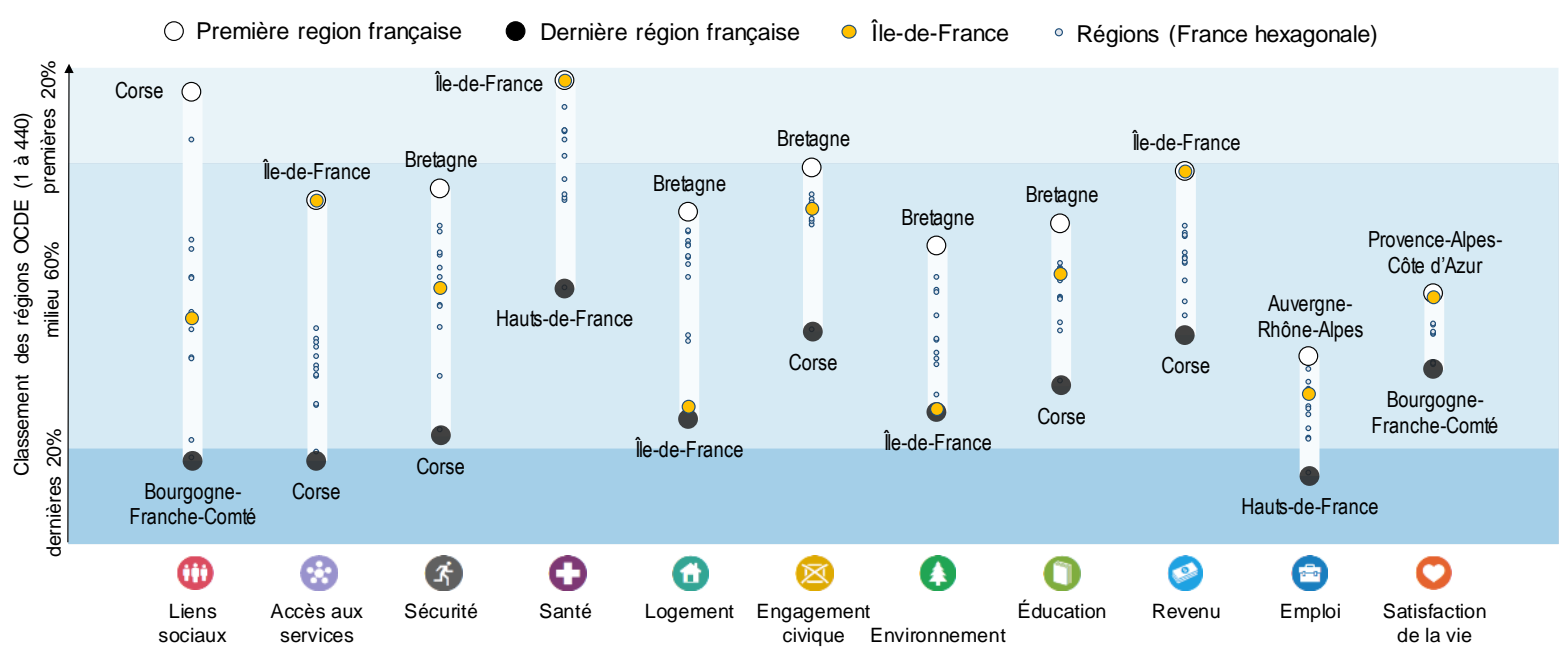

Note : classement relatif des régions selon leurs résultats pour les 11 dimensions du bien-être, pour l'ensemble des 440 régions de l'OCDE. Les onze dimensions sont classées par ordre décroissant des disparités régionales dans le pays.

Source : Base de données régionale de l'OCDE 
- Les régions mettent, par ailleurs, l'accent sur le soutien à l'export de leurs entreprises. Cette orientation rejoint les conclusions des évaluations des programmes de soutien à l'export qui montrent non seulement un impact positif important sur la performance des entreprises, particulièrement les PME (Munch et Schaur, 2018), mais aussi une augmentation de la résilience de ces entreprises (Van Biesebroeck et al., 2016)

- Cependant cet appui semble peu connecté à une autre cible de l'internationalisation avec laquelle on aurait pu imaginer que les articulations soient plus importantes: les investisseurs étrangers. On pourrait penser en effet que les PME de la Région et leurs produits d'exportation constituent des « vitrines ", des «messagers » de la performance de leur territoire d'origine. Ce faisant, ils pourraient donc attirer des investisseurs étrangers ou faire bénéficier de cette réputation d'autres PME potentiellement exportatrices.

- Alors que les projets d'attractivité et d'export, et même de soutien aux activités touristiques, occupent une large place dans les SRDEII, l'intérêt à répondre aux besoins locaux immédiats de l'emploi par l'accueil et l'intégration de talents étrangers sont largement absents des stratégies portées par les SRDEll qui attestent cependant des carences ressenties par les Régions dans les métiers du numérique et de certains secteurs-clés (comme l'agriculture).

- La lecture des SRDEII renvoie, de manière assez systématique, à d'autres documents stratégiques traitant de l'aménagement du territoire (SRADDET), du tourisme (SRDTL) ou de la recherche et de l'innovation (SRESRI). II serait très utile de disposer d'un document unique synthétique,$^{50}$ poussant les programmes de développement régional à intégrer leurs différentes politiques, dont l'internationalisation, dans une vision stratégique tendant vers une mise en cohérence des priorités régionales en lien avec les orientations nationales et européennes. Un tel document de référence (qui pourrait par exemple consister en un SRDEII " élargi » permettrait de gagner en efficacité en forçant les différents acteurs à développer des synergies.

Au-delà de ces quelques remarques, les orientations stratégiques des SRDEll prennent une dimension nouvelle dans le contexte de la pandémie de COVID-19. En effet, en mettant l'accent sur la volonté de disposer des ressources essentielles, la crise pousse les acteurs régionaux et leurs partenaires nationaux à s'interroger de manière prioritaire sur leur positionnement dans les chaînes de valeur mondiales, une dimension qui n'est pas centrale à la plupart des SRDEll. II s'agit non seulement de s' y inscrire par l'attraction des capitaux étrangers, mais aussi de garantir que les investissements étrangers créent des emplois durables dans les firmes implantées ainsi que dans le tissu régional des petites et moyennes entreprises d'une part et, d'autre part, que ces investissements soutiennent la dynamique locale d'innovation. ${ }^{51}$ II s'agit aussi de garantir l'accès aux ressources essentielles et la survie économique et sociale des entreprises de leurs territoires (notamment quand elles sont dépendantes d'exportations ou de composants importés).

Il s'agit enfin, et de manière cruciale notamment dans le cadre du green deal européen, de tenir compte de l'évolution des préférences pour une économie plus soutenable et plus inclusive qui conditionne à la fois les relations marchandes internationales (avec la tentation d'adopter le " précautionnisme » plutôt que le «protectionnisme ») (Lamy, 2020) mais aussi la nécessité de disposer des compétences et des connaissances pour mettre en place les transitions nécessaires pour numériser les activités et pour répondre aux défis de la transition écologique (climat et biodiversité en particulier).

\footnotetext{
${ }^{50}$ Certaines régions en ont fait un objectif : par exemple, la Martinique souhaite produire un document unique, le Plan d'Aménagement et de Développement Durable de la Martinique (PADDMA), dont le SRDEIl constituerait le volet économique.

51 Selon Lembcke et Wildnerova (2020), si les investissements directs étrangers permettent d'insérer les entreprises et leur écosystème "local» dans les chaînes de valeur mondiales par un effet de "spill-over 》 [de simple ruissellement], ils n'ont qu'un effet positif que très limité sur les gains en matière d'emploi dans les PME, voire négatifs pour les $\mathrm{PME}$ « régionales ».
} 
Déjà, dans leur SRDEIl élaborés bien avant la pandémie, certaines régions plaçaient leur stratégie d'internationalisation comme un levier central de leur stratégie de développement. C'est le cas de certaines Régions d'Outre-mer, dans la volonté de s'intégrer de manière plus active et profitable dans leur «bassin » de fait internationalisé mais aussi la Région Grand-Est, qui souhaite améliorer la balance commerciale, tout en intensifiant la venue de talents étrangers et la coopération internationale en matière de recherche et de développement.

La crise économique risque d'accroitre les disparités territoriales au sein des États (et des Régions), déjà aggravées par la crise financière mondiale de 2008. Dès la rédaction de leur première génération de SRDEII, la plupart des régions (13 sur 17) prêtaient déjà une attention particulière à des territoires à enjeux, en incluant un volet territorial précisant les aides et services spécifiques dans un contexte d'internationalisation - par exemple les territoires de montagne pour Auvergne-Rhône-Alpes et la Corse, les bourgs ruraux en Martinique, ou certains départements pour la Région Sud, les territoires politique de la ville en lle de France qui sont souvent parfois inscrits, comme certains territoires de Guyane, dans des programmes de soutien nationaux.

Dans quelle mesure les priorités établies dans les SRDEll et les évolutions qu'elles ont pu connaitre depuis sont-elles bouleversées par la pandémie de COVID-19 ? S'il est une certitude que les analyses de l'OCDE ont pu développer, c'est que la crise actuelle - qui n'est plus simplement sanitaire, mais aussi économique et sociale - requiert une approche intégrée et coordonnée État-Région de l'internationalisation (OCDE, 2020b). Dans cette perspective, la lecture des SRDEII fait apparaitre des politiques publiques « multi-objectifs » et des dispositifs de gouvernance parfois novateurs, qui dépassent les simples mesures sectorielles et impliquent d'autres acteurs que les seules régions. La section suivante présente ces politiques intégrées et les dispositifs de gouvernance que les Régions proposent pour mettre en œuvre leur stratégie d'internationalisation. Elle rappelle tout d'abord, pour ce faire, la distribution des compétences en matière d'internationalisation entre les administrations (notamment le développement économique pour les Régions ; l'immobilier d'entreprise pour les intercommunalités ; l'action de l'État pour les infrastructures, les politiques d'attractivité et d'exportations)

On notera également que les SRDEII témoignent de la volonté des Régions françaises de travailler de manière interterritoriale avec leurs Régions voisines et frontalières, pour soutenir leurs entreprises et leurs territoires.

Les dispositifs mis en place pour coordonner les différentes politiques d'internationalisation et les différents acteurs à différents niveaux de gouvernement visaient jusque-là à exploiter au mieux le potentiel d'internationalisation des territoires. Ils doivent aujourd'hui répondre aux conséquences de la pandémie sur le développement régional dans un nouvel environnement global.

\section{Quelle gouvernance pluri-niveaux des politiques d'internationalisation des régions?}

Les Régions ne participent pas seules à l'internationalisation de leurs territoires. Elles s'inscrivent dans une gouvernance pluri-niveaux de l'internationalisation qui comprend à la fois l'État, les acteurs infranationaux, et au centre, les entreprises. La gouvernance de l'internationalisation est cruciale afin que les acteurs à tous niveaux de gouvernement puissent répondre ensemble aux mégatendances changements climatique, démographique, technologique (OCDE, 2019c) - ainsi qu'aux nouveaux défis liés à la pandémie de COVID-19 - qui risquent de continuer d'accroitre les disparités territoriales entre les Régions, et entre les territoires en leur sein. Cette section s'attache tout d'abord aux dispositifs de gouvernance des stratégies d'internationalisation figurant dans les SRDEIl et présente ensuite, à titre d'exemples de gouvernance pluri-niveaux des politiques d'internationalisation, des dispositifs nationaux dans lesquelles les Régions s'inscrivent et qui visent exportations et attractivité ainsi que les infrastructures logistiques et numériques. 


\section{SRDEII : Les propositions des régions en matière de gouvernance pluri-niveaux pour I'internationalisation des territoires}

Les SRDEll constituent en eux-mêmes un exercice de gouvernance pluri-niveaux. En effet, la loi NOTRe (voir plus haut), requiert une concertation spécifique avec les EPCI, l'organisation d'un débat au sein de la CTAP, et l'association obligatoire de certains acteurs à l'élaboration du Schéma (l'article 4251-14 du CGCT). Les Régions ne se limitent pas aux exigences légales et « font plus », notamment en élargissant les consultations aux acteurs privés et à la société civile, en déployant des ateliers de consultations thématiques, en lançant des consultations en ligne.

Le cadre juridique qui régit les SRDEIl les incite à ce partenariat car il prévoit un suivi de leur mise en œuvre, qui implique a minima la Chambre de Commerce et d'Industrie Régionale (CCIR) et la Chambre Régionale de l'Économie Sociale et Solidaire (CRESS). Néanmoins, on note que toutes les Régions n'ont pas mentionné dans les SRDEII la manière dont devait être effectué ce suivi et l'évaluation qui doit le compléter. ${ }^{52}$

La dimension partenariale se retrouve également dans l'inscription de la mise en œuvre du SRDEII dans des dispositifs de gouvernance pluri-niveaux déjà installés (notamment les Contrats de Plan État-Région ou les programmes européens pour les connexions de connaissances) ou plus novateurs. Ces derniers concernent surtout les exports et l'attractivité des territoires, mais aussi le marketing territorial, qui est repris systématiquement dans tous les SRDEII (voir Encadré 2.2).

\section{Encadré 2.2. SRDEII : Stratégies de marketing territorial et internationalisation}

Les SRDEIl témoignent d'une volonté partagée de renforcer le marketing territorial pris en charge par les Agences régionales de développement (Choose Paris Region; Made in Centre-Val de Loire...). Ces initiatives sont relativement détaillées dans 10 des 17 Régions, elles visent la mise en valeur les atouts régionaux spécifiques auprès des investisseurs, des talents et des visiteurs.

Certaines régions veulent s'appuyer sur une " marque régionale " générale ou décliner la marque nationale Choose France/Made in France (Paris Region, " Invest in Réunion/Made in France ; BIG EST dans la Région Grand-Est) ou un label se déclinant selon les filières et activités (Martinique, Occitanie, Bourgogne-Franche-Comté, Centre-Val-de-Loire, Nouvelle Aquitaine, AURA, Bretagne).

La préoccupation des régions est d'acquérir une image de marque (compétitivité hors prix), mais aussi une identité propre (fondée sur leurs " avantages comparatifs ", comme le souligne la Guadeloupe) à l'international.

Dans ce cadre les Régions souhaitent soit agir en première ligne pour élaborer une marque régionale (Normandie) ou agir comme coordinatrices - ou " marque ombrelle » - des différentes stratégies de marketing des acteurs infranationaux (Corse, Pays de la Loire).

Source : SRDEll de 17 régions

Les régions ont indiqué dans les SRDEII, leur volonté de constituer des instances ad hoc pour l'export ( "task force », comités "thématique » ou "stratégique », "guichet export renouvelé » - Corse, Bourgogne-Franche-Comté, Sud, Occitanie) comprenant souvent les entreprises. La mise en œuvre des politiques d'attractivité par ailleurs peut être portée par un large ensemble d'acteurs publics et privés

529 Régions fournissent des mesures détaillées au sujet de l'évaluation, alors que toutes mentionnent les mécanismes de consultation ayant permis l'élaboration du SRDEII. Par ailleurs, la Région Sud a communiqué une évaluation de suivi d'avancement du SRDEII deux ans après - voir Délibération № 19-581 du Conseil régional) 
(CorsicaNetworks ; « G20 » et « C100 » de la Région Grand Est) ou des entités plus resserrées (Comité Commissariat spécial pour la revitalisation et la réindustrialisation des Hauts-de-France, ${ }^{53}$ Comité stratégique "attractivité » de l'Occitanie ${ }^{54}$ ). La multiplicité des dispositifs envisagés pour l'attractivité est illustrée en particulier dans le SRDEll de la Région Sud (voir Encadré 2.2).

En première ligne pour l'export et/ou l'attractivité, les agences régionales de développement, comprises au sens large, ${ }^{55}$ ne sont cependant pas les seules instances pour mettre en œuvre l'internationalisation des Régions. Leur rôle semblait s'inscrire dans un large ensemble d'acteurs de l'internationalisation que les Régions présentaient dans les SRDEII mais se limitait généralement soit aux politiques d'export, soit à celles d'attractivité (Hauts-de-France, Pays de la Loire, Occitanie), soit aux deux (Corse, AURA, Centre Val de Loire, Nouvelle-Aquitaine par exemple). ${ }^{56}$ Même lorsque leurs attributions sont élargies - comme dans le cas d'AURA $-{ }^{57}$ elles ne sont pas en charge d'un portefeuille intégré touchant les différentes " cibles » de l'internationalisation (investisseurs, talents, visiteurs). II sera important de regarder lors de la prochaine étape de ce travail, si cet état de fait a évolué.

Les régions soulignent par ailleurs l'importance de la coordination entre niveaux de gouvernement pour réussir les politiques d'internationalisation. Dans 16 cas sur 17, les régions mentionnent le besoin d'agir de concert avec les instances nationales, leurs opérateurs et leurs services déconcentrés, notamment Business France, Bpifrance, la DIRECCTE, ${ }^{58}$ les Douanes, etc.

Toutes les régions mentionnent également la nécessaire coopération avec les autorités infrarégionales, en particulier les métropoles, mais aussi les acteurs économiques, notamment les $\mathrm{CCl}$.

Enfin, quelques régions (5) ajoutent à cette coordination verticale une coordination horizontale interrégionale. La région Pays de la Loire souhaite par exemple organiser une consultation régulière sur la question du tourisme, avec les régions voisines de la Nouvelle-Aquitaine, la Bretagne, et la région Centre-Val de Loire) ; alors que la région lle-de-France souhaite elle structurer des pôles de compétitivité interrégionaux et développer l'axe Seine avec les régions limitrophes. La Nouvelle-Aquitaine estime que " l'attractivité (ou la compétitivité) d'un territoire ne peut plus être analysée de manière isolée. Elle est nourrie par les performances intrinsèques du territoire et les performances des territoires voisins qui disposent autour d'eux d'autres atouts comme la dynamique de leur tissu industriel et des services » (Région Nouvelle-Aquitaine, 2017).

\section{II n'existe pas un modèle " type " de la gouvernance pluri-niveaux pour l'internationalisation, notamment avec le niveau national. La Guadeloupe propose la création "d'une instance de}

\footnotetext{
53 Introduite dans le SRDE-II des Hauts-de-France, cette mission a été confiée par le ministre de l'Économie et le président du conseil régional Hauts-de-France le 31 mai 2016 à Philippe Vasseur, Commissaire Spécial à la Revitalisation et à la Réindustrialisation des Hauts-de-France (2016-2017), avec une équipe comprenant les services de l'Etat, les services du Conseil régional, les services de la Chambre de Commerce et d'Industrie Nord-de-France, les établissements publics bancaires, et l'Agence Nord France Invest (République française, 2017).

${ }^{54} \mathrm{Ce}$ comité se compose de la Région (Présidente, VP Economie, VP attractivité, VP Tourisme) et ses agences, l'Etat (Préfet) et son agence Business France, les collectivités locales représentant les 18 bassins d'emplois ( 2 métropoles, agglomérations, autres $\mathrm{EPCl}$ ), et de 10 à 15 dirigeants d'entreprises à capitaux étrangers.

${ }^{55}$ Par exemple, l'agence de développement économqiue risingSUD (qui a succédé à l'Agence régionale d'innovation et d'internationalisation en 2019) constitue le « bras armé » de la Région et associe notamment dans sa gouvernance la $\mathrm{CCl}$ de la région, mais aussi l'Etat, Bpifrance, le Groupe Caisse des dépôts (voir Encadré 2.5)

${ }^{56}$ En Corse, il est ainsi proposé d'instituer un référent internationalisation auprès de l'Agence de développement économique de la Corse. En Nouvelle-Aquitaine, l'Agence de développement et d'innovation de Nouvelle-Aquitaine se focalise sur 11 filières pour l'export et l'investissement.

${ }^{57}$ La région AURA propose de fusionner les deux anciennes agences ARDI de Rhône-Alpes et d'Auvergne, la nouvelle structure prenant en charge le développement économique, l'innovation, l'attractivité et marketing territorial, l'emploiformation et l'international. En revanche, le SRDE-II précise que le Comité régional du tourisme conservera sa prérogative concernant les politiques vis-à-vis des visiteurs.

${ }^{58}$ DIRECCTE : Directions régionales des entreprises, de la concurrence, de la consommation, du travail et de l'emploi. Elles constituent un service déconcentré commun au Ministère de l'Économie et des Finances et au Ministère du Travail, de l'Emploi, de la formation professionnelle et du dialogue social.
} 
gouvernance rassemblant la région, le département, les EPCl et l'État » appelée « G9 »; les Pays de la Loire envisagent « d'amplifier la collaboration avec Business France »; et la Nouvelle-Aquitaine propose « un observatoire régional des échanges internationaux et du développement » co-piloté par la Région et la Chambre de commerce et d'industrie de région. Ces éléments témoignent aussi des attentes des Régions en ce qui concerne la clarification de l'action publique pluri-niveaux en faveur de l'internationalisation. Les SRDEII ne mentionnaient donc pas dans quelle mesure, les réformes alors récentes, notamment en matière d'export et d'attractivité, répondaient aux attentes des Régions en matière de coopération avec les autres niveaux de gouvernement, et en particulier l'État (voir la section suivante (3.2.2)

Au-delà des acteurs nationaux, la gouvernance pluri-niveaux proposée par les Régions comprend aussi une dimension spécifiquement «internationale». Tout d'abord, les SRDEll s'inscrivent dans des dispositifs de coopération européens (notamment pour cette première génération les programmes Horizon 2020, COSME, LEADER). ${ }^{59} \mathrm{Si}$ la région - autorité de gestion des fonds européens depuis 2014- travaille en coordination avec les autorités nationales (ANCT en particulier), ces programmes élargissent le nombre de ses partenaires européens. Les régions proposent aussi de maintenir, de consolider ou d'étendre les dispositifs transfrontaliers et de coopération décentralisée existants (Guyane, Corse, Occitanie) (voir Encadré 2.3 concernant la coopération décentralisée). Pour d'autres Régions frontalières en revanche, l'innovation institutionnelle s'incarne dans divers dispositifs spécifiques tels que la création de zones d'activités transfrontalières (Grand Est, Bourgogne-Franche-Comté), la «bi-localisation » d'entreprises (AURA), des instances communes de dialogue et de relais politique au niveau européen (Grand-Est, AURA) ou de dispositifs de soutien à l'export ou au développement économique (Hauts-de-France, Grand Est).

\footnotetext{
59 La Bretagne estime par exemple que les programmes Horizon 2020 permettront de coupler l'innovation et l'exportation. La Corse se propose de renforcer l'appui en ingénierie à destination des entreprises et associations par le biais d'une task force d'accompagnement des projets européens chargée de faciliter et de coordonner les initiatives sur le territoire corse.
} 


\section{Encadré 2.3. L'engagement des régions dans les agendas internationaux}

Les SRDEII constituent pour nombre de régions le pilier économique de leur stratégie de développement régional. Leur volet international n'épuise cependant pas la variété des engagements mondiaux des régions.

En particulier, les régions contribuent aux agendas en matière de développement durable. Si la grande majorité des SRDEII ne fait pas référence aux Objectifs du Développement Durable (2015) et à l'Accord de Paris (2016), socles de l'action pour le développement durable que s'est fixée la communauté internationale (et qui sont mentionnés dans les SRADDET) , 14 des 17 régions s'intéressent dans leur grande majorité aux effets du développement économique sur la préservation des ressources ; ainsi qu'à la valorisation des actions menées pour faire émerger une économie « verte » et «bleue ». La Martinique, par exemple, s'interroge sur la manière de valoriser le « patrimoine environnemental, vivier incontestable d'activités à forte valeur ajoutée, tout en assurant la nécessaire protection des écosystèmes et de la biodiversité » et en «en faisant des vecteurs d'une meilleure lisibilité à l'international »; tandis que le Centre Val de Loire établit que chacune des actions proposées - y compris pour l'internationalisation - sera inspirée du développement durable.

Par ailleurs, les régions mettent en œuvre des programmes de coopération décentralisée dans de multiples secteurs et avec de nombreux collectivités territoriales partenaires. Depuis 2015, Régions et autres collectivités territoriales rendent compte de l'Aide publique au développement fournie en répondant aux enquêtes de la Commission nationale de la coopération décentralisée (CNDC). ${ }^{60} \mathrm{La}$ CNCD fournit des conseils pour l'établissement de rapports et des informations sur le cofinancement des projets. Depuis 2011, la Délégation pour l'action extérieure des collectivités territoriales (DAECT, Ministère de l'Europe et des Affaires étrangères) a mis en place un programme appelé PACT3 qui fournit une certification d'expertise technique aux collectivités territoriales françaises et les aide à établir des partenariats de coopération décentralisée pour l'échange d'expertise au niveau international.

Enfin, les régions contribuent aussi sur leur territoire à d'autres agendas internationaux, comme celui relatif au Pacte mondial pour les réfugiés (2018). Ainsi, si la gestion des migrations et l'aide aux réfugiés demeurent une prérogative nationale, certaines régions ont œuvré en faveur de l'insertion des demandeurs d'asile et bénéficiaires d'une protection internationale. La Région Occitanie soutient par exemple financièrement les communes, établissements publics et structures d'accueil conventionnées avec l'État pour offrir des conditions d'accueil décentes à ces populations et favoriser leur intégration, notamment dans le marché du travail. ${ }^{61}$

Source : OECD (2018), Reshaping Decentralised Development Co-operation: The Key Role of Cities and Regions for the 2030 Agenda, OECD Publishing, Paris, https://doi.org/10.1787/9789264302914-en; OECD (2019d), "Decentralised development co-operation: Unlocking the potential of cities and regions", OECD Development Policy Papers, No. 22, OECD Publishing, Paris, https://doi.org/10.1787/e9703003-en.

\footnotetext{
60 Présidée par le Premier Ministre, sa vice-présidence est assurée par un représentant des collectivités territoriales, et son Secrétariat par la délégation pour l'action extérieure des collectivités territoriales (DAECT) au sein du Ministère de l'Europe et des Affaires étrangères (MEAE).

61 Les projets soutenus par la Région Occitanie peuvent comprendre l'apprentissage de la langue française, l'accompagnement psychologique, l'interprétariat, l'accompagnement en zone rurale (aide à la domiciliation, à la mobilité), la formation et l'insertion - voir Région Occitanie (2020), “ Soutien à l'accueil et à l'intégration des demandeurs d'asile et des bénéficiaires d'une protection internationale », https://www.laregion.fr/Soutien-a-l-accueilet-a-l-integration-des-demandeurs-d-asile-et. Cette démarche a fait l'objet d'un travail d'évaluation de l'OCDE et a permis l'échange de bonnes pratiques avec d'autres régions européennes (la Catalogne, Espagne ; et le Latium, Italie)
} 


\section{Les autres partenaires de l'internationalisation des régions}

Cette section vise à clarifier l'allocation des compétences et les relations entre niveaux de gouvernement en matière d'internationalisation.

(i) Les autres autorités locales

Au niveau infranational, les compétences des Régions s'articulent avec celles d'autres collectivités territoriales. Les Régions détiennent la compétence pour le soutien aux entreprises (les aides à la création/reprise, développement y compris aides à l'export, directement versées aux entreprises ou via des organismes partenaires comme BpiFrance) tandis que les communes, les $\mathrm{EPCl}$, dont les métropoles, sont compétentes en matière de création, d'extension de zones d'activités, et de soutien à l'immobilier d'entreprise (la région pouvant intervenir en complément et de manière financière). Les métropoles disposent aussi de la compétence de développement économique (conférée par la loi MAPTAM - pour modernisation de l'action publique territoriale et d'affirmation des métropoles- du 27 janvier 2014). Les orientations relatives à l'internationalisation des SRDEll encadrent néanmoins l'action des métropoles (après concertation), même si ces dernières peuvent, à défaut d'accord avec la région, élaborer leur propre document d'orientations qui prendra en compte le schéma régional (articles L. 4251-15 et L. 4251-17 du Code général des collectivités territoriales).

L'organisation administrative décentralisée française connaît trois types de collectivités territoriales : les communes, les départements et les régions, auxquelles se surajoutent les établissements publics de coopération intercommunale et leurs variantes adaptées aux ensembles urbains les plus importants : les métropoles (largement consolidées par la loi MAPTAM). Le SRDEII de la Région lle-de-France resitue la répartition des compétences des autorités locales françaises en matière d'aide aux entreprises et l'immobilier qui sont, comme cela a été mentionné plus haut, des leviers de l'internationalisation des territoires. Au sein même de ces compétences les marges de manœuvre des acteurs infrarégionaux diffèrent selon les aides faisant état de la complexité de la mise en œuvre des responsabilités.

(ii) L'État

Les régions françaises ont d'importantes compétences en matière de développement économique, et dépensent relativement plus pour leur développement économique que la plupart des régions des autres États unitaires de l'OCDE (excepté la Norvège et la Pologne) comme cela a été mentionné précédemment. En revanche leurs budgets, dépenses et investissements ${ }^{62}$ restent faibles au regard des régions des autres pays unitaires de l'OCDE. Le Graphique 2.7 montre que les dépenses des Régions françaises en 2016 figurent parmi les plus faibles des pays de l'OCDE. ${ }^{63}$ La mise en œuvre de stratégies d'internationalisation, dans ce contexte, requiert l'intervention des autorités nationales. Celles-ci sont par ailleurs, via les services déconcentrés de l'État tels que DREAL et DRAC, en charge des autorisations environnementales pour l'installation d'entreprises étrangères. La coordination entre État et Régions est donc nécessaire à la fois pour des raisons financières mais aussi réglementaires.

\footnotetext{
62 En 2016, les investissements des régions françaises avoisinent $5 \%$ de l'investissement public réalisé, et moins de $0,2 \%$ du PIB, soit le taux le plus faible des régions des pays unitaires de l'OCDE

${ }^{63}$ Les régions françaises dépensent peu par rapport aux autres autorités infranationales (11,3\% du total des dépenses des collectivités territoriales en 2016), niveau parmi les plus faibles des États unitaires de l'OCDE - seules les régions de la Turquie, de la Nouvelle-Zélande, des Pays-Bas et de la Pologne dépensent en proportion moins - voir OECD (2020e).
} 
Graphique 2.7. Dépenses des régions en pourcentage du PIB et des dépenses publiques totales (2016)

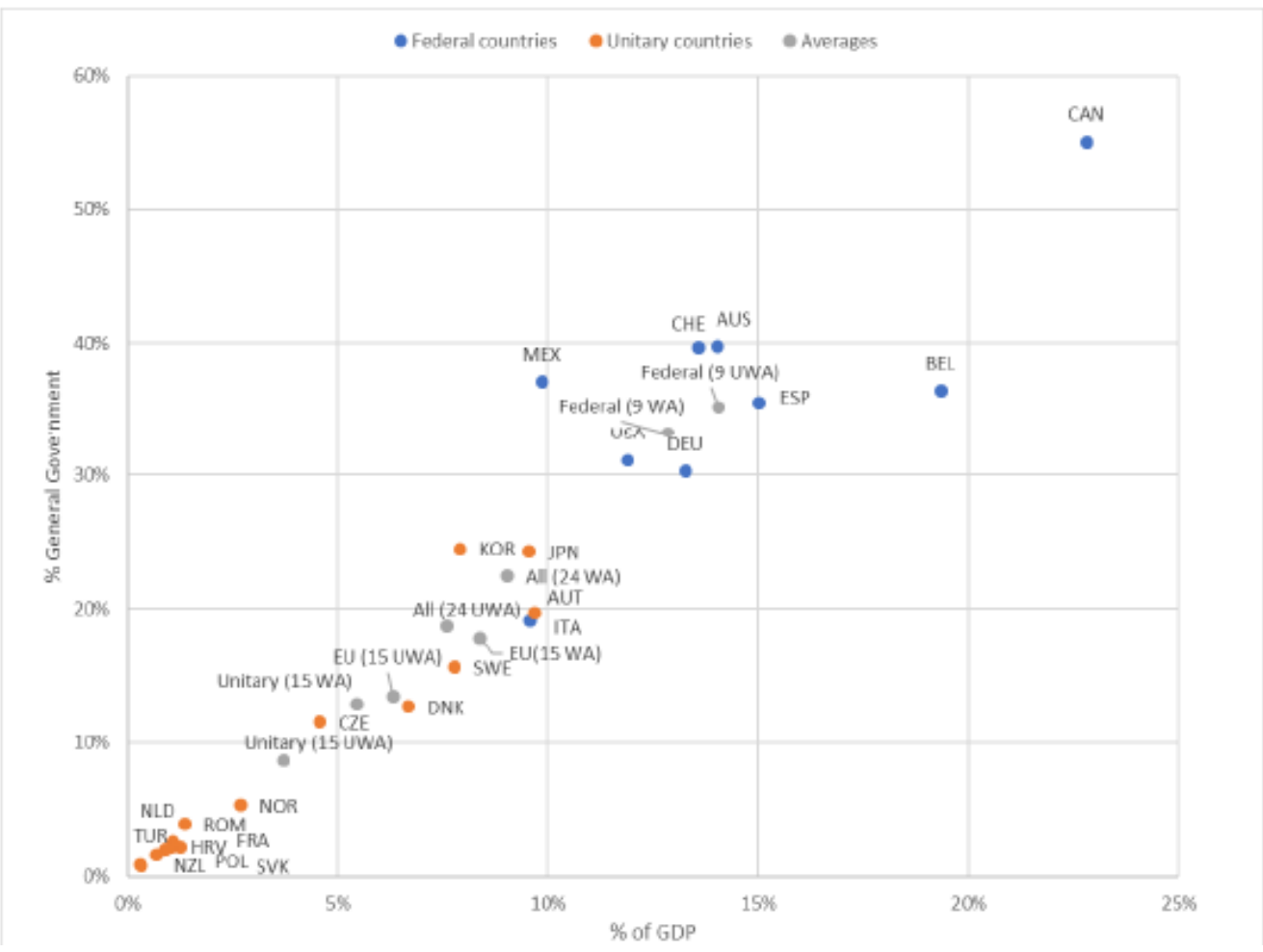

Source: OECD Regional Government Investment and Finance Database

L'État est un acteur majeur de l'internationalisation, que ce soit pour soutenir l'exportation des entreprises françaises ou identifier et favoriser l'accueil d'investisseurs, de talents ou de visiteurs étrangers. Au niveau national, plusieurs réformes d'envergure favorisent la collaboration avec les Régions en faveur de l'internationalisation. L'État a notamment exprimé dès avril 2019 sa volonté de "transformer les relations entre l'État et les collectivités territoriales". Ce mouvement se poursuit et s'ajuste au contexte de pandémie de mondiale avec la parution en décembre 2020 de l'avant-projet de réforme "4D" (Déconcentration, Décentralisation, Différenciation et Décomplexification) (Vie Publique, 2020). 


\section{Encadré 2.4. Le rôle de l'Agence nationale pour la cohésion des territoires dans l'internationalisation des Régions}

Le $1^{\text {er }}$ janvier 2020 a été instituée l'Agence nationale pour la cohésion des territoires, ${ }^{64}$ issue du Commissariat général à l'égalité des territoires, et placée sous la tutelle du Ministère de la Cohésion des territoires et des relations avec les collectivités territoriales. L'ANCT a pour mandat de conseiller et d'aider les autorités infranationales dans l'exercice de leurs compétences, dans le but de réduire les disparités territoriales, notamment par un meilleur accès aux installations digitales à large bande. L'ANCT est une agence nationale qui représente l'État sur l'ensemble du territoire et qui, grâce à ses services déconcentrés, est au service des différents acteurs - les collectivités territoriales et l'État - pour atteindre les objectifs convergents de la politique de développement régional - y compris en matière d'internationalisation. L'agence est notamment chargée de l'interaction et de la contractualisation avec les gouvernements infranationaux. Pour soutenir les politiques d'internationalisation et d'attractivité régionale, I'ANCT coordonne un réseau d'acteurs infranationaux, tels que les clusters et les pôles de compétitivité impliqués dans les politiques d'innovation ; et fonctionne comme un organe interministériel, en partenariat étroit avec un certain nombre d'acteurs à vocation internationale, tels que Business France et Atout France. L'ANCT est également l'autorité de coordination, en coopération avec les ministères et les autorités infranationales, pour les fonds structurels européens (en particulier le Fonds européen de développement régional) - que les Régions considèrent comme un des leviers majeurs d'internationalisation. ${ }^{65}$

Source : ANCT (2019; 2020); OCDE (2019), « France », dans OECD Regional Outlook 2019 : Leveraging Megatrends for Cities and Rural Areas, Éditions OCDE, Paris, https://doi.org/10.1787/9e936eee-fr

Pour ce qui concerne la politique de soutien à l'export, la stratégie du Gouvernement en matière de commerce extérieur a été présentée à Roubaix, le 23 février 2018 (République française, 2018), et vise à rationaliser et simplifier l'attractivité économique de la France à l'international. Ce discours a souligné en particulier la nécessaire coordination entre niveaux de gouvernement pour mieux accompagner les entreprises vers l'export et favoriser les investissements étrangers, les "deux faces d'un même combat ». Dans ce nouveau contexte, les régions constituent l'instance de définition et de pilotage des stratégies de développement à l'international, réaffirmant les orientations fixées dans les SRDEII.

\section{La coordination actuelle État-Région pour l'internationalisation des régions : exemples de politiques publiques}

Les prochaines sections exposent, sous forme de cartographies, l'organisation réglementaire des actions coordonnées entre État et Régions en faveur des exportations et de l'attractivité. Elles présentent ensuite brièvement et à titre d'exemples concernant d'autres dimensions de l'internationalisation, l'action pluriniveaux des autorités nationales et infranationales à travers les cas des politiques en faveur des infrastructures de connexion numériques et portuaires.

\footnotetext{
${ }^{64}$ L'ANCT fusionne en son sein le Commissariat général à l'égalité des territoires (CGET), l'Agence du Numérique devenue « Direction Générale Déléguée au Numérique » de l'ANCT - et Epareca. Le CGET comprenait déjà parmi ses prérogatives certaines liées à l'internationalisation, comme l'inclusion numérique ; aide aux mobilités ; l'attractivité économique ; transitions écologique et numérique ; redynamisation des territoires fragiles et des centres-villes en déprise.

65 L'ANCT assure ainsi la coordination générale entre plusieurs fonds structurels européens - le FEDER, ainsi que le Fonds social européen et le Fonds européen pour la mer et la pêche.
} 


\section{Stratégies de soutien à l'export des entreprises (y compris dispositif Team France Export)}

Au niveau national, les stratégies de soutien territorialisé aux exportations comprenant le dispositif Team France Export animé par Business France, sont pilotées par trois ministères, co-tutelles de cet opérateur d'État : le Ministère de l'Économie et des Finances, le Ministère de de la Cohésion des territoires et des Relations avec les collectivités territoriales et le Ministère de l'Europe et des Affaires étrangères. ${ }^{66}$ Ces ministères exercent diverses tutelles sur les opérateurs principaux de l'export - Business France, $\mathrm{CCl}$ France et Bpifrance, qui sont représentés à la fois aux échelles nationale et régionale. Concrètement, la vision portée par le Gouvernement dans le « discours de Roubaix » mentionné précédemment s'incarne notamment dans le dispositif Team France Export (TFE), qui a pour objectif d'augmenter le nombre d'entreprises françaises à l'export y compris les primo exportatrices ainsi que, par voie de conséquence, le volume des exportations. Animé par Business France et rassemblant CCI France (et CCI Internationale) et BPI France, cette Team France Export, sous le pilotage de la Région en tant que responsable de la stratégie d'internationalisation des entreprises, se déploie progressivement dans chaque région (souvent hébergée dans les locaux de la $\mathrm{CCl}$ régionale). Dans le cadre de conventions régionales -14 conclues à ce jour - (Normandie, Hauts- de- France, Sud, Pays de la Loire, Bourgogne-Franche-Comté, Centre-Val de Loire, Nouvelle-Aquitaine, Auvergne-Rhône-Alpes, Ile-de-France, Occitanie, Grand Est, Bretagne, Corse et régions d'Outre-mer) (CCl, 2019 ; Team France Export, 2020), TFE s'appuie sur la mise en commun des ressources humaines des $\mathrm{CCIR},{ }^{67}$ des représentants régionaux de Business France ${ }^{68}$ et de Bpifrance ${ }^{69}$.

Ce guichet unique permet d'orienter les entreprises exportatrices vers les services adaptés (juridique, assurances, traductions, recrutements, etc.), fournis par trente partenaires et réseaux tant publics (Direction régionale des Douanes et droits directs) que privés (banques commerciales) afin de soutenir leur action à l'export (Team France Export, 2020). Ainsi, chaque entreprise implantée dans un territoire cible et qui souhaite se développer à l'export devrait pouvoir disposer dans sa région d'un coach international spécialisé qui sera son conseil et son référent dans le dispositif public de l'export.

En parallèle, un outil commun de gestion client (CRM) est mis en place pour soutenir les 250 « conseillers TFE » (Banque des territoires, 2019) ${ }^{70}$, ainsi qu'un portail appelé «plateforme des solutions » permettant d'informer sur les aides et services offerts (par les structures publiques et privées) et d'orienter les entreprises vers les interlocuteurs pertinents pour les accompagner vers l'export. ${ }^{71}$

\footnotetext{
66 Il est à noter en particulier au niveau interministériel qu'en matière de commerce extérieur, le Ministre de l'Europe et des affaires étrangères supervise la direction générale du Trésor (DGT) et a également autorité, conjointement avec le ministre de l'Économie, sur les services économiques à l'étranger (Ministère de l'Europe et des affaires étrangères, 2020).

${ }^{67}$ Le Contrat d'objectifs et de performance signé par le réseau de CCI France avec son ministère de tutelle, le Ministère de l'économie et des finances, inscrit dans son axe 3 (Accompagnement des entreprises à l'international) le rapprochement avec Business France dans le cadre de Team France Export et met à disposition 159 conseillers des CCIR auprès de TFE - Ministère de l'Économie des Finances et CCI France (2019), Contrat d'objectifs et de performance, 15 avril 2019.

68 TFE est animé par Business France, et créé dans le cadre de la réforme de l'opérateur, traduite dans le Contrat d'objectifs et de moyens 2018-2022 (COM). Le dispositif TFE repose sur une plus grande territorialisation de l'action de Business France, selon un déploiement progressif en Région

${ }^{69}$ L'association de Bpifrance et des régions à TFE permet de valoriser les dispositifs gérés par Bpifrance, et cofinancés par les régions, notamment les assurances prospection et les assurances crédits.

70170 sont issus des CCIR et 80 de Business France.

${ }^{71}$ Cette plateforme propose notamment de fournir des outils digitaux et des solutions innovantes et adaptées aux entreprises, en fonction de leurs profils, pour les aider à démarrer, structurer et accélérer leur développement à l'international ; de constituer de manière organisée un véritable centre de ressources et de conseils et proposer des réponses et une chaîne de valeur animée par la Team France Export et ses partenaires, qui répondent précisément aux besoins des entreprises ; et de proposer à chacun un parcours en toute autonomie, mais également offrir une mise en relation avec ceux, qui en proximité territoriale sont en mesure de conseiller et accompagner l'entreprise (Team France Export, 2020) - https://www.teamfrance-export.fr/
} 
À l'étranger, le dispositif Team France Export est présent dans 65 pays et se déploie via un correspondant unique pour les entreprises exportatrices à l'étranger qui peut être soit un représentant de Business France (bureau Export) soit le référent TFE d'une entreprise privée. ${ }^{72} \mathrm{Si}$ le dispositif déployé à l'étranger dépend essentiellement du niveau national, les Agences régionales de développement agissent en lien avec le correspondant unique TFE afin de promouvoir «leurs " entreprises à l'étranger (par exemple dans la participation à des salons internationaux, ou pour l'organisation de visites prospectives, etc.) (voir Graphique 2.8). Ce schéma donne à voir la complexité de l'organisation des dispositifs de soutien à l'exploration avec un rôle pivot joué par Business France. Cette complexité est liée au grand nombre d'institutions impliquées dans cette politique très "transverse" et ne constitue pas n'est pas un problème en soi. Elle requiert cependant un système de coordination très efficace, fondé sur : le partage d'informations, des d'objectifs communs, l'approche multi sectorielle/interministérielle, la disposition de capacité aux différents niveaux, des financements adaptés, la bonne échelle administrative pour la mise en place de l'action et un suivi d'évaluation en transparence (Charbit, 2011).

Des informations à ce sujet pourront être obtenues dans le cadre des études de cas régionales réalisées à la suite de ce premier rapport.

\footnotetext{
72 Ce référent agit alors dans le cadre d'une délégation de service public, d'une concession de service public ou d'une convention de référencement. En 2019, des concessions ont été attribuées en Norvège, à Singapour, en Belgique, en Hongrie, aux Philippines et au Maroc (Banque des territoires, 2019)
} 
Graphique 2.8. Cartographie institutionnelle des politiques territorialisées de soutien à l'export (incluant Team France Export)

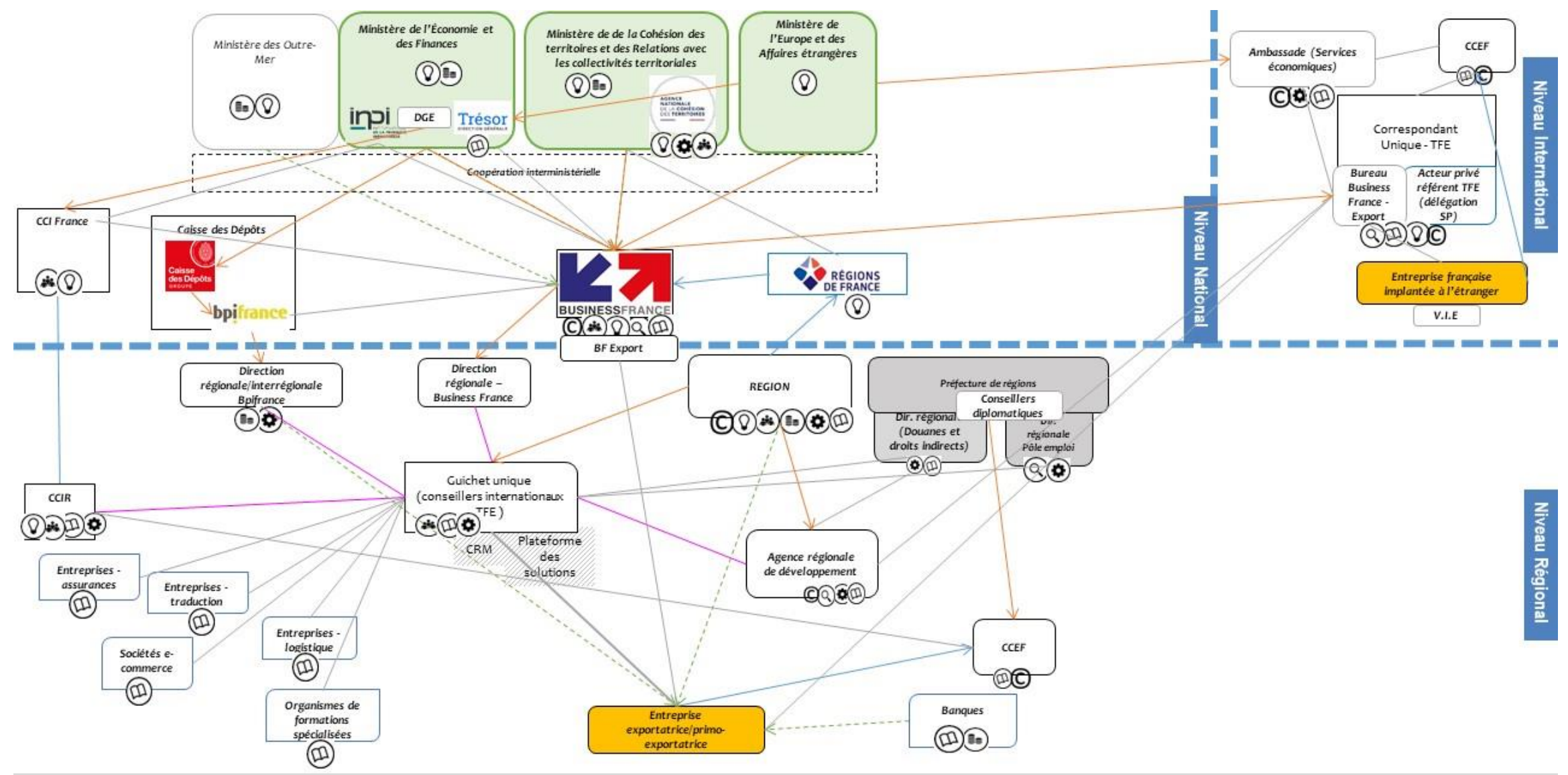

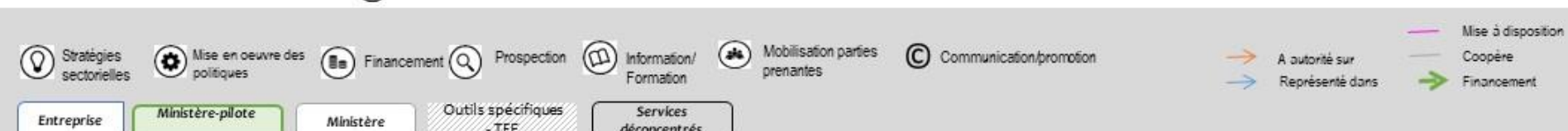

Source : Documents réglementaires et stratégiques partagés par l'ANCT et le Ministère de l'Europe et des affaires étrangères ; ainsi que les ressources en ligne proposées par le Ministère de l'Économie et des finances ; Régions de France ; Business France ; les Conseillers du commerce extérieur de la France ; CCl France ; Groupe Caisse des dépôts.

\section{LES RÉGIONS DANS LA MONDIALISATION @ OCDE 2021}




\section{Encadré 2.5. Team France Export dans le contexte de crise liée à la pandémie liée au COVID-19}

Depuis le début du confinement dû au COVID-19, les Conseillers de l'International Team France Export basés dans les $\mathrm{CCl}$, ont fait paraitre le Baromètre de l'activité internationale des entreprises françaises, reprenant les considérations de plus de 2600 entreprises. Cette enquête a notamment permis de souligner que $55 \%$ des entreprises exportatrices ont maintenu leur activité internationale durant la période du confinement (chiffres valables jusqu'au 10 avril), tout en identifiant les principaux freins aux exportations durant la pandémie (manque de visibilité sur l'avenir, limitations logistiques - à la fois pour l'export et l'approvisionnement, baisse des commandes provenant de l'étranger, etc.).

Par ailleurs, TFE a mis à disposition un programme de plus de 170 webinaires (par secteur et par zone géographique) ainsi qu'une carte interactive recensant les mesures prises dans les pays d'exportation (climat des affaires, niveau de confinement, évolution des réglementations, etc.), afin d'aider les entreprises à adapter leur stratégie internationale durant la pandémie.

Enfin, le plan national de relance de l'économie annoncé le 3 septembre par le Gouvernement français inclut un "volet export", d'un montant total de 247 millions d'euros, qui mobilisera l'ensemble la Team France Export, et soutiendra entre autres les mesures suivantes :

- Renforcement des moyens de l'assurance-prospection, outil très sollicité par les PME et ETI qui se lancent à l'export.

- Soutien financier aux PME-ETI pour l'achat des prestations de projections à l'export (comme la participation aux salons internationaux, etc.)

- Soutien financier de l'Etat l'envoi en mission d'un Volontaire Internationale en Entreprise (VIE) par une PME-ETI

- Mise en place d'une veille-information sur les marchés, personnalisée et gratuite pour les exportateurs, proposée sur les interfaces de Business France.

Source : Business France (2020); Team France Export - Hauts-de-France (2020)

\section{Stratégie d'attractivité des territoires à l'international (y compris dispositif Team France Invest)}

La loi NOTRe fait de l'attractivité une compétence partagée des Régions et des EPCl (métropoles principalement) (voir section 2.2.2). Néanmoins, comme l'a indiqué le Premier Ministre dans le discours de Roubaix, l'État joue un rôle primordial, en particulier pour attirer les investissements étrangers.

Au niveau national, les trois ministères-pilotes - le Ministère de l'Économie et des Finances, le Ministère de de la Cohésion des territoires et des Relations avec les collectivités territoriales et le Ministère de l'Europe et des Affaires étrangères (qui comprend depuis le 31 juillet 2020 un Ministère délégué au Commerce extérieur et à l'attractivité ${ }^{73}$ )- partagent la responsabilité en matière d'attractivité ${ }^{74}$ dans le cadre de l'exercice de leur tutelle respective sur les opérateurs d'État (Business France, Atout France, ${ }^{75}$

\footnotetext{
73 Décret $n^{\circ} 2020-964$ du 31 juillet 2020 relatif aux attributions du ministre délégué auprès du ministre de l'Europe et des affaires étrangères, chargé du commerce extérieur et de l'attractivité

${ }^{74}$ En matière de tourisme, le Ministère de l'Europe et des affaires étrangères dispose de la direction générale des entreprises (DGE).

${ }^{75}$ Afin de rationaliser l'action pour l'attractivité économique de la France, l'État envisage le rapprochement entre Atout France et Business France dans leur représentation à l'étranger (des projets-pilotes sont à l'étude en Espagne et aux Émirats arabes unis).
} 
Bpifrance en particulier). Le niveau national se caractérise également par l'importance du travail interministériel effectué dans le cadre d'un comité de pilotage réunissant tous les deux mois les " référents attractivité ${ }^{76}$ sous l'autorité des services du Premier ministre ${ }^{77}$. Si l'ANCT est citée en tant que membre de ce comité, les Régions n'y sont pas représentées.

La coopération État-Région pour l'attractivité est régie principalement par deux types de conventions :

- La Charte nationale des Investissements Directs Étrangers, ${ }^{78}$ appelée à être déclinée dans chaque région, prévoit que la mise en œuvre des stratégies pour les IDE relève d'abord des Régions, "chefs de file », avec le concours des préfets de région, de Business France et des autres opérateurs et services de l'État. ${ }^{79}$

- Les conventions «Invest » signées entre Business France et les ARD qui précisent de manière détaillée le mode opératoire de suivi des projets étrangers (aux échelles nationale et régionale) dans le cadre du dispositif «Team France Invest » (TFI), également animé par Business France, comme pour la TFE. La création d'une Team France Invest, sur le modèle de la Team France Export, a été annoncée au printemps 2018 pour rendre plus efficace la politique de détection et d'attraction des investisseurs étrangers potentiels en France..$^{80}$

\footnotetext{
${ }^{76}$ La désignation de ces référents fait suite à la décision interministérielle du 29 mars 2018 pour désignation d'un référent attractivité dans les cabinets ministériels et les administrations centrales.

${ }_{77}^{78}$ Le secrétariat de ce Comité de pilotage est assuré par la DG Trésor (Ministère de l'économie et des finances)

78 Cette Charte a fait l'objet d'une circulaire du Premier Ministre relative au Renforcement du dispositif d'accompagnement des investissements des entreprises étrangères et d'accueil des talents étrangers en France. Mise en œuvre de la charte des Investissements directs étrangers (14 décembre 2018)

${ }^{79}$ Deux déclinaisons régionales de de la circulaire relative à la Charte nationale des IDE régionales ont été signées à ce jour (déclinaisons régionales) avec les Régions Centre-Val de Loire et Pays de la Loire avec la volonté d'ici la fin 2020 d'étendre ces dispositifs à toutes les régions.

${ }^{80}$ La convention relative à la création du dispositif Team France Invest a été signée le 17 juillet 2018 entre la direction générale du Trésor et Business France, aux côtés du Ministère de l'Europe des affaires étrangères et du Commissariat général à l'égalité des territoires.
} 


\section{Encadré 2.6. L'organisation de l'attractivité dans les pays de l'OCDE et sa dimension territoriale}

La mobilisation d'agences nationales travaillant en coordination avec les responsables territoriaux pour orienter les « prospects " étrangers en évitant une concurrence régionale trop intense est un moyen largement utilisé par les pays de l'OCDE pour éviter les « jeux à somme nulle " où le succès de certaines de leurs régions se ferait au prix d'un renoncement réglementaire ou d'un déséquilibre territorial.

L'articulation des différents acteurs de tourisme ou la coordination entre des agences nationales de promotion et les stratégies régionales pour attirer les investisseurs sont encore souvent embryonnaires. Dans le meilleur des cas c'est une des dimensions de l'attractivité qui est éclairée mais on ne dispose pas de vision d'ensemble qui permettrait d'identifier les " nœuds » institutionnels clés pour bénéficier des synergies entre les politiques orientées vers des cibles différentes. La cartographie des agences de promotion et d'attraction de l'investissement dans les pays de l'OCDE souligne par exemple qu'une répartition claire des rôles et responsabilités entre niveaux de gouvernement est nécessaire pour une mise en œuvre efficace des politiques mais invite à des recherches plus approfondies pour comparer les approches nationales.

L'enquête menée en 2018 par l'OCDE et la Banque interaméricaine de développement identifie cependant la forte coopération entre Business France et les agences régionales de promotion de l'investissement, notamment grâce un solide dispositif d'échange d'informations, comme une bonne pratique de la France.

Source : OECD (2018), Mapping of Investment Promotion Agencies in OECD countries, http://www.oecd.org/investment/investmentpolicy/mapping-of-investment-promotion-agencies-in-OECD-countries.pdf

Au niveau régional, les préfectures de région et les ARD sont les principaux acteurs de l'attractivité. Sous l'autorité des Régions, qui définissent les orientations relatives aux secteurs et territoires prioritaires pour les investissements directs étrangers dans le cadre des SRDEII, les ARD sont les interlocuteurs opérationnels privilégiés des acteurs nationaux au sein d'instances de suivi des projets d'investissements étrangers, le Comité d'Orientation et de Suivi des Projets Étrangers (COSPE) (voir Encadré 2.7). 


\section{Encadré 2.7. Le COSPE, instance centrale du dispositif Team France Invest}

Le Comité d'Orientation et de Suivi des Projets Étrangers (COSPE) se matérialise par des réunions hebdomadaires animées par le bureau national Invest de Business France (BF) et les ARD - autour des demandes d'implantation émanant des bureaux étrangers de BF et diffusées via une plateforme commune à BF et aux ARD - « Sinpa ».81

Le COSPE a ainsi pour objet d'orienter les projets en fonction des cahiers des charges des investisseurs étrangers - surface de foncier, proximité d'infrastructures, main d'œuvre, etc - vers les régions identifiées par ces investisseurs, quand cela est le cas.

Lors du COSPE, les projets sont examinés et les régions se positionnent pour décider d'établir une offre régionale capable de répondre au cahier des charges. Deux types de projets sont examinés : les projets ne précisant pas de régions a priori et les projets ciblant une ou plusieurs régions.

Les ARD sont appelées à se positionner en fonction des priorités régionales (SRDEII). Ainsi certaines ARD peuvent décider de ne pas répondre à la demande d'investisseurs dont les projets ne correspondent pas aux orientations de leur SRDEII.

Lorsque plusieurs régions sont ciblées par l'investisseur, Business France coordonne "l'offre » en préparant avec l'aide des ARD concernées une offre intégrée résumant les atouts de chacune des régions, Business France se chargeant de la partie réglementaire (valorisation des dispositifs nationaux...). Cette offre est alors relayée au bureau Business France Invest à l'étranger pour négociation avec l'investisseur potentiel. Les ARD sont par la suite amenées à organiser localement une visite des sites potentiels.

Source : Documents partagés par l'ANCT

En plus du COSPE national, la Charte nationale des IDE prévoit :

i. Un COSPE régional, associant en plus de l'ARD -qui assure la dimension opérationnelle des politiques d'attractivité, à travers les missions de prospection, d'accueil et d'accompagnement des ID- et de la Région, les services déconcentrés de l'Etat (principalement la Direccte, DREAL, sous la coordination du Préfet de région) ainsi que le Référent unique aux investissements et le Commissaire au redressement productif, tous deux rattachés au Secrétariat général pour les affaires régionales (SGAR), et la direction régionale de Bpifrance ;

ii. Un Conseil de l'attractivité régionale, qui réunit la Région, les services déconcentrés de l'État, et les entreprises étrangères déjà implantées sur le territoire (voir Graphique 2.9).

81 Outil collaboratif du COSPE (dans un logiciel appelé SINPA/CRM), il est partagé entre Business France, les ARD et les bureaux à l'étranger dépendant de Business France). 
Graphique 2.9. Cartographie institutionnelle des politiques d'attractivité régionale (y compris Team France Invest)

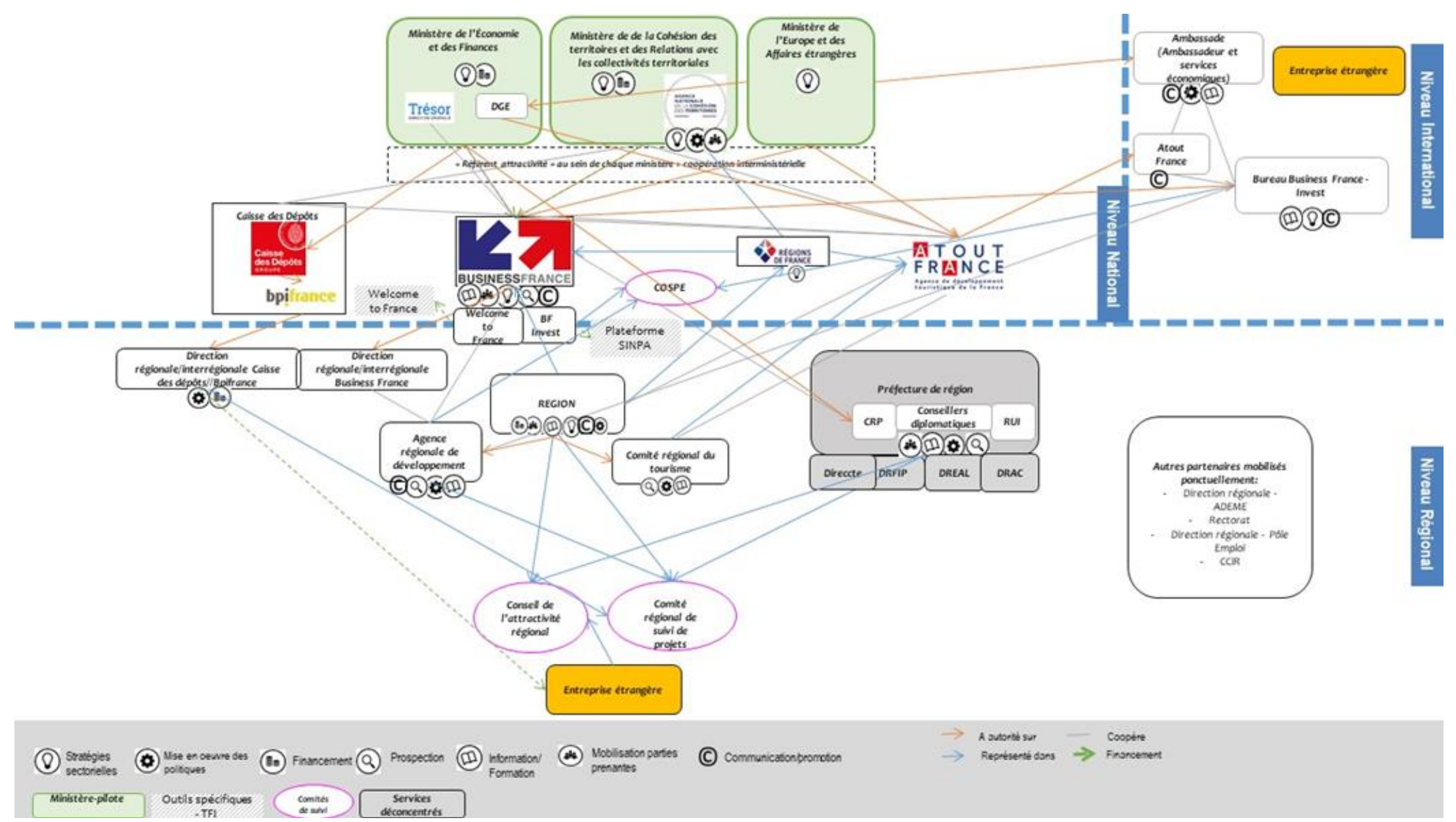

Source : Documents réglementaires et stratégiques partagés par l'ANCT et le Ministère de l'Europe et des affaires étrangères ; ainsi que les ressources en ligne proposées par le Ministère de l'Économie et des finances ; Régions de France ; Business France ; Atout France; $\mathrm{CCl}$ France ; Groupe Caisse des dépôts. 


\section{Encadré 2.8. La politique d'attractivité des régions et leur coordination avec l'État face à la crise}

L'attractivité de la France est croissante, comme en atteste l'édition 2020 du Baromètre de l'attractivité de EY, qui place la France en tête des pays européens les plus attractifs. Cependant, les bouleversements liés à la crise de la pandémie de COVID-19, notamment le durcissement des contrôles sur les investissements directs étrangers pour la protection d'actifs stratégiques, risquent de compromettre cette performance pour 2020.

En réponse, des pistes d'orientations proposées par Business France en mai 2020, ont été communiquées aux préfectures de Régions, appelées à être discutées avec les ARD et adaptées le cas échéant selon les orientations régionales :

- Sauvegarder les emplois et le tissu local fragilisé par la crise, notamment par la recherche de repreneurs étrangers pour les entreprises françaises en difficulté ou en cours de redressement judiciaire ;

- Mieux capitaliser sur les atouts actuels des territoires, en renforçant les actions de conseil en marketing territorial et en améliorant le suivi des investisseurs étrangers dans les territoires, y compris par des actions pour la simple rétention des investisseurs étrangers dans un contexte de relocalisation des chaînes de valeur)

- Ouvrir de nouvelles opportunités aux territoires : faire naitre et diffuser des offres territoriales adaptées aux besoins des investisseurs et partager des opportunités internationales nées de la relocalisation des chaînes de valeur des entreprises étrangères ou issus des dispositifs européens.

En complément, le processus de signature des déclinaisons régionales de la Charte nationale pour les investissements directs étrangers devrait se poursuivre, alors qu'à ce jour deux ont été signées (Centre-Val de Loire, Pays de la Loire).

Par ailleurs, les Régions se sont mobilisées pour demeurer attractives dans un contexte de ralentissement voire d'arrêt - brutal des échanges internationaux, particulièrement dans le secteur du tourisme. Ces mesures concernent aussi bien l'attractivité dans le cadre de la relocalisation d'entreprises souhaitant rapatrier une partie de leur chaîne d'approvisionnement; que la volonté de maintenir les entreprises étrangères déjà implantées sur le territoire.

Ainsi, le plan France Relance annoncé par le Gouvernement le 3 septembre 2020 a été conçu comme « un accélérateur de souveraineté » et prévoit plus d'un milliard d'euros d'ici 2022 pour la relocalisation et le maintien d'activités économiques par l'investissement dans les domaines « stratégiques » de la santé, les intrants industriels, l'électronique, l'agroalimentaire ou les télécommunications (600 millions d'euros), ainsi que par le soutien à la relocalisation d'activités industrielles dans les 148 «Territoires d'industrie » (450 millions d'euros). Alors que la relance sera " territorialisée ", l'État et les autorités régionales travaillent déjà de concert pour favoriser la relocalisation d'activités économiques, comme à travers le Programme Territoires d'industrie ${ }^{82}$ qui s'est engagé dans l'identification d'opportunités régionales pour la relocalisation ou le soutien à la relocalisation de certaines filières (comme la filature de lin en Alsace) (Banque des territoires et ANCT, 2020).

Les régions sont aussi parties prenantes à ce mouvement: la région Grand Est a proposé un Pacte de relocalisation pour encourager, aider et accompagner les entreprises qui souhaitent rapatrier une partie de leur chaîne d'approvisionnement en région, en France ou en Europe plutôt qu'en Asie. La région Sud souhaite consacrer 17 millions d'euros à la relocalisation dans le cadre de son plan régional de relance économique (4 milliards d'euros). La région Centre-Val de Loire et son agence économique Dev'Up agissent pour relocaliser des activités dans les secteurs de productions pharmaceutiques, cosmétiques, agroalimentaires, de la logistique et du numérique ; tandis que la région Occitanie bâtit un plan de relocalisation de l'industrie en priorité dans les secteurs de la santé, l'alimentation, l'environnement et l'énergie.

Source : Documents partagés par l'ANCT ; Commission européenne (2020) ; Saudemont (2020) 
La pandémie de COVID-19 a mis en exergue à la fois la fragilité de certains secteurs pourtant moteurs des économies régionales (notamment le tourisme), tout en soulignant l'importance de la réponse coordonnée à la crise, afin que les Régions françaises mettent à profit les nouvelles opportunités au lendemain de la pandémie. La prochaine section présente, à cet effet, un aperçu des vecteurs importants d'internationalisation des Régions : les infrastructures logistiques et numériques.

\section{Autres stratégies nationales pour l'internationalisation des territoires}

\section{Infrastructures logistiques}

La pandémie de COVID-19 a souligné l'importance des chaînes logistiques pour résister aux conséquences économiques de la crise sanitaire. En effet, l'intégration des Régions dans la mondialisation passe nécessairement par leur intégration dans des chaînes de valeur mondiales, et donc dans des chaînes logistiques. Ces dernières sont à la fois les plus exposées aux chocs (crise sanitaire, mais aussi mouvements sociaux, événements climatiques, etc.) et l'un des secteurs les plus résilients. La crise du COVID-19, qui a bloqué les mouvements de personnes mais n'a pas empêché une large circulation des marchandises, l'a illustré à nouveau, puisque les chaînes logistiques ont relativement bien affronté la crise et partant, ont permis de soutenir l'activité dans de nombreux secteurs-clé pour les économies régionales (Ministère de l'agriculture et de l'alimentation, 2020).

La crise liée à la pandémie de COVID-19 a aussi mis en lumière des disparités territoriales existantes et la dépendance de certains territoires vis-à-vis d'autres pour leur approvisionnement : $60 \%$ des flux de marchandises transitent sur 3 axes du territoire national et la majorité des entrepôts et plateformes logistiques d'envergure sont concentrées dans les zones urbaines de la moitié Nord de la France (Paris et Lille notamment) et en Auvergne-Rhône-Alpes (Lyon) (Ministère de l'Environnement, de l'énergie, et de la mer en charge des relations internationales sur le climat, 2017). Cet état de fait a pris une dimension nouvelle dans le cadre de la pandémie, la sécurité alimentaire étant devenue une préoccupation majeure des responsables locaux et régionaux (Régions de France, 2020).

La crise de la pandémie de COVID-19 a ainsi renforcé la nécessité d'améliorer la coopération horizontale (interrégionale) et verticale (État, Régions et autres collectivités) pour organiser des flux qui ne se limitent pas aux frontières administratives. En effet, même si certaines Régions sont particulièrement actives pour soutenir l'internationalisation des territoires par les infrastructures logistiques (section 3.1.2 sur l'analyse des Connexions d'infrastructures des SRDEII), la compétence des régions sur les transports ne concerne pas les marchandises, et celle du développement économique n'inclut pas la logistique. Par ailleurs, améliorer l'internationalisation des territoires passe aussi par une meilleure prise en compte de la géographie partagée des infrastructures logistiques.

Les infrastructures portuaires en particulier, offrent un potentiel encore relativement inexploité pour renforcer la place des régions françaises dans le commerce international. Les grands ports maritimes (GPM) - Dunkerque, de l'axe Seine (Le Havre, Rouen, Paris) et Marseille créent une richesse et des

\footnotetext{
82 Le programme Territoires d'industrie, lancé par le Premier ministre à l'occasion du Conseil national de l'industrie le 22 novembre 2018, est une stratégie nationale de reconquête industrielle par les territoires. Le programme cible 148 Territoires d'industrie dans les territoires hexagonaux et ultramarins, composés de plus de 500 intercommunalités à forte identité industrielle, regroupées dans une logique partenariale de projets communs au service du développement local de l'industrie. Ces territoires bénéficient d'un panier de services mis à disposition par l'État et ses opérateurs (Banque des Territoires, Bpifrance, Business France, Pôle emploi, Ademe, Action Logement), afin de concentrer les moyens autour de quatre enjeux majeurs : attirer : favoriser l'attractivité des territoires et des métiers de l'industrie ; recruter : faciliter la formation, le recrutement et la mobilité des salariés afin de répondre aux besoins en main d'œuvre des entreprises ; innover : accompagner les entreprises et les territoires dans les transitions numérique et écologique ; simplifier : accélérer les procédures administratives et faciliter les implantations industrielles, à l'image des « sites clés en main ».
} 
emplois qui dépassent largement les périmètres portuaires. S'ils ont été réformés en 2008 afin de recentrer leurs activités sur l'aménagement et la mise en valeur économique et environnementale de leur domaine ; leur gouvernance est remise en question (Colrat et al., 2018). La plupart des acteurs de l'axe Méditerranée-Rhône-Saône adhèrent à l'idée d'une gouvernance renforcée des infrastructures logistiques, cependant « une telle démarche n'est pas forcément simple car la dispersion des acteurs y est forte et les pratiques de rapprochement encore peu fréquentes » (Baudouin, 2018) (voir Encadré 2.9).

\section{Encadré 2.9. Renforcer la gouvernance pluri-niveaux : le cas des infrastructures portuaires sur l'axe Méditerranée-Rhône-Saône}

Le rapport de la Délégation interministérielle au développement de l'axe portuaire et logistique Méditerranée-Rhône-Saône vise à rendre les ports attractifs et à développer les chaînes logistiques afférentes dans le cadre de la concurrence mondiale accrue

En France, la multiplicité des acteurs du secteur, ainsi que la segmentation territoriale, font obstacle à l'émergence d'une stratégie portuaire attractive à l'international, permettant à la fois le renforcement des grands ports à vocation mondiale (Marseille, Dunkerque et HAROPA - Ports de Paris Seine Normandie), celui des ports décentralisés (maritimes et fluviaux) et l'hinterland. Pour créer un système portuaire à l'échelle du périmètre Méditerranée-Rhône-Saône, il est ainsi proposé de :

- consolider le Grand Port Maritime de Marseille dans sa position de leader méditerranéen ;

- constituer un front maritime méditerranéen fondé sur les atouts de chacun des ports et les complémentarités qui en découlent ;

- améliorer le fonctionnement logistique de l'axe et ses connexions avec les flux internationaux ;

- construire un hinterland productif et maillé à l'échelle de l'ambition portuaire de l'ensemble portuaire méditerranéen ainsi créé.

Cette démarche vise enfin à renforcer l'usage des ports pour le commerce extérieur des quatre régions concernées, (Sud, AURA, Occitanie et Bourgogne-Franche-Comté), puisque celles-ci, commercent surtout avec l'Allemagne (AURA et Bourgogne-Franche-Comté) et hors de l'UE (Occitanie), plutôt qu'avec la zone méditerranéenne, où les ports espagnols et italiens dominent. ${ }^{83}$

Dans ce cadre, un rôle est envisagé pour les régions, dans le cadre d'un schéma logistique métropolitain élaboré en concertation avec les services déconcentrés de l'État ; la participation dans un « Conseil des territoires " aux côtés de l'État et des autres collectivités concernées, ou à l'évolution du périmètre du Contrat de Plan Interrégional État-Région Rhône, qui intègre 4 régions de l'axe.

Source : Baudouin, Jean-Christophe (2018), Propositions pour le renforcement de l'intégration de la gouvernance sur l'axe MéditerranéeRhône-Saône - Rapport à Monsieur le Premier ministre, Délégation interministérielle au développement de l'axe portuaire et logistique Méditerranée-Rhône-Saône (26 juin 2018)

\section{Infrastructures numériques}

La France est caractérisée par un territoire vaste et diversifié, ainsi qu'un espace rural important occupant $54 \%$ de son territoire (OECD 2018b), et une grande dispersion de l'habitat en dehors des grandes villes. $\mathrm{Si}$ ces dernières disposent de réseaux d'accès haut débit efficaces et concurrentiels la question de la couverture des territoires moins denses (voire des banlieues) interpellent directement les autorités publiques (Régions de France, 2019) et les opérateurs privés. ${ }^{84}$ La loi pour la confiance dans l'économie

\footnotetext{
${ }^{83}$ La Région Sud entretient des échanges commerciaux dans la zone méditerranéenne, notamment avec l'Italie.

84 La filière Infrastructures du numérique représente en France 130 entreprises, 150000 emplois directs et indirects et 10 milliards d'euros investis dans les réseaux (2017) (Conseil national de l'industrie, 2020)
} 
numérique (2004) a confié aux régions et autres collectivités territoriales la compétence d'établir et d'exploiter des réseaux de communication électronique; le Plan France Très Haut Débit les a ensuite désignées comme « moteur » dans le déploiement du très haut débit fixe (Arcep, 2020) ${ }^{85}$, notamment pour lutter contre la fracture numérique (Régions de France, 2020b). Les Régions coopèrent avec les autorités nationales via les programmes gouvernementaux d'amélioration de la couverture mobile, comme ceux portés par l'ANCT (projets de territoire « France Très Haut Débit » et "Société Numérique ») (ANCT, 2020) ; ainsi que via des instances de coordination comme «la Commission régionale de stratégie numérique $^{86} \gg$ (CGET, 2017).

En ce qui concerne les réseaux fixes, et ainsi que le rappellent les SRDEII, l'objectif de desserte de 100 $\%$ de la population en débits supérieurs ${ }^{87}$ a été fixé pour 2022 dans le cadre du plan France Très Haut Débit (Arcep, 2020). Les opérateurs capables de déployer la fibre ont été invités à déclarer leurs intentions individuelles de déploiement de réseaux optiques jusqu'à l'habitant, ainsi que leurs intentions de coinvestissement. ${ }^{88}$ Les Régions, ainsi que les autres collectivités territoriales, sont maîtres d'ouvrage de réseaux d'envergure au moins départementale sur les zones moins denses, soit $80 \%$ du territoire national, et procèdent à des mises en concurrence aboutissant le plus souvent à des délégations de services publics, le cas échéant concessives. Selon Régions de France, trois à quatre millions de foyers et entreprises restent à connecter à la fibre d'ici 2025, année-butoir pour le développement de cette technologie sur l'ensemble du territoire (Régions de France, 2019).

Dans le domaine des réseaux mobiles et après une action d'envergure menée par l'État en 200,89 le programme "New Deal Mobile » a été initié en 2018 pour assurer la couverture numérique mobile des territoires ruraux, en s'appuyant sur les opérateurs privés, ${ }^{90}$ ce qui devrait permettre d'offrir un service $4 G$ à $99,6 \%$ de la population.

L'aménagement numérique est décisif pour l'attractivité, la compétitivité et l'égalité des territoires. Comme le souligne un récent avis du Conseil économique, social et environnemental, " jamais les réseaux n'ont été autant porteurs de services absolument nécessaires : ne plus y avoir accès, ou à des prix jugés discriminatoires, provoque une relégation » (Arav, 2020). La crise liée à la pandémie de COVID-19 a révélé l'énorme demande potentielle d'équipement et donc d'accès et d'amélioration des usages du numérique. Cette demande provient tant des PME, que des salariés en télétravail ; ainsi que pour répondre à l'ensemble des services publics "numérisables " (médecine, éducation, etc.) notamment au niveau régional (De Mello et Ter-Minassian, 2020). II reste à voir si le déploiement des infrastructures numériques peut effectivement permettre de « rebattre les cartes » entre territoires français, alors que les grandes métropoles sont les plus affectées par la pandémie (OCDE, 2020c) ${ }^{91}$ mais aussi celles qui sont les plus adaptées pour développer le télétravail à grande échelle (OCDE, 2020e). Les infrastructures numériques pourraient bénéficier à d'autres territoires, et en particulier les villes petites et moyennes, notamment celles situées à la périphérie des grandes métropoles. Les régions, accompagnés par l'État, ont un rôle important à jouer pour assurer que le virage numérique s'effectue au profit de la diversité de leurs territoires et des relations urbain-rural.

\footnotetext{
85 L'Arcep est une autorité administrative indépendante (AAl). Elle assure la régulation des secteurs des communications électroniques et des postes, au nom de l'Etat, mais en toute indépendance par rapport au pouvoir politique et aux acteurs économiques (Arcep, 2020)

${ }^{86}$ Remplaçant la Commission de concertation régionale pour l'aménagement numérique du territoire, celle-ci se tient une fois par an à l'initiative du préfet de Région pour faire évoluer les dispositifs existants et à mobiliser les collectivités, opérateurs et acteurs impliqués.

${ }^{87} \mathrm{Si}$ un plancher de débit à $30 \mathrm{Mb} / \mathrm{s}$ a été fixé par une norme européenne, le plan France THD vise un taux de $80 \%$ de raccordement à la fibre $(100 \mathrm{Mb} / \mathrm{s})$.

${ }^{88}$ En 2019, environ 7000 communes seraient concernées.

893500 communes ont été équipées d'infrastructures passives construites par la puissance publique, sur lesquelles les 4 opérateurs ont l'obligation de fournir un service.

90 En cas de manquement, les opérateurs privés sont passibles d'importantes sanctions financières prononcées par l'Arcep.

${ }^{91}$ Cela est dû aux pénalités liées aux effets d'agglomération (densité, etc.).
} 


\section{Conclusion : Vers une vision plus intégrée et cohérente de l'internationalisation des régions}

Comprendre le positionnement des régions dans la mondialisation est une nécessité impérative pour que celle-ci puissent, dans les pays où elles ont la latitude pour le faire, perfectionner leurs stratégies de développement et l'adapter à l'évolution du contexte global, qui peut être impacté par des crises comme celle générée par la pandémie de COVID-19 et ses conséquences.

Ce rapport aborde cette question sous trois angles complémentaires :

- la proposition d'une méthodologie statistique d'une part ;

- son application au cas des régions françaises, d'autre part ; et enfin,

- une première analyse des stratégies d'internationalisation s'appuyant principalement sur les SRDEll et la mise en œuvre de ces politiques dans le cadre des programmes nationaux.

Le travail sur le recensement et la valeur des indicateurs d'internationalisation des régions (chapitre I) a permis de proposer une méthodologie originale reposant sur quatre familles d'indicateurs, éclairant chacune une dimension particulière des connexions qui lient les Régions à la mondialisation. II s'agit :

- des connexions d'infrastructure (notamment en termes de réseaux de transports et d'accès à l'internet haut débit) qui conditionnent les interactions des territoires avec le reste du monde ;

- des connexions humaines (en particulier en ce qui concerne les visiteurs et les migrants) qui permettent de caractériser les flux de visiteurs de court et de long terme et donc d'approcher une des composantes importantes de la diversité des populations locales ( ce qui peut inclure les liens potentiels avec les territoires d'origine des diasporas et des talents présents dans les régions) ainsi que le poids des activités touristiques dans l'économie régionale ;

- des connexions de connaissance (en termes d'enseignement, de recherche et d'expertise) qui positionnent les régions dans l'économie mondiale de la connaissance et signalent l'attraction qu'elles exercent sur les étudiants et chercheurs étrangers ( ce qui renvoie également aux connexions " humaines » et surtout sa capacité à être un des nœuds d'échanges contribuant à l'innovation globale);

- des connexions d'affaires (en particulier en termes d'exportations et d'investissements directs étrangers ainsi que de spécialisations sectorielles dans des biens et services ouverts à la concurrence internationale) qui renseignent sur la position des entreprises locales au sein de l'économie mondiale.

Certaines des données utilisées ne permettent de couvrir qu'une partie du phénomène traité ou une partie des pays de l'OCDE (parfois uniquement européens voire uniquement les régions françaises). Des indicateurs additionnels devraient par ailleurs pouvoir figurer dans cette grille d'analyse, en particulier ceux qui concernent les biens culturels proposés par les régions (musées, patrimoine mondial, festivals, etc.) et les pôles locaux d'innovation dans la famille des connexions de connaissance. Ces éléments pourront 
être développés ultérieurement si les données sont disponibles afin de proposer une version plus complète de l'internationalisation régionale.

Au-delà des indicateurs de base, des élaborations statistiques permettraient par ailleurs d'éclairer à la fois les questions de dépendance et de résilience des territoires dans la crise de COVID-19 et les réponses à conforter dans le cadre de plans de relance régionaux, en cours de structuration. II s'agit notamment des données économiques fines et territorialisées d'importation et d'exportation des entreprises afin de positionner la Région dans les chaînes de valeur mondiales. Comme l'ont montré un certain nombre de travaux académiques (Antras et al., 2017 ; Beatie, 2020 ; Gershel et al., 2020 ; Barrot et al., 2020), les indicateurs suivants comptent aussi pour comprendre la dépendance locale à l'échange international : la diversité des spécialisations sectorielles et de la taille des acteurs économiques; la diversité de leurs partenaires commerciaux étrangers ; ou encore la nature des entreprises étrangères présentes sur le territoire (siège ou filiale).

Un résultat important de cette étude concerne la réalisation de " profils d'internationalisation des régions " qui, en s'appuyant sur les indicateurs les plus représentatifs par famille de connexions, permettent de distinguer différentes situations régionales. Le groupe des « régions frontières » soulignent le poids des relations de proximité avec les régions étrangères voisines dans le positionnement international de ces territoires. Si cette dimension est structurante pour les régions hexagonales concernées (en particulier Grand Est et Hauts-de-France) elle n'est pas représentative des Régions d'Outre-Mer. Dans l'ensemble, ces dernières, bien qu'insérées dans des bassins internationaux (par nature) et conscientes de l'avantage que ce positionnement leur confère, semblent plutôt fonder leur approche sur des politiques publiques diversifiées (réseau haut débit, tourisme) que par une démarche tournée vers l'international. Ces régions ultramarines ne forment pas un «bloc homogène " mais bien au contraire une variété de situations singulières. Un dernier groupe de régions hexagonales est connecté à l'international selon une approche qui ne permet pas de faire ressortir à ce stade de spécificités majeures.

Ces profils de régions dans la mondialisation soulignent l'intérêt à croiser les différentes dimensions que les autorités régionales et leurs partenaires peuvent activer pour se développer internationalement. Le rapport analyse la variété de ces stratégies (chapitre II) en s'appuyant sur les SRDEII élaborés par les régions françaises en 2016-17 pour tracer leur programme d'action jusqu'en 2022. Il s'agit là de documents de référence pour montrer la variété des approches et des projets qui tous cependant illustrent et confirment la pertinence de la taxonomie des connexions proposées. Ils donnent cependant une place majeure à la dimension économique de l'internationalisation (soutien à l'export, attractivité des investisseurs étrangers en particulier) et aux enjeux du développement des infrastructures (notamment numérique).

La crise pandémique, notamment, bouleverse ces intentions initiales et il sera utile de revisiter les projets indiqués par les régions à l'aune de la recherche de réponses de court et de moyen/long termes à ses conséquences. En effet, l'interruption des chaînes de valeur et la volonté de limiter la dépendance envers des ressources et des acteurs clés, suscitant des politiques dites de "re-localisation » ou tout au moins de gestion des stocks en flux moins tendu, soulignent combien l'internationalisation ne peut pas être considérée comme une fin en soi mais un des moyens pour les autorités régionales d'améliorer le bienêtre des habitants et la résilience économique des entreprises et de l'emploi local. Les évolutions ne concernent d'ailleurs pas que l'organisation des activités internationales des entreprises, mais s'inscrivent dans une mégatendance de fond à la numérisation (et l'automatisation) qui transforment les modes de production, de travail, de consommation et de loisir. Plutôt qu'un frein, la pandémie, malgré son caractère tragique, semble là jouer un rôle paradoxal d'accélérateur renforçant les ambitions des régions, déjà inscrites dans les SRDEII, de développer l'accès et les usages de l'internet haut débit dans les territoires.

II est bien difficile de prédire aujourd'hui l'impact de ces tendances variées sur les disparités territoriales. Elles agissent cependant aussi comme une opportunité vers un développement urbain-rural plus équilibré et plus favorable aux deux dimensions majeures du bien-être encore non évoquées : la cohésion sociale 
(Algan and Cahuc, 2014) et la préservation du climat et de la biodiversité. Les attentes des populations en la matière peuvent infléchir les modes opératoires de la mondialisation d'avant la pandémie en poussant les politiques à l'adoption d'incitations plus efficaces auprès des multinationales et autres opérateurs mondiaux pour que l'internationalisation concoure plus efficacement à l'inclusion et au respect de l'environnement. Elles peuvent aussi renforcer l'adoption de politiques d'intégration des migrants qui sont peu mentionnés dans les Schémas actuels des régions. La pandémie a en effet montré la grande dépendance vis-à-vis des migrants et des travailleurs saisonniers à la fois pour les métiers qualifiés tels que les médecins, et moins qualifiés comme les livreurs, les aides à domicile, les agents de nettoyage ou les ouvriers agricoles. En lien avec d'autres études menées par l'OCDE, il semble que la résilience des territoires passe par un meilleur accueil de ces populations, par ailleurs plus propices à s'engager dans la création d'entreprise, et l'exploitation de leurs connexions internationales pour le développement des territoires d'accueil.

Ces évolutions ne peuvent émaner ni d'un seul domaine de politique internationale, ni de la seule action des Régions, même fortes de leur compétence en matière de développement économique et d'internationalisation. À l'heure de l'annonce de la territorialisation du plan France Relance et suite à l'Accord de méthode signé le 30 juillet 2020 entre l'Etat et les Régions, le rapport met d'ailleurs en évidence les dispositifs mentionnés par les Régions pour mettre en œuvre leur programme d'internationalisation en intégrant différents objectifs et en interagissant avec la variété des acteurs concernés (entreprises, opérateurs d'Etat, et autres collectivités territoriales notamment). L'étude rappelle par ailleurs que les stratégies d'internationalisation des Régions s'inscrivent dans des programmes nationaux et européens dont l'efficacité est conditionnée par la qualité de la gouvernance pluri-niveaux qui permet la cohérence de l'action. À titre d'illustration, sont proposées les cartographies institutionnelles des politiques d'appui à l'exportation et l'attractivité soutenant le développement économique international des territoires. Des éléments d'information additionnels soulignent enfin le rôle de l'État en matière de politiques d'infrastructures régionales en prenant l'exemple des chaînes logistiques, des ports et de la couverture numérique des territoires. Ces illustrations soulignent la nécessité de concevoir les politiques d'internationalisation de manière complémentaire aux autres politiques de développement régional. Ils montrent aussi la «dépendance mutuelle (Charbit et Michalun, 2009) entre État et Régions pour répondre aux défis de la résilience dans l'environnement global " post COVID "; ainsi que le rôle que peut jouer dans le cas des régions européennes, l'échelon supranational. ${ }^{92}$ Une étude complémentaire permettra d'approfondir les connaissances en identifiant les difficultés comme les bonnes pratiques et innovations sur le terrain et de fournir des recommandations utiles en comparant les cas des régions françaises avec ceux d'autres régions de l'OCDE, en particulier européennes. Elle permettra de mettre en évidence les possibles obstacles comme les bonnes pratiques pour l'élaboration et la mise en œuvre des politiques d'internationalisation régionale visant le développement inclusif et durable dans le nouvel environnement mondial. Soutenir les régions dans leurs stratégies d'internationalisation pour les rendre plus résilientes est une mission de l'ANCT que ce travail futur permettra de soutenir tant de manière conceptuelle que de façon opérationnelle.

\footnotetext{
92 Au-delà de l'approbation d'un cadre financier pluriannuel pour 2021-2027, l'Union européenne a annoncé d'ambitieux programmes de relance pour un moment total de 750 milliards d'euros (programme Next Generation EU, initiatives Recovery and Resilience facility, Recovery Assistance for Cohesion and the Territories of Europe - REACT$E U$ ), ainsi que le renforcement programmes soutenant les régions européennes ( programmes de développement rural, Just Transition Mechanism, etc.)(Commission européenne, 2020b).
} 


\section{Références}

Algan, Y., C. Malgouyres, C. Senik (2020), «Territoires, bien-être et politiques publiques », Les notes du conseil d'analyse économique, No. 55, Conseil d'analyse économique.

Allain-Dupre, D. (forthcoming) "The Multi-level Governance Imperative" in the Multi-Level Governance 'Breakthrough' Symposium in the British Journal of Politics and International Relations

ANCT (2020), «L'Agence nationale de la cohésion des territoires », https://www.cohesionterritoires.gouv.fr/lagence-nationale-de-la-cohesion-des-territoires\#scroll-nav 2

ANCT (2019), «Édouard Philippe et Jacqueline Gourault présentent le projet de loi « 3D », 15e congrès de Régions de France, 8 octobre 2019, https://www.cget.gouv.fr/actualites/edouard-philippe-etjacqueline-gourault-presentent-le-projet-de-loi-3d

Annoni, P. et L. Dijkstra (2019), EU Regional Competitiveness Index, European Commission, Publications Office of the European Union, Luxembourg.

Annoni, P. - Dijkstra, L. (2013), European Regional Competitiveness Index.. European Commission, Publications Office of the European Union, Luxembourg.

Arav, Fanny (2020), L'impact des infrastructures de réseaux dans l'économie, Avis du Conseil économique, social et environnemental (mai 2020), https://www.lecese.fr/sites/default/files/pdf/Avis/2020/2020 08 impact infrastructures reseaux.pdf

Arcep (2020), La régulation de l'Arcep au service des territoires connectés, Rapport d'activité (mars 2020).

Banque des territoires (2019), « Team France Export : 26.000 entreprises accompagnées en région d'ici 2022 », https://www.banquedesterritoires.fr/team-france-export-26000-entreprises-accompagneesen-region-dici-2022

Banque des territoires (2017), « Développement économique - Quelle mise en oeuvre pour les SRDEII ? ", https://www.banquedesterritoires.fr/quelle-mise-en-oeuvre-pour-les-srdeii

Barrot, J N, B Grassi and J Sauvagnat (2020), "Sectoral Effects of Social Distancing", Covid Economics: Vetted and Real-Time Papers 3.

Batista e Silva, F et al. (2018). " Analysing spatiotemporal patterns of tourism in Europe at highresolution with conventional and big data sources", Tourism Management, No. 68, pp. 101-115, https://doi.org/10.1016/j.tourman.2018.02.020

Baudouin, Jean-Christophe (2018), Propositions pour le renforcement de l'intégration de la gouvernance sur l'axe Méditerranée-Rhône-Saône - Rapport à Monsieur le Premier ministre, Délégation interministérielle au développement de l'axe portuaire et logistique Méditerranée-Rhône-Saône (26 juin 2018)

Beatie, A. (2020) Be wary of scapegoating 'just-in-time' supply chains, Financial Times: Opinion Trade Secrets

Bpifrance (2018), La région Nouvelle-Aquitaine, L’Etat, Business France, Bpifrance et la CCI Régionale créent la «Team France Export Nouvelle-Aquitaine » au service des entreprises qui veulent réussir à l'international, https://presse.bpifrance.fr/la-region-nouvelle-aquitaine-letat-business-france-bpifranceet-la-cci-regionale-creent-la-team-france-export-nouvelle-aquitaine-au-service-des-entreprises-quiveulent-reussir-a-lin/

Brezzi, M. and P. Luongo (2016), "Regional Disparities In Access To Health Care: A Multilevel Analysis 
In Selected OECD Countries", OECD Regional Development Working Papers, No. 2016/04, OECD Publishing, Paris, https://doi.org/10.1787/5jm0tn1s035c-en.

Buissou Julien, « Pascal Lamy : « Le COVID-19 va accélérer le passage du protectionnisme au précautionnisme », Le Monde, 9 avril 2020, https://www.lemonde.fr/economie/article/2020/04/09/pascal-lamy-le-COVID-19-va-accelerer-lepassage-du-protectionnisme-au-precautionnisme 6036080 3234.html

Business France (2020), "Baromètre de l'activité internationale des entreprises françaises -période Covid-19 » (10 avril 2020), https://www.businessfrance.fr/barometre-de-l-activite-internationale-desentreprises-francaises-periode-COVID-19

Campus France (2018), Observatoire territorial de la mobilité internationale des étudiants et des chercheurs, https://www.campusfrance.org/fr/ressource/observatoire-territorial-de-la-mobiliteinternationale-des-etudiants-et-des-chercheurs

CCI (2019), "Team France Export : le nouveau dispositif en ordre de marche », Chambre de commerce et d'industrie, 7 février 2019, https://www.cci.fr/web/presse/communiques-fiches/lasset publisher/ul50/content/cp-team-france-export

CGET (2017), "Circulaire sur les Commissions régionales de stratégie numérique » (22 février 2017), https://www.cget.gouv.fr/circulaire-commissions-regionales-de-strategie-numerique

CGET (2015), Synthèse des stratégies régionales de l'innovation en vue de la spécialisation intelligente des régions françaises, https://www.cget.gouv.fr/ressources/publications/synthese-des-strategiesregionales-de-l-innovation-en-vue-de-la-specialisation-intelligente-des-regions-francaises

Charbit, C. et M. Tharaux (2020), « Migrants: A critical aspect of COVID policy responses and recovery ", The OECD Forum Network (28 May 2020), https://www.oecd-forum.org/posts/migrants-acritical-aspect-of-covid-policy-responses-and-recovery

Charbit, C. (2011), "Governance of Public Policies in Decentralised Contexts: The Multi-level Approach", OECD Regional Development Working Papers, 2011/04, OECD Publishing http://dx.doi.org/10.1787/5kg883pkxkhc-en

Charbit, C. and M. Michalun (2009), "Mind the Gaps: Managing Mutual Dependence in Relations among Levels of Government", OECD Working Papers on Public Governance, No. 14, OECD Publishing, Paris, https://doi.org/10.1787/221253707200

Charbit, Cl. (2020) "From « de jure » to « de facto » decentralised public policies: the Multi-Level Governance approach" in the Multi-Level Governance 'Breakthrough' Symposium in the British Journal of Politics and International Relations, https://journals.sagepub.com/eprint/D4IXIUSAPG2JAVZIIKE3/full

Charron, N., Djikstra, L. and Lapuente V. (2014), "Regional Governance Matters: Quality of Government within European Union Member States" Regional Studies, Vol. 48; https://doi.org/10.1080/00343404.2013.770141

Cheriet, Foued (2010), Modèle d'Uppsala et implantation des firmes multinationales agroalimentaires, Revue française de gestion, no. 201, pp. 45-64

CIEDEL (2017), L'irrésistible internationalisation des villes et des territoires : Enjeux, Dynamiques, Perspectives, Centre International d'Etudes pour le Développement Local, Actes du Colloque, 11-12 décembre 2017, Lyon, https://www.ciedel.org/wp-content/uploads/2018/05/synth\%C3\%A8secolloque-internationalisation-des-villes-et-des-territoires.pdf

Colrat, A., A. Decludt, J. Cartier, F. Gomez, P. Gudefin, G. Caude, B. Fulda, F. Marendet (2018), La transformation du modèle économique des grands ports maritimes, Rapport de l'Inspection générale des finances et du Conseil général de l'environnement et du développement durable (novembre 2018).

Commission européenne (2020), Communication de la commission - Orientations à l'intention des États 
membres concernant les investissements directs étrangers et la libre circulation des capitaux provenant de pays tiers ainsi que la protection des actifs stratégiques européens, dans la perspective de l'application du règlement (UE) 2019/452 (règlement sur le filtrage des IDE), https://eurlex.europa.eu/legal-content/FR/TXT/HTML/?uri=OJ:C:2020:0991:FULL\&from=EN

Commission européenne (2020b), « Recovery plan for Europe », https://ec.europa.eu/info/live-worktravel-eu/health/coronavirus-response/recovery-plan-europe en

Conseil national de l'industrie (2020), « La filière infrastructures numériques », https://www.conseilnational-industrie.gouv.fr/la-filiere-infrastructures-numeriques

Cour des comptes (2020), L'entrée, le séjour et le premier accueil des personnes étrangères, Rapport public thématique, https://www.vie-publique.fr/sites/default/files/rapport/pdf/274248.pdf

De Mello, L. et T. Ter-Minassian (2020), "The COVID-19 crisis creates an opportunity to step up digitalisation among subnational governments" (20 April 2020), https://oecdecoscope.blog/2020/04/20/the-covid-19-crisis-creates-an-opportunity-to-step-updigitalisation-among-subnational-governments/

Gerschel, E., Martinez, A., \& Mejean, I. (2020). Propagation des chocs dans les chaînes de valeur internationales: le cas du coronavirus. Notes IPP.

Hendrickson C. and Muro M. (2020), Will COVID-19 rebalance America's uneven economic geography? Don't bet on it, Brookings Institute, The Avenue

Hirst, P. et G. Thompson (2002), "The Future of Globalization", Cooperation and conflict, No. 37 (3), pp. 247-265, https://doi.org/10.1177/0010836702037003671

Hombert, A. and A. Matray (2015), "US manufacturing firms, R\&D and resilience to import competition from China", VOX CEPR Policy Portal, https://voxeu.org/article/innovative-firms-and-resiliencechinese-import-competition.

ICC International (n.d.), Team France Export des Hauts -De-France, https://cci-international.net/fr/teamfrance-export/

Knight, F. (1921), Risk, Uncertainty and Profit.

Lembcke, A. and L. Wildnerova (2020), "Does FDI benefit incumbent SMEs?: FDI spillovers and competition effects at the local level", OECD Regional Development Working Papers, No. 2020/02, OECD Publishing, Paris, https://doi.org/10.1787/47763241-en.

Lileeva, A. and D. Trefler (2020), "Improved access to foreign markets raises plant-level productivity... For some plants", The Quarterly Journal of Economics, Volume 125, Issue 3, August 2010, Pages 1051-1099, https://doi.org/10.1162/qiec.2010.125.3.1051.

McCann, Ph. (2020) "Perceptions of regional inequality and the geography of discontent: insights from the UK", Regional Studies, 54:2, 256-267, DOI: 10.1080/00343404.2019.1619928

Ministère de l'agriculture et de l'alimentation (2020), « COVID-19 : poursuite de la chaîne logistique du transport de marchandises » (18 mars 2020), https://agriculture.gouv.fr/covid-19-poursuite-de-lachaine-logistique-du-transport-de-marchandises

Ministère de l'Economie des Finances et CCI France (2019), Contrat d'objectifs et de performance, 15 avril 2019.

Ministère de l'Environnement, de l'énergie, et de la mer en charge des relations internationales sur le climat (2017), Atlas des entrepôts et des aires logistiques en France en 2015, Datalab (mars 2017).

Ministère de l'Europe et des affaires étrangères (2020), https://www.gouvernement.fr/ministere-de-leurope-et-des-affaires-etrangere

Ministère de la cohésion des territoires et des relations avec les collectivités territoriales (n.d.), Les principaux établissements publics, https://www.cohesion-territoires.gouv.fr/agences-etetablissements-publics-du-ministere 
Ministère de l'Economie des Finances (n.d.), La Team France Export est le dispositif public d'accompagnement des entreprises à l'international structuré autour de Business France, des régions, des Chambres de Commerce et d'Industrie et de Bpifrance.

https://www.tresor.economie.gouv.fr/services-aux-entreprises/team-france-export

Mouhoud, El Mouhoub (2020), "Délocalisations : comment faire machine arrière ?" Alternatives économiques (Mai 2020)

OECD (2021), Fostering economic resilience in a world of open and integrated markets: risks, vulnerabilities and areas for policy action, https://www.oecd.org/newsroom/OECD-G7-ReportFostering-Economic-Resilience-in-a-World-of-Open-and-Integrated-Markets.pdf

OECD (2020a), Perspectives économiques de l'OCDE: L'économie mondiale sur une ligne de crête, (Juin 2020), https://doi.org/10.1787/0d1d1e2e-en

OECD (2020b), L'impact territorial du Covid-19 : Gérer la crise entre niveaux de gouvernement, (Mise à jour, avril 2020) http://www.oecd.org/coronavirus/policy-responses/limpact-territorial-du-covid-19gerer-la-crise-entre-niveaux-de-gouvernement-2596466b/

OECD (2020c), Coronavirus (COVID-19) From pandemic to recovery: Local employment and economic development, (Updated 27 April 2020), http://www.oecd.org/coronavirus/policy-responses/frompandemic-to-recovery-local-employment-and-economic-development-879d2913/

OECD (2020d), Pilot Database on Regional Government Finance and Investment: Key findings, OECD Publishing, Paris, http://www.oecd.org/cfe/regionaldevelopment/REGOFI Report.pdf

OECD (2020e), Capacity for remote working can affect lockdown costs differently across places, http://www.oecd.org/coronavirus/en/policy-responses

OECD (2020f), COVID-19 and global value chains: Policy options to build more resilient production networks, , http://www.oecd.org/coronavirus/en/policy-responses

OECD (2019a), Déclaration sur les politiques permettant de forger un avenir meilleur pour les régions, les villes et les zones rurales, Athènes, 4 e Réunion ministérielle du Comité des politiques de développement régional (RDPC) de l'OCDE, https://www.oecd.org/regional/ministerial/RDPCMinisterial-Declaration-FR.pdf

OECD (2016), « Examen par l'OCDE des initiatives statistiques visant à mesurer le tourisme à l'échelon infranational », Études de l'OCDE sur le tourisme, 2016/01, Éditions OCDE, Paris. http://dx.doi.org/10.1787/cf0cfa00-fr

OECD (2019), «France », dans OECD Regional Outlook 2019 : Leveraging Megatrends for Cities and Rural Areas, Éditions OCDE, Paris, https://doi.org/10.1787/9e936eee-fr

OECD (2019b), Panorama des administrations publiques 2019, OECD Publishing, Paris, https://doi.org/10.1787/8be847c0-fr.

OECD (2019c), Réussir la décentralisation: Manuel à l'intention des décideurs, OECD Publishing, Paris, https://doi.org/10.1787/551847c0-fr.

OECD (2019d), "Decentralised development co-operation: Unlocking the potential of cities and regions", OECD Development Policy Papers, No. 22, OECD Publishing,

Paris, https://doi.org/10.1787/e9703003-en.

OECD (2019e), "Tendances actuelles de la décentralisation", in Réussir la décentralisation: Manuel à l'intention des décideurs, OECD Publishing, Paris, https://doi.org/10.1787/7d478b76-fr.

OECD (2019f), "Innovative multi-level governance to address future challenges", in OECD Regional Outlook 2019: Leveraging Megatrends for Cities and Rural Areas, OECD Publishing, Paris, https://doi.org/10.1787/34e0eb81-en.

OECD (2018b), Regions and Cities at a Glance 2018, page 69, OECD Publishing, Paris, https://doi.org/10.1787/reg cit glance-2018-en 
OECD (2018), Job Creation and Local Economic Development 2018: Preparing for the Future of Work, OECD Publishing, Paris, https://doi.org/10.1787/9789264305342-en.

OECD (2018), Productivity and Jobs in a Globalised World: (How) Can All Regions Benefit?, OECD

Publishing, Paris. http://dx.doi.org/10.1787/9789264293137-en.

OECD (2018), Reshaping Decentralised Development Co-operation: The Key Role of Cities and Regions for the 2030 Agenda, OECD Publishing, Paris, https://doi.org/10.1787/9789264302914-en

OCDE, Recommandation du Conseil sur l'investissement public efficace entre niveaux de gouvernement, OECD/LEGAL/0402

OECD (2015), Policy Framework for Investment, 2015 Edition, OECD Publishing,

Paris, https://doi.org/10.1787/9789264208667-en.

OECD (2010), Measuring Globalisation: OECD Economic Globalisation Indicators 2010, OECD Publishing, Paris, https://doi.org/10.1787/9789264084360-en.

Poulhès, M. (2015). Are Enterprise Zones benefits capitalized into commercial property values? The French case.

Région Occitanie (2020), « Soutien à l'accueil et à l'intégration des demandeurs d'asile et des bénéficiaires d'une protection internationale ", https://www.laregion.fr/Soutien-a-l-accueil-et-a-lintegration-des-demandeurs-d-asile-et

Régions de France (2020), « Donner aux territoires les moyens de reconquérir notre souveraineté alimentaire » (8 juin 2020), http://regions-france.org/actualites/actualites-nationales/donner-auxterritoires-moyens-de-reconquerir-souverainete-alimentaire/

Régions de France (2020a), "Plan de relance de l'économie : les Régions proposent un New Deal industriel et environnemental », 6 avril 2020, http://regions-france.org/actualites/actualites-

nationales/regions-remercient-gouvernement-plan-relance/

Régions de France (2020b), « La Région, quelles compétences ? », http://regionsfrance.org/observatoire-politiques-regionales/la-region-quelle-comptetence/

Régions de France (2019), " Risque de fin du plan France Très Haut Débit: les députés sont le dernier recours ! (13 décembre 2019), http://regions-france.org/actualites/actualites-nationales/fibreoptique-menace-plan-france-tres-haut-debit/

Régions de France (2018), Le rôle économique des régions : De l'ambition à l'action.

République française (2020a), "Code général des collectivités territoriales », Legifrance, https://www.legifrance.gouv.fr/affichCode.do?cidTexte=LEGITEXT000006070633

République française (2020b), "Éclairage : les compétences des régions : aperçu après la loi NOTRe », Vie publique, https://www.vie-publique.fr/eclairage/38411-les-competences-des-regions-apercuapres-la-loi-notre

République française (2020c), Décret $n^{\circ} 2020-964$ du 31 juillet 2020 relatif aux attributions du ministre délégué auprès du ministre de l'Europe et des affaires étrangères, chargé du commerce extérieur et de l'attractivité, Legifrance, https://www.legifrance.gouv.fr/jorf/id/JORFTEXT000042185565/

République française (2018), Discours du Premier ministre sur la "Stratégie du Gouvernement en matière de commerce extérieur 》 (Roubaix, 23 février 2018), https://www.gouvernement.fr/sites/default/files/document/document/2018/02/discours de m. edouar d philippe premier ministre presentation de la strategie du gouvernement en matiere de commerce exterieur a roubaix 23.02.2018.pdf

République française (2017), « Revitalisation et réindustrialisation - Bilan du commissariat spécial des Hauts-de-France », Préfecture de Région des Hauts-de-France (6 décembre 2017), https://www.prefectures-regions.gouv.fr/hauts-de-france/Actualites/Revitalisation-etreindustrialisation-Bilan-du-commissariat-special-des-Hauts-de-France 
Rodríguez-Pose, Andrés (2017), "The revenge of the places that don't matter (and what to do about it)", Cambridge Journal of Regions, Economy and Society, No. 11 (1), pp. 189-209, https://doi.org/10.1093/cjres/rsx024

Saudemont, E. (2020), “ [Covid-19] Les régions françaises se mobilisent pour soutenir les entreprises en difficultés » (13 mars 2020), L'Usine nouvelle, https://www.usinenouvelle.com/editorial/les-regionsaffirment-leur-soutien-aux-entreprises.N939891

Scholte, J. (2008), «Defining globalisation », The World Economy, Vol. 31, pp 1471-1502, https://doi.org/10.1111/j.1467-9701.2007.01019.x

Sénat (2019), Projet de loi de finances pour 2019 : Action extérieure de l'État : Diplomatie culturelle et d'influence, Rapport législatif, http://www.senat.fr/rap/a18-149-2/a18-149-23.html

Sénat (2020), Projet de loi de finances pour 2017 : Économie, https://www.senat.fr/rap/l16-140-311/116140-3118.html

Sodupe, K. (1999), 'The European Union and Inter-regional Cooperation.' In F. Aldecoa and M. Keating (eds.), Paradiplomacy in Action: The Foreign Relations of Subnational Governments, Psychology Press, London.

Subramanian A. (2020), "After Capital A Radical Agenda to Tame Inequality, Foreign Affairs:

Review Essays", Foreign Affairs (July/August 2020),

Team France Export (2019), Comité directeur, 26 septembre 2019.

Team France Export (2020), "[COVID-19] Webinaires marchés et solutions face à la crise » (1 ${ }^{\text {er }}$ juin 2020), https://www.teamfrance-export.fr/hautsdefrance/actualites/vos-marches-face-a-la-crise--nosreponses-en-direct

Team France Export (n.d.), 30 Partenaire et Réseaux Porteurs de « Solutions Team France Export » https://www.teamfrance-export.fr/documents/partenaires.pdf

Team France Export National (n.d.), « Vous faire gagner à l' international », https://team-france-exportnational.cdn.prismic.io/team-france-export-national\%2Fcbe11435-e59e-4a13-9ff1526c63029388 tfe leaflet 105x250 web.pdf

Tuccio, M. (2019) Measuring and Assessing Talent Attractiveness in OECD Countries, OECD Publishing, Paris, https://doi.org/10.1787/b4e677ca-en

World Economic Forum (2016), The Global Competitiveness Report 2016-2017. Insight Report. World Economic Forum. Geneva, Switzerland. 


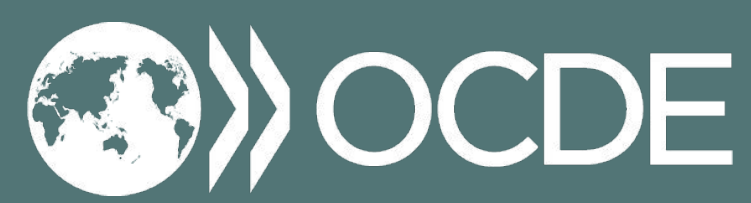

https://www.oecd.org/fr/cfe/ 